\title{
Vocal Variability in Autism Spectrum Disorders: Assessment and Intervention to Increase Novel Vocalizations in Non-Verbal Children
}

\author{
Allison Serra Tetreault \\ West Virginia University
}

Follow this and additional works at: https://researchrepository.wvu.edu/etd

\section{Recommended Citation}

Tetreault, Allison Serra, "Vocal Variability in Autism Spectrum Disorders: Assessment and Intervention to Increase Novel Vocalizations in Non-Verbal Children" (2012). Graduate Theses, Dissertations, and Problem Reports. 187.

https://researchrepository.wvu.edu/etd/187

This Dissertation is protected by copyright and/or related rights. It has been brought to you by the The Research Repository @ WVU with permission from the rights-holder(s). You are free to use this Dissertation in any way that is permitted by the copyright and related rights legislation that applies to your use. For other uses you must obtain permission from the rights-holder(s) directly, unless additional rights are indicated by a Creative Commons license in the record and/ or on the work itself. This Dissertation has been accepted for inclusion in WVU Graduate Theses, Dissertations, and Problem Reports collection by an authorized administrator of The Research Repository @ WVU.

For more information, please contact researchrepository@mail.wvu.edu. 
Vocal Variability in Autism Spectrum Disorders:

Assessment and Intervention to Increase Novel Vocalizations in Non-Verbal Children

Allison Serra Tetreault

\author{
Dissertation submitted to the \\ Eberly College of Arts and Sciences \\ at West Virginia University \\ in partial fulfillment of the requirements \\ for the degree of
}

Doctor of Philosophy

in

Psychology

\author{
Joseph R. Scotti, Ph.D., Chair \\ K. Andy Lattal, Ph.D. \\ Cheryl McNeil, Ph.D. \\ Tracy Morris, Ph.D. \\ Susannah Poe, Ed.D., BCBA-D \\ Department of Psychology \\ Morgantown, West Virginia \\ 2012
}

Keywords: autism; operant variability; communication interventions; stereotypy; maintenance

Copyright 2012 Allison Serra Tetreault 


\begin{abstract}
Vocal Variability in Autism Spectrum Disorders:

Assessment and Intervention to Increase Novel Vocalizations in Non-Verbal Children
\end{abstract}

Allison Serra Tetreault

Autism spectrum disorders (ASDs) are disorders characterized by repetitive and stereotyped behavior. Research shows that these behaviors interfere with typical development and with the acquisition of new skills, including vocal communication. For many children with ASD who are unable to imitate others and who have limited vocal repertoires, few vocal training interventions are available. Research on operant variability, however, indicates that the direct reinforcement of varied sounds may create a larger set of vocal responses. This enlarged response class could then be used to shape functional vocal communication. In the first of three studies, the existing vocal repertoires of 10 children with ASD were assessed for level of variability within vocalizations and for phoneme production. Three children with moderate to low vocal variability then were exposed to lag schedules of reinforcement. All participants produced new phonemes under these conditions, but novel vocalizations increased for only one. The final study investigated whether this increased variability could be maintained when exposed to reinforcement delivered independent of variability (i.e., yoked control). Limitations and suggestions for future research are discussed. 


\section{Acknowledgements}

I would like to thank my family for accepting my absence and my husband for accepting my presence while these studies were conducted. I know this has been a long and winding road, but we have finally come to the end of it together. Upwards and onwards!

I would like to thank my advisor, Joseph R. Scotti, for his unwavering support and enthusiasm during this process. Scotti took me into his lab when I was down and out, and he insisted that I acknowledge my skill and talent at every turn. He trusted my ability to conduct this research even when I did not. Without Scotti, this dissertation would not exist. His willingness to assist and the unending wells of time he devoted to my questions knew no bounds. I can never fully express my gratitude.

This research could not have been completed without the help of some very skilled data collectors. I thank Amanda Shanklin, Brittany Glass, April Lloyd, and Steven Thompson for taking a lead role as undergraduate research assistants. I would also like to thank Shantel Pugliese, Jackie Owens, Mia Caccavale, Sydney Perate, Samantha Hicks, Alexandra Gibson, Sarah Rudy, Josh Dye, Mike Barnett, Katie Wiskow, and Sierra Conyers; your contributions cannot be overstated. Lastly, I would like to thank the members of my committee, Tracy Morris, Cheryl McNeil, Andy Lattal, and Susannah Poe, for their patience and support throughout this process. Their helpful comments made this project a stronger one. 
Table of Contents

General Introduction 1

Vocal stereotypy in autism spectrum disorders ..................................2

Communication intervention in autism spectrum disorders .........................4

Augmentative and alternative communication ............................ 5

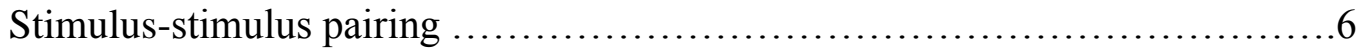

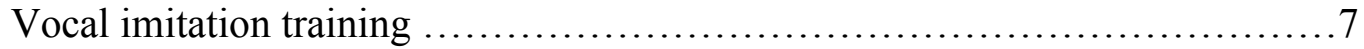

A role for variability in communication interventions $\ldots \ldots \ldots \ldots \ldots \ldots \ldots \ldots \ldots$

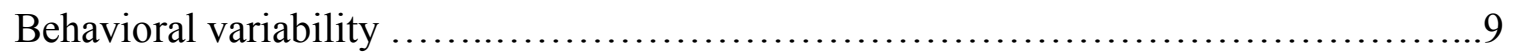

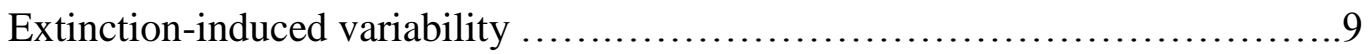

Variability through intermittent reinforcement ............................ 10

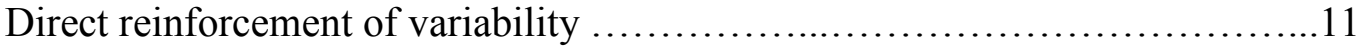

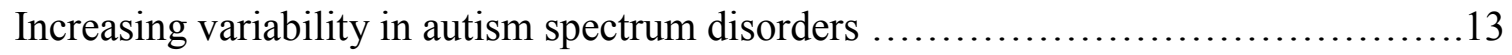

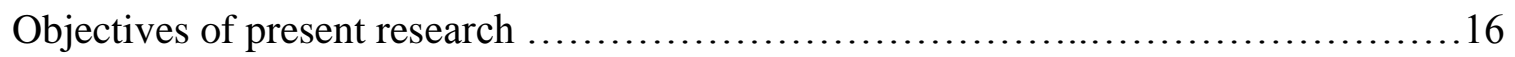

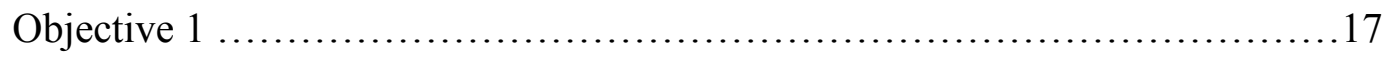

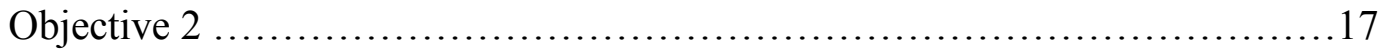

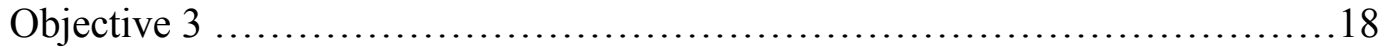

General Methods .............................................................. 19

Participants.........................................................19

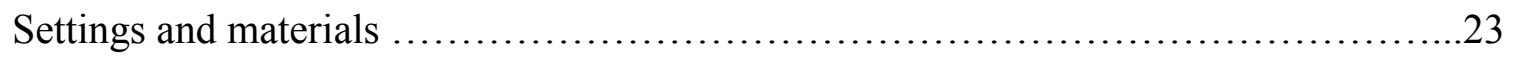

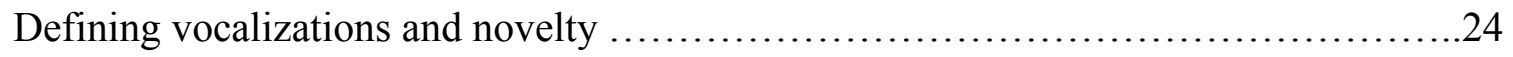

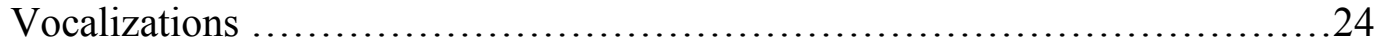

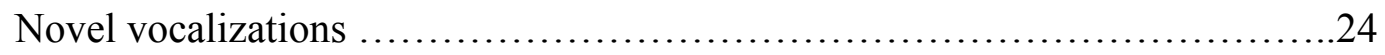

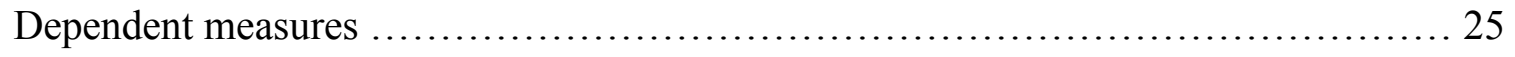

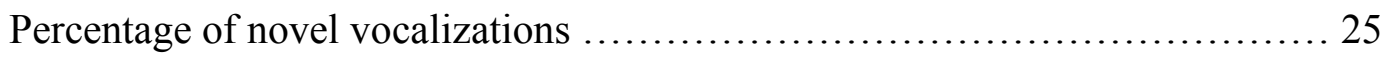

Cumulative novel vocalizations .......................................25

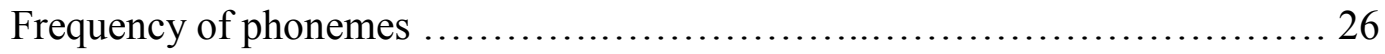


Proportion of phonemes ................................................ 27

Proportion of vocalizations ............................................. 27

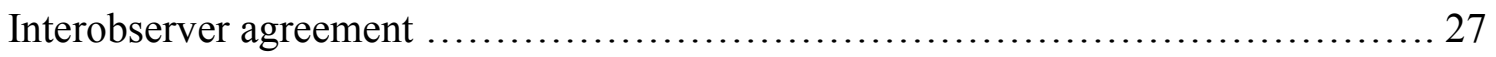

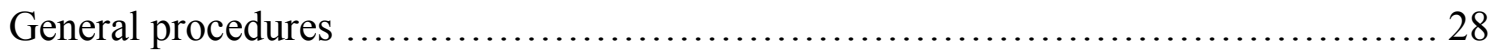

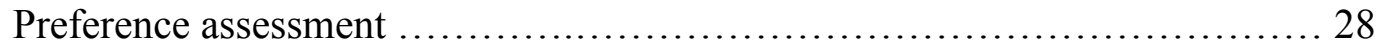

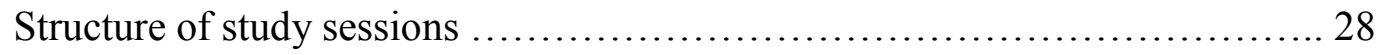

Procedural fidelity ........................................................... 29

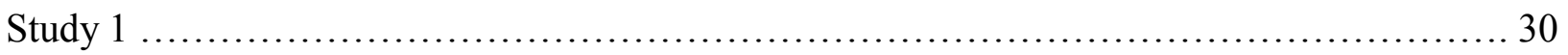

Methods ............................................................................ 30

Participants .......................................................... 30

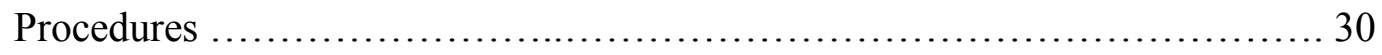

Baseline .......................................................... 30

Procedural fidelity ................................................ 31

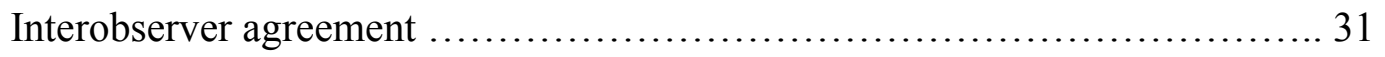

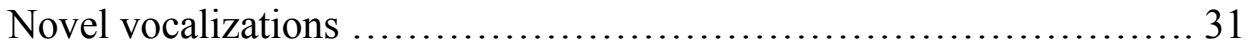

Frequency of phonemes …....................................... 31

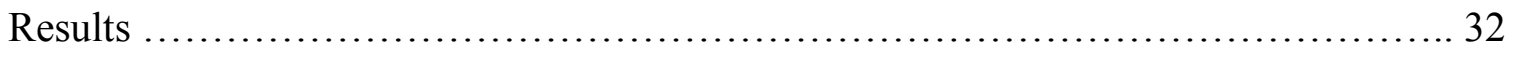

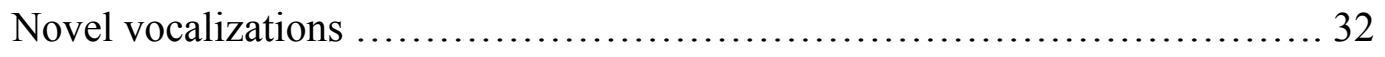

Cumulative novel vocalizations ....................................... 32

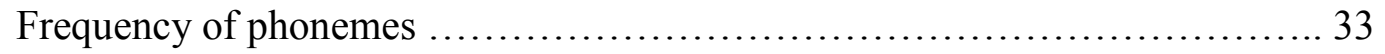

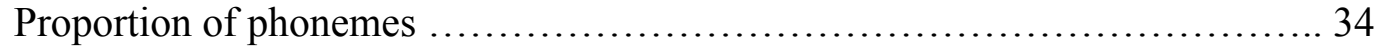

Proportion of vocalizations ................................................... 36

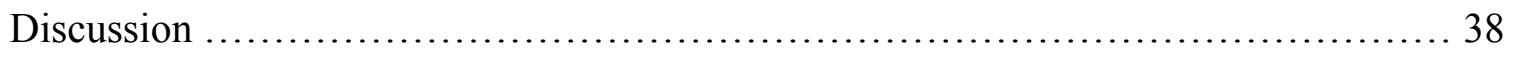

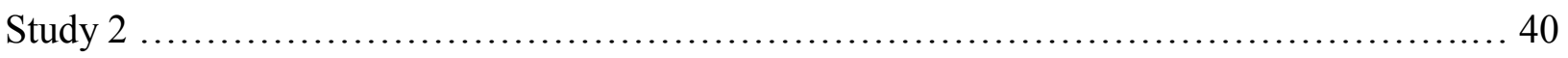

Methods ............................................................................. 40

Participants ................................................................. 40

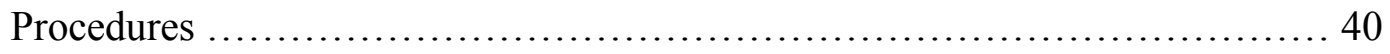


Baseline ............................................................ 40

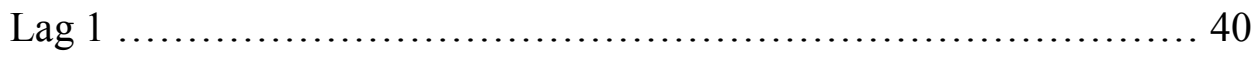

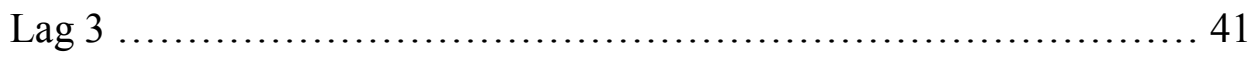

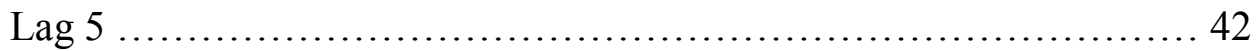

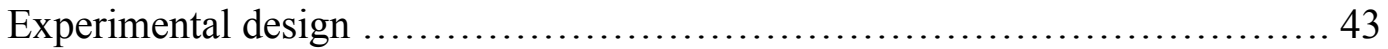

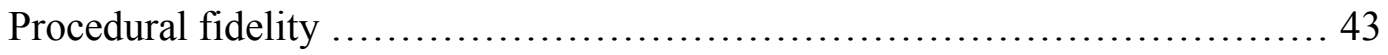

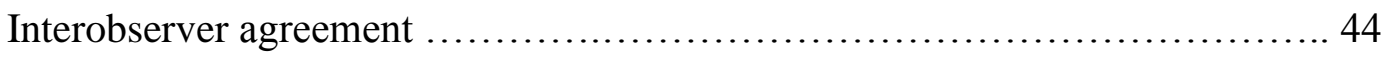

Novel vocalizations .............................................. 44

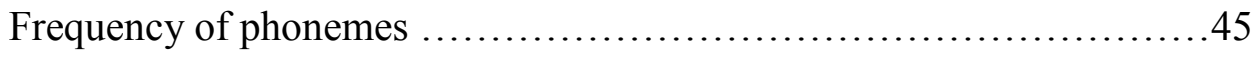

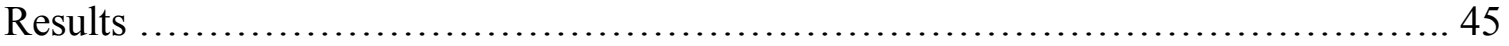

Percentage of novel vocalizations ...................................... 45

Nicholas .......................................................... 45

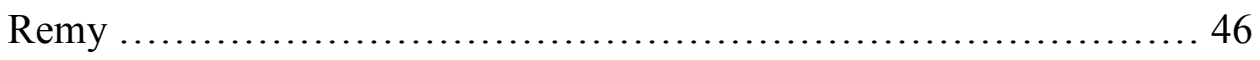

Isabel f........................................................ 46

Cumulative novel vocalizations ......................................... 46

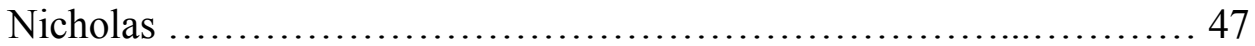

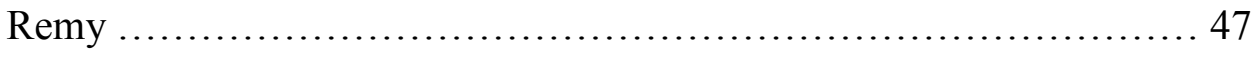

Isabel ............................................................. 48

Frequency of phonemes ................................................. 49

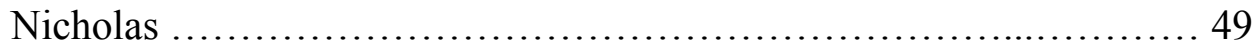

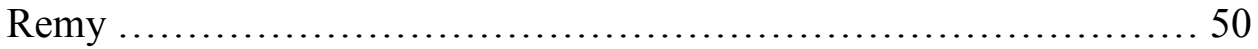

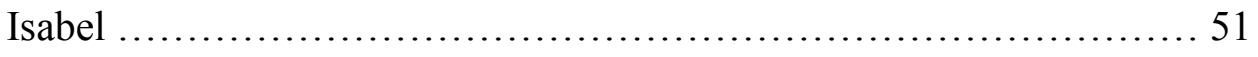

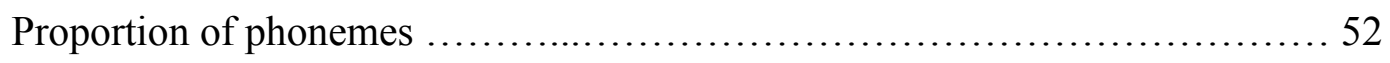

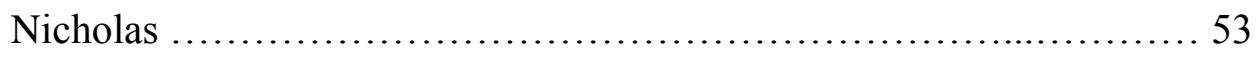

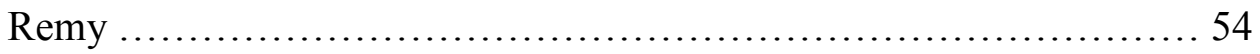

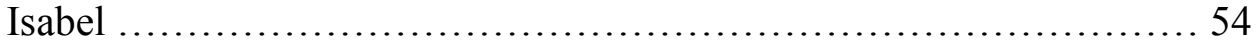

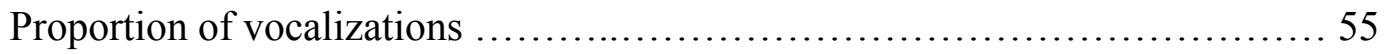


Nicholas ............................................................. 56

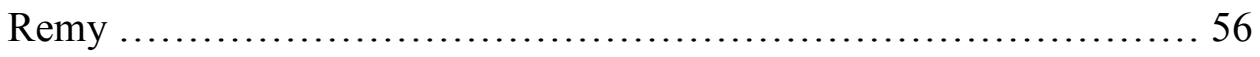

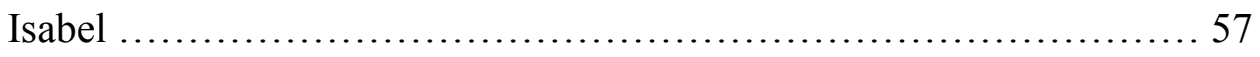

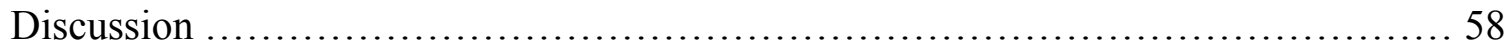

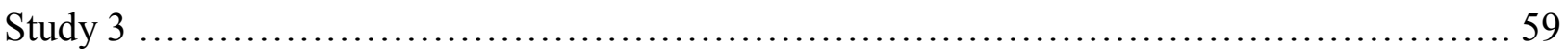

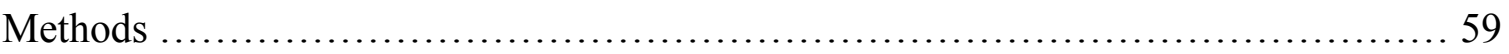

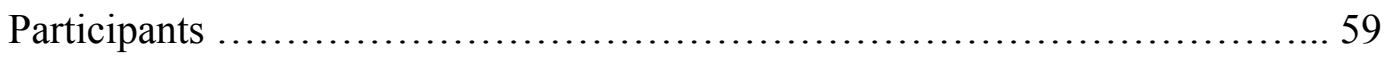

Procedures ............................................................ 59

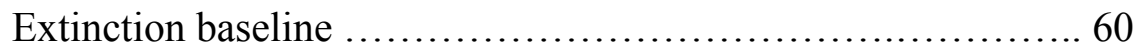

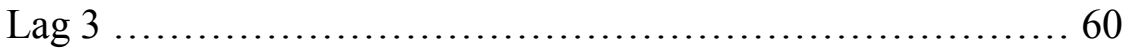

Yoked control ......................................... 60

Experimental design ............................................ 60

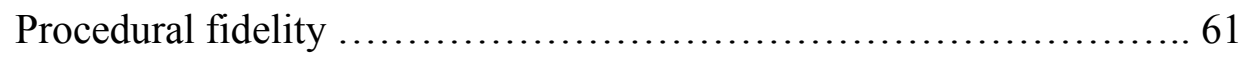

Fidelity of session termination .............................. 61

Fidelity of reinforcement procedures ........................ 61

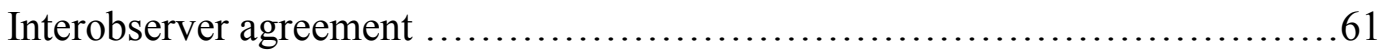

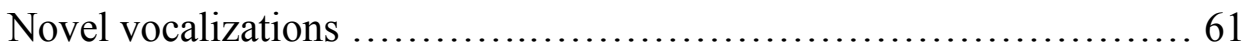

Frequency of phonemes ......................................... 61

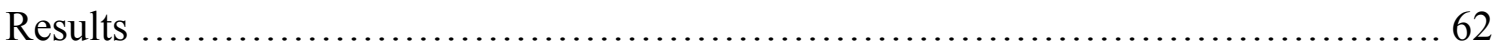

Percentage of novel vocalizations .......................................... 62

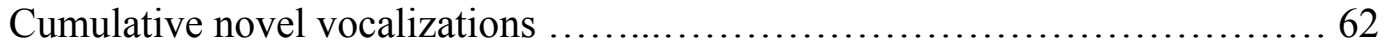

Frequency of phonemes .................................................. 64

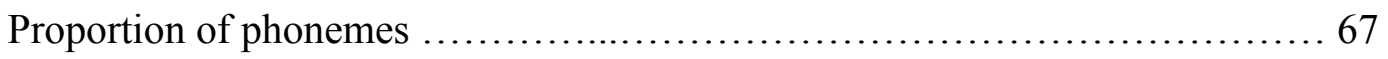

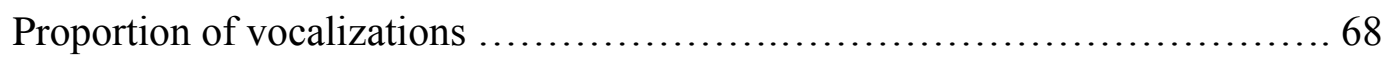

Discussion ....................................................................... 70

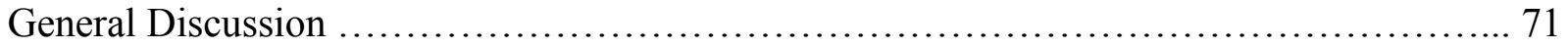

Developmental implications ..................................................... 74 


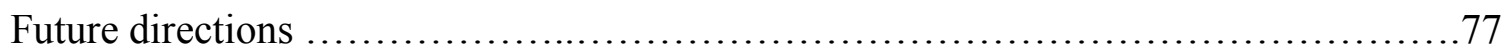




\section{List of Tables}

Table 1: Participant Characteristics, Study Inclusion and Settings, and Preferred Items Used as

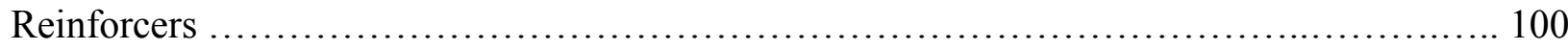

Table 2: Summary of Novel Vocalization Data for each Participant in Study 1 ................ 101

Table 3: Summary of Phoneme Frequency Data for each Participant in Study 1 ............... 102

Table 4: Order of Conditions in Study 2 for each Participant .............................. 103 


\section{List of Figures}

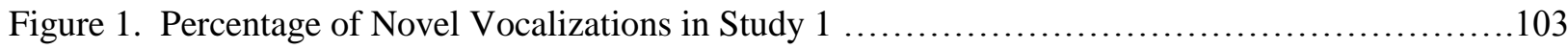

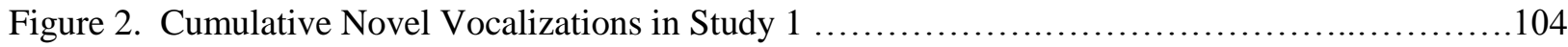

Figure 3. Percentage of Vocalizations and Novel Vocalizations per Session in Study 1 ...............105

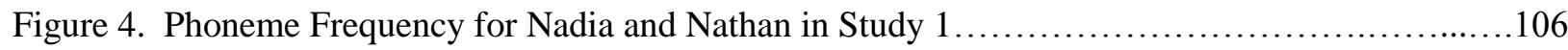

Figure 5. Phoneme Frequency for Kali and Dillon in Study 1 ................................. 107

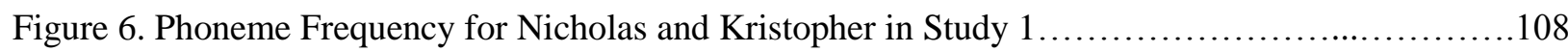

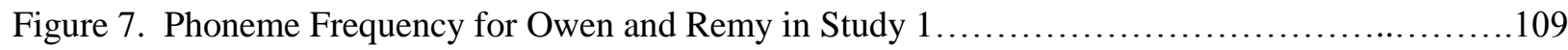

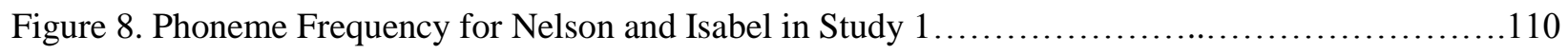

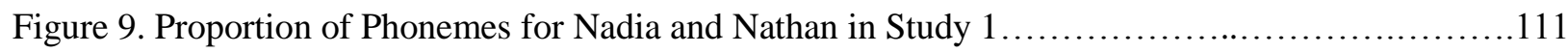

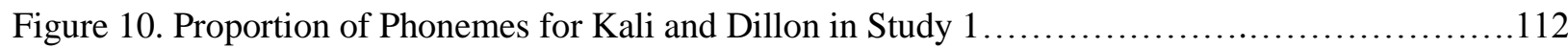

Figure 11. Proportion of Phonemes for Nicholas and Kristopher in Study $1 \ldots \ldots \ldots \ldots \ldots \ldots \ldots \ldots \ldots \ldots \ldots$

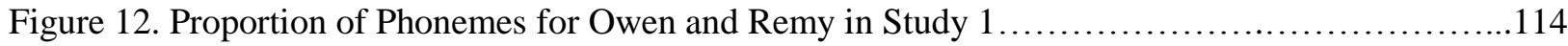

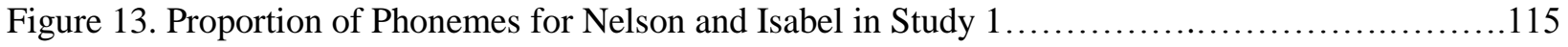

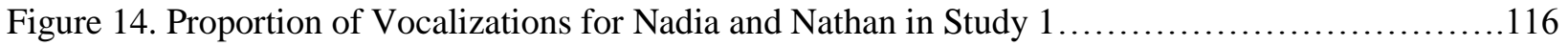

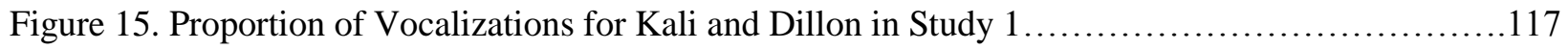

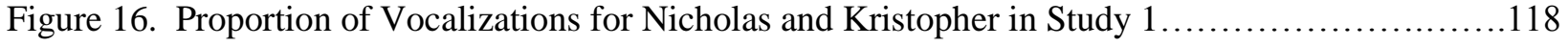

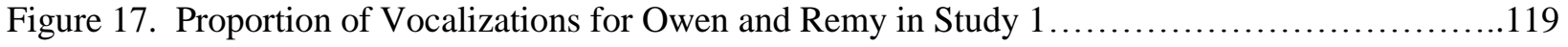

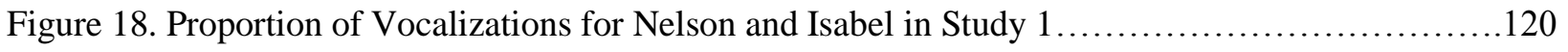

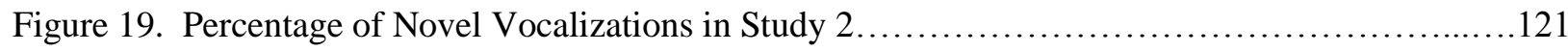

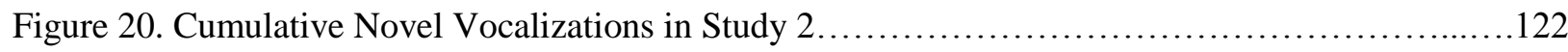

Figure 21. Percentage of Vocalizations and Novel Vocalizations per Session in Study 2 ...............123

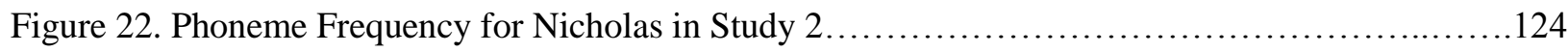

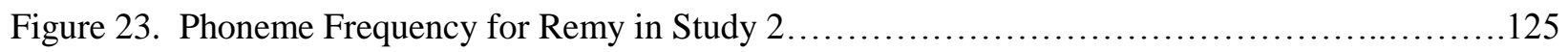

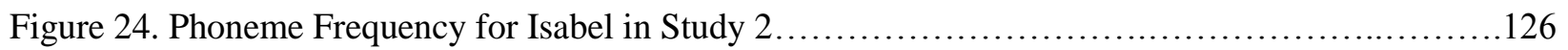

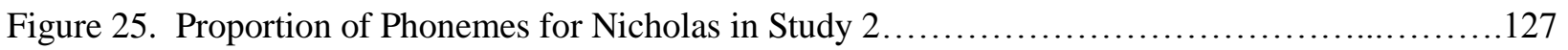




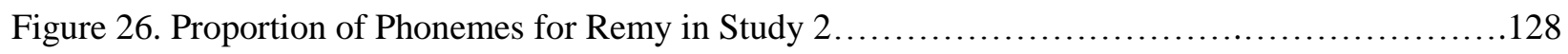

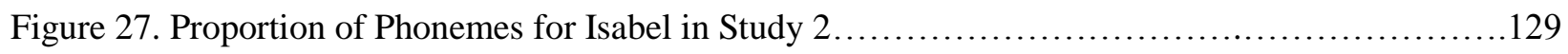

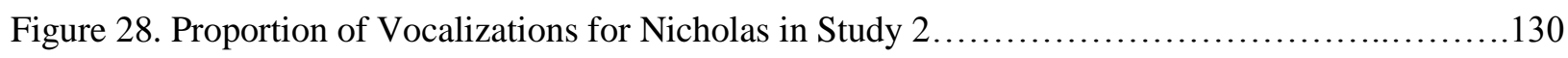

Figure 29. Proportion of Vocalizations for Remy in Study 2 ..................................... 131

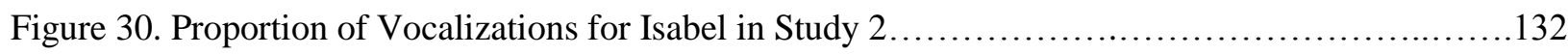

Figure 31. Percentage of Novel Vocalizations in Study 3 ..................................... 133

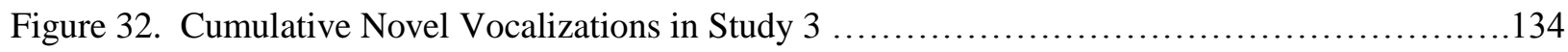

Figure 33. Percentage of Vocalizations and Novel Vocalizations per Session in Study 3 ................135

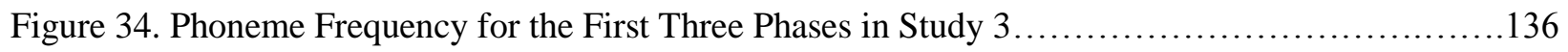

Figure 35. Phoneme Frequency for the Last Three Phases in Study 3 .........................137

Figure 36. Proportion of Phonemes for the First Three Phases in Study 3........................138

Figure 37. Proportion of Phonemes for the Last Three Phases in Study 3...........................139

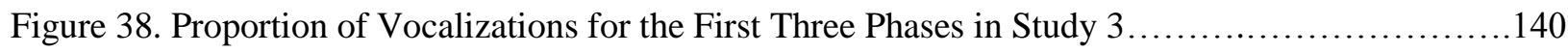

Figure 39. Proportion of Vocalizations for the Last Three Phases in Study 3......................141

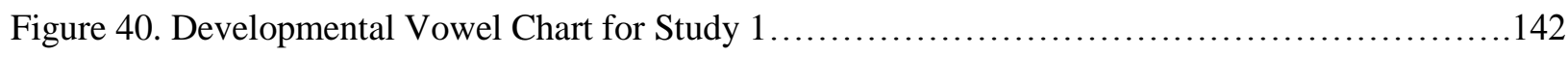

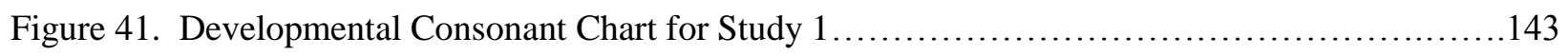

Figure 42. Developmental Vowel Chart for Nicholas in Study 2 ................................. 144

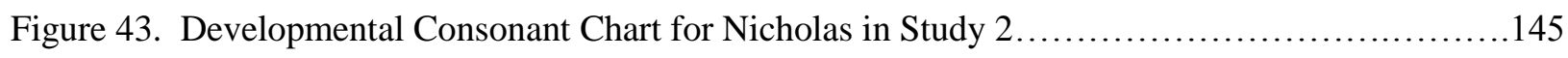

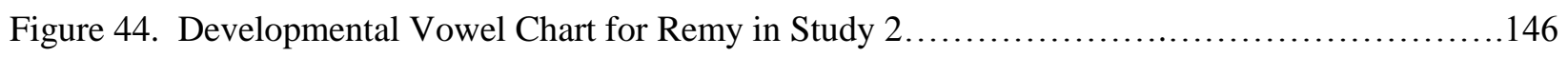

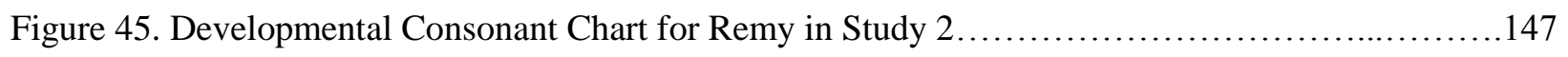

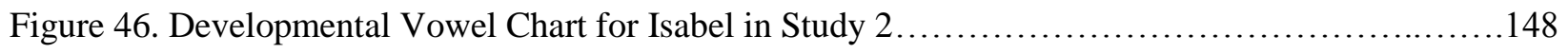

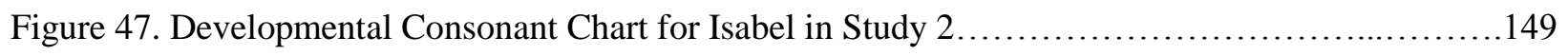

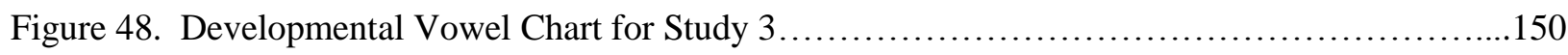

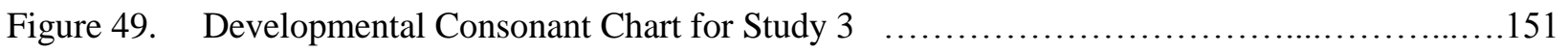


General Introduction

Autism spectrum disorders (ASDs; autistic disorder, Asperger syndrome, and pervasive developmental disorder, not otherwise specified [PDD-NOS]) are characterized by considerable impairment in social interaction and communication, as well as by restricted, repetitive, and stereotyped patterns of behavior, interests, and activities (American Psychiatric Association [APA], 2000). Individuals with ASD often engage in a greater variety and intensity of repetitive and stereotyped behavior than developmentally matched controls (Bodfish, Symons, Parker, \& Lewis, 2000; Goldman et al., 2008; Mullins \& Rincover, 1985; Richler, Bishop, Kleinke, \& Lord, 2007; Watt, Wetherby, Barber, \& Morgan, 2008). Such stereotypy often both impedes the occurrence of developmentally appropriate behavior (Lovaas, Newsom, \& Hickman, 1987; Koegel, Firestone, Kramme, \& Dunlap, 1974) and interferes with the acquisition of important adaptive skills (Koegel \& Covert, 1972; Matson, Kiely, \& Bamburg, 1997). In addition, longitudinal data suggest that these behaviors become more prevalent as individuals with ASD age (Richler, Huerta, Bishop, \& Lord, 2010). Moreover, in a cross-sectional study, MacDonald et al. (2007) compared motor and vocal forms of stereotypy in two-, three-, and four-year-old children with and without ASD. They found that two-year-olds with ASD engaged in more frequent stereotypy when compared to same-aged, typically developing, peers. The prevalence of stereotypy increased with age in the children with ASD, but not in the age-matched typical children. These data suggest that as individuals with ASD age, they engage in higher rates and more forms of stereotypy. This finding is particularly important because the continued presence of these behaviors may impact negatively on an individual's developmental trajectory.

Although the presence of stereotypy is a criterion for autism spectrum diagnoses, categorizing behavior in this way does not prescribe a functional intervention (Cunningham \& 
Schreibman, 2008); that is, the way a behavior looks tells you nothing about how to treat it.

Indeed, researchers have identified disparate functions of stereotypy, including social positive (i.e., attention from others or access to preferred items or activities), social negative (i.e., escape from demands), and sensory (e.g., visual, auditory, or tactile stimulation) functions, in isolation or in combination, each of which entail different intervention strategies (see, Hanley, Iwata, \& McCord, 2003; Kennedy, Meyer, Knowles, \& Shukla, 2000, for reviews). Possibly because stereotypy inhibits the acquisition of appropriate and adaptive forms of behavior, most interventions focus on the reduction or elimination of these behaviors (Lanovaz \& Sladeczek, 2012). Reducing behavior maintained by sensory sources of reinforcement (i.e., when the reinforcer is not under control of the social environmental), however, is less straightforward than reducing behavior maintained by social positive or social negative reinforcers. This may make intervening on stereotypy particularly challenging considering that Hanley et al. (2003) found that over $60 \%$ of published functional analyses identify sensory sources of reinforcement for stereotypy. For these reasons, further discussion of stereotypy will focus on behaviors maintained by the direct sensory reinforcement they produce.

\section{Vocal Stereotypy in Autism Spectrum Disorders}

Vocal stereotypy, which includes repeated sentences, words, or sounds, is difficult to treat in persons with ASD. Although motor or physical stereotypies can be physically blocked or prevented (e.g., with the use of gentle deflection or holding, protective equipment, or mechanical restraints), the same is not true of vocal stereotypy. Despite these difficulties, multiple researchers have reported interventions that reduce or eliminate vocal stereotypy. These interventions include antecedent access to stimuli that are either matched to or independent of the sensory stimulation provided by the stereotypic behavior (Lanovaz, Fletcher, \& Rapp, 2009; 
Lanovaz \& Sladeczek, 2011; Rapp, 2007; Wong et al., 1987), reinforcing the absence of stereotypy (Rozenblat, Brown, Brown, Reeve, \& Reeve, 2009; Taylor, Hoch, \& Weissman, 2005), punishing vocal stereotypy (Ahearn, Clark, MacDonald, \& Chung, 2007; Ahrens, Lerman, Kodak, Worsdell, \& Keegan, 2011; Anderson \& Le, 2011; Athens, Vollmer, Sloman, \& St. Peter Pipkin, 2008; Cassella, Sidener, Sidener, \& Progar, 2011; Liu-Gitz \& Banda, 2010; Miguel, Clark, Tereshko, \& Ahearn, 2009; Rapp, Patel, Ghezzi, O’Flaherty, \& Titterington, 2009; Schumacher \& Rapp, 2011), or some combination of these interventions (Falcomata, Roane, Hovanetz, Kettering, \& Keeney, 2004; Haley, Heick, \& Luiselli, 2010; O’Connor, Prieto, Hoffman, DeQuinzio, \& Taylor, 2011; Watkins, Paananen, Rudrud, \& Rapp, 2011). In many of these studies, however, several interventions were attempted prior to identifying one that successfully reduced or eliminated vocal stereotypy (e.g., Anderson \& Le, 2011; Lanovaz et al., 2009), suggesting that intervention selection for vocal stereotypy is still trial and error.

Of the above studies, only a few reported maintenance of appropriate vocalizations while intervening on vocal stereotypy (e.g., Ahearn et al., 2007; Ahrens et al., 2011; Miguel et al., 2009). That is, most studies reported reduced rates of vocal stereotypy, but did not report on appropriate vocal behavior (e.g., initiating social interactions, answering questions, requesting items). Given the communication deficits inherent in ASD (APA, 2000), and given the impact of stereotypy on appropriate behavior (Lovaas et al., 1987; Koegel \& Covert, 1972; Koegel et al., 1974; Matson et al., 1997), treatments that fail to address the maintaining or increasing of appropriate vocal behavior may have unwanted side effects (Lanovaz \& Sladeczek, 2012; Taylor et al., 2005).

One program of research that tracked appropriate vocalizations while intervening on vocal stereotypy involves response interruption and redirection (RIRD; Ahearn et al., 2007), a 
punishment procedure (see Ahrens et al., 2011, for a discussion) that entails the delivery of demands contingent on the occurrence of the target behavior (Ahearn et al., 2007; Ahrens et al., 2011; Cassella et al., 2011; Liu-Gitz \& Banda, 2010; Miguel et al., 2009; Schumacher \& Rapp, 2011). Although RIRD decreased rates of vocal stereotypy for all participants in these studies, RIRD only increased appropriate vocalizations for participants who demonstrated functional use of language prior to beginning the study. For example, one participant in the Ahearn et al. (2007) study (Nikki) used few intelligible sounds and no words to communicate prior to intervention for vocal stereotypy. When RIRD was implemented, vocal stereotypy decreased, but appropriate vocalizations were completely suppressed. Thus, alternative approaches for reducing vocal stereotypy in individuals who do not engage in functional vocal communication may be necessary.

\section{Communication Interventions in Autism Spectrum Disorders}

Because those who lack effective functional communication often engage in a range of excess behaviors (e.g., aggression, disruption, self-injury; Kurtz, Boelter, Jarmolowicz, Chin, \& Hagopian, 2011), extensive research has been conducted on communication interventions for individuals with ASD. Although functional communication training (FCT; Carr \& Durand, 1985) is an empirically supported treatment for problem behavior (Kurtz et al., 2011), there are no standard guidelines for identifying or teaching a target response. Instead, several general approaches to teaching communication have been developed. One such intervention is to train alternative and augmentative forms of communication (AAC), which include communication modalities such as graphic symbol systems (e.g., Bondy \& Frost, 2001; Ganz \& Simpson, 2004), sign language (e.g., Bartman \& Freeman, 2003; Tincani, 2004), voice-output devices (e.g., Olive, Lang, \& Davis, 2008), and writing (e.g., Windsor, Doyle \& Siegel, 1994). Another intervention 
is stimulus-stimulus pairing (SSP), a procedure that arranges for the simultaneous presentation (i.e., pairing) of a target sound and a preferred item regardless of participant behavior (e.g., Brigham \& Sherman, 1968; Stock, Schulze, \& Mirenda, 2008; Sundberg, Michael, Partington, \& Sundberg, 1996). Lastly, vocal imitation training, in which the therapist models the target sound or word and reinforces the participant's successive approximations to the model, has been studied as a communication intervention (e.g., Ayllon \& Kelly, 1974; Brigham \& Sherman, 1968; Lovaas, Berberich, Perloff, \& Schaeffer, 1966; Risley \& Wolf, 1967; Sabatasso \& Jacobson, 1970; Sherman, 1965).

Augmentative and alternative communication (AAC). For young children who are not engaging in functional speech, AAC is commonly recommended by speech and language practitioners (American Speech-Language-Hearing Association [ASHA], 2012). Here, prompting is used to teach an individual to engage in the target response. Typically, problem behavior is blocked or ignored while successively independent communications are reinforced. Teaching alternative modes of communication can reduce problem behavior when the communicative response provides access to the same source of reinforcement as an excess behavior (e.g., Carr \& Durand, 1985; Charlop-Christy, Carpenter, Le, LeBlanc, \& Kellet, 2002; Olive et al., 2008). However, there are no clear guidelines for determining which system will be most effective for any one individual (Mirenda, 2003), and comparisons between systems have identified idiosyncratic outcomes across learners both in terms of appropriate communication and problem behavior (Lancioni et al., 2007; Sundberg \& Sundberg, 1990; Tincani, 2004; Vignes, 2007; Wraikat, Sundberg, \& Michael, 1991). Additionally, prerequisite skills are necessary for successful training with alternative forms of communication (Gregory, DeLeon, \& Richman, 2009) and, when these skills are absent, they must be taught prior to communication 
training. Moreover, alternative systems that require materials for communication (e.g., graphic symbol systems and voice output devices) can be bulky and cumbersome to transport and maintain (Mirenda, 2003). And lastly, teaching communication through alternative modalities does not necessarily lead to vocal production (Ganz, Heath, Rispoli, \& Earles-Vollrath, 2010; Mirenda, 2003; Schlosser \& Wendt, 2008), which, for many parents and caregivers, is the ultimate goal of communication training (Tincani, 2009).

Stimulus-stimulus pairing (SSP). The underlying theoretical assumption of SSP is that vocal behavior itself becomes a conditioned reinforcer when paired with preferred items (Brigham \& Sherman, 1968; Lovaas, Varni, Koegel, \& Lorsch, 1977; Sundberg et al., 1996). In this procedure, a therapist delivers preferred stimuli while emitting a target sound. The participant is not required to produce the sound to obtain the preferred items. The hypothesis is that, after sufficient paring, the target vocalization produces the conditioned reinforcer (i.e., the sound), thereby increasing the future likelihood of that vocalization. This approach was originally set forth as an explanatory mechanism for language acquisition in the absence of direct reinforcement (Skinner, 1957; Vaughan \& Michael, 1982).

Despite this theoretical underpinning, SSP has not consistently been shown to increase the production of target sounds (Brigham \& Sherman, 1968). In particular, SSP is often unsuccessful for participants with ASD (Esch, Carr, \& Michael, 2005; Carroll \& Klatt, 2008; Miguel, Carr, \& Michael, 2002; Normand \& Knoll, 2006; Stock et al., 2008). Although a minimal prerequisite vocal repertoire is needed for SSP, the procedure is least successful for increasing completely novel sounds (i.e., sounds not previously observed in the vocal-verbal repertoire; Carroll \& Klatt, 2008). In cases wherein SSP has been successful, participants began emitting the target sound during the SSP period, making it difficult to tease out the direct effects 
of reinforcement and stimulus pairing during the subsequent post-training observations (e.g., when reinforcers were no longer paired with the target sound; Stock et al., 2008). Even when the target vocalization does occur in post-pairing observations, the effect is short-lived in that most participants no longer produce the sound once the pairing procedure is discontinued (Miguel et al., 2002; Smith, Michael, \& Sundberg, 1996; Sundberg et al., 1996; Yoon \& Bennett, 2000; Yoon \& Feliciano, 2007). Researchers have attempted to capture post-pairing vocalizations by directly reinforcing the occurrence of the target vocalization during these observations, but the approach yields equivocal results (Carroll \& Klatt, 2008; Esch et al., 2005; Esch, Carr, \& Grow, 2009; Ward, Osnes, \& Partington, 2007; Yoon \& Feliciano, 2007). Moreover, investigations of the reinforcer conditioning processes suspected to underlie SSP also have been inconclusive (Petursdottir, Carp, Matthies, \& Esch, 2011).

Vocal imitation training. Most vocal training programs teach new forms of vocal communication via imitation procedures (DeThorne, Johnson, Walder, \& Mahurin-Smith, 2009; LeBlanc, Esch, Sidener, \& Firth, 2006). Reinforcers typically are delivered for successive approximations to modeled sounds, and once sounds are mastered, words, phrases, and sentences are taught in the same manner. However, the reinforcement of successive approximations requires sufficient variation in behavior for the selection of new responses that receive reinforcement (Skinner, 1981). That is, if the participant does not produce the target sound or an approximation of it, a reinforcer cannot be delivered. This may be particularly troublesome in minimally vocal individuals with ASD. Indeed, many young children with ASD do not exhibit imitative behavior (Metz, 1965; Rogers, Hepburn, Stackhouse, \& Wehner, 2003). Even when they engage in object- and gross-motor imitation, children with ASD frequently have difficulty with oral-motor, facial, and vocal imitation (Page \& Boucher, 1998). Moreover, imitative- 
shaping procedures are labor intensive and produce minimal response generalization; although production of the target might increase, other vocal behavior might not (Harris, 1975; Newman, Reinecke, \& Ramos, 2009). Alternative techniques for introducing novel vocal responses are necessary for these individuals.

A role for variability in communication interventions. Each of the above procedures, AAC, SSP, and vocal imitation training, frequently has been used to teach functional communication to non-verbal individuals with ASD. However, these procedures do not specifically outline how to respond to vocal stereotypy during training procedures. During AAC training, because the form of the communicative response (e.g., hand and finger motions, exchanging a picture) does not prohibit vocal stereotypy, it is unlikely that stereotypy would decrease. Indeed, vocal stereotypy could co-occur with the target communicative response and be inadvertently paired with social reinforcers. The same is true of SSP because the participant's behavior is independent of the delivery of preferred items, and vocal stereotypy potentially could be strengthened through this procedure. In vocal imitation, if the sound produced by the participant does not match the model, reinforcement is withheld and a new teaching trial is initiated. Although vocal stereotypy would be considered an incorrect response withholding the reinforcer for appropriate responding may not impact the rate of stereotypy because stereotypy is often maintained by its sensory consequences. Stereotypy would be likely to maintain under these conditions.

All of these procedures present limitations for communication training, particularly vocal training with learners with ASD who have impoverished or stereotyped response repertoires. If an individual vocalizes repetitively yet does not produce functional speech, the current bestpractice approach appears to be to eliminate vocalizations altogether and to teach an alternative 
form of communication (e.g., AAC). For most parents and caregivers, this does not represent a socially acceptable intervention. One area of research that has implications for improvements in both vocal stereotypy and communication training for this population is that of behavioral variability. If a repetitive vocal repertoire could be changed such that there is more variability in the sounds produced, more sounds are available to contact reinforcement and therefore become available for communication interventions.

\section{Behavioral Variability}

Responses can vary along many dimensions, such as the frequency, force, pitch, volume, or sub-units (e.g., left and right lever presses in a sequence; Neuringer, 2002, 2004, 2009). Variability is inversely related to repetition; that is, the more different ways a response is produced, the less repetitive that response is. The study of behavioral variability is robust, with demonstrations of environmental control over variable behavior in both basic and applied research, across species, behavioral topographies, and response dimensions. In addition to phylogenic origins of variable behavior (Aase \& Sagvolden, 2006; Hopkinson \& Neuringer, 2003; Hunziker, Saldana, \& Neuringer, 1996; Johansen, Killeen, \& Sagvolden, 2007; Neuringer, 2002, 2004, 2009; Saldana \& Neuringer, 1998), there are several operant origins of variability. These operant origins include extinction-induced variability, variability as a concurrent effect of intermittent reinforcement, and direct reinforcement of variable behavior (see, Lee, Sturmey, \& Fields, 2007; Neuringer 2002, 2004, 2009 for reviews). However, because behavior under sensory control produces its own reinforcement, it may be particularly challenging to operantly induce variability in sensory-maintained responding.

Extinction-induced variability. Elimination of response-reinforcer contiguity increases the variability with which a target response is produced (Antonitis, 1951; Eckerman \& Lanson, 
1969; Lane, \& Shinkman, 1963; Thompson, Heistad, \& Palermo, 1963). Researchers have demonstrated that extinction-induced variability can be provoked effectively and then captured with direct reinforcement as part of mand (i.e., requesting; Betz, Higbee, Kelley, Sellers, \& Pollard, 2011; Grow, Kelley, Roane, \& Shillingsburg, 2008; Hernandez, Hanley, Ingvarsson, \& Tiger, 2007) and during play-skills interventions (Lalli, Zanolli, \& Wohn, 1994). However, the occurrence of extinction-induced variability depends on the schedule of reinforcement under which the performance was developed initially (Kinloch, Foster, \& McEwan, 2009; Morgan \& Lee, 1996; Stokes, 1995). This reinforcement history is frequently unknown in the natural environment, making extinction an unpredictable method of inducing variability. Although less prevalent responses can occur with extinction, the distribution of relative response frequencies tends to remain the same as when reinforcers are delivered (Maes, 2003; Neuringer, Kornell, \& Olufs, 2001); that is, behavior consists of previously observed responses in most cases. In addition, extinction-induced variability is short-lived because as extinction decreases the rate of responding, both prevalent repetitive and less-prevalent variable behaviors decrease, and varied behavior may not come in contact with reinforcement when contingencies are re-applied (Antonitis, 1951; Maes, 2003). Thus, if one's initial repertoire consists of a limited range of repetitive sensory reinforcement maintained, it is unlikely that completely novel responses will be emitted during extinction.

Variability through intermittent reinforcement. When reinforcers are delivered intermittently, various dimensions of a response become less repetitive (Boren, Moerschbaecher, \& Whyte, 1978; Eckerman \& Lanson, 1969; Lane \& Shinkman, 1963; Lee, 1999; Lopatto \& Brown, 1994; Tatham, Wanchisen, \& Hineline, 1993; Tremont, 1984). During treatment procedures, behavioral variability increases when reinforcement is thinned from a dense to a lean 
schedule of delivery, but usually this is an undesired side effect (i.e., new forms of problem behavior, more intense problem behavior; Hagopian, Contrucci Kuhn, Long, \& Rush, 2005; Volkert, Lerman, Call, \& Trosclair-Lasserre, 2009). When rigorous yoked control procedures are used, however, responding is less variable under intermittent reinforcement than when directly reinforcing variability (Maes, 2003; Maes \& van der Goot, 2006; Morgan \& Neuringer, 1990; Neuringer, Deiss, \& Imig, 2000; Page \& Neuringer, 1985). Despite the considerable basic literature, and frequent clinical observations, the applied literature has yet to develop techniques to capitalize on the variability that occurs under intermittent reinforcement.

Direct reinforcement of variability. Variability is an operant dimension of behavior (Neuringer, 2002, 2004, 2009) that can come under the control of discriminative stimuli (Denney \& Neuringer, 1998; Odum, Ward, Barnes, \& Burke, 2006; Ward, Kynaston, Bailey, \& Odum, 2008) and be modified through the application of contingencies (Machado, 1992; Madelain, Champrenaut, \& Chauvin, 2007; Morris, 1987; Neuringer, 1986). Variability of one response dimension (e.g., force, rate, topography) can be targeted and increased separately from other response dimensions (Catania, Ono, \& de Souza, 2000; Ross \& Neuringer, 2002). Moreover, delays of reinforcement typically induce variability (Odum et al., 2006; Wagner \& Neuringer, 2006), whereas instructional control often suppresses variability (Baumann, Abreu-Rodrigues, \& da Silva Souza, 2009; Joyce \& Chase, 1990; Stokes \& Balsam, 2003).

Variability can be developed and maintained under several contingency arrangements that specifically program for the delivery of reinforcers for varied responding. These reinforcer arrangements include percentile schedules (e.g., Machado, 1989), threshold-value schedules (e.g., Ross \& Neuringer, 2002), lag $x$ schedules (e.g., Page \& Neuringer, 1985), and differentialreinforcement-of-least-probable-responses or of-novel-responses (Blough, 1966; Bryant \& 
Church, 1974; Cammilleri \& Hanley, 2005; Duker, \& van Lent, 1991; Goetz \& Baer, 1973; Harding, Wacker, Berg, Rick, \& Lee, 2004; Hernandez et al., 2007; Lalli et al., 1994; Machado, 1993; Pryor, Haag, \& O’Reilly, 1969). Even though each of these contingency arrangements increases variability, some require complex calculations to evaluate the relative variability of the current response to determine whether a reinforcer should be delivered (e.g., Ross \& Neuringer, 2002). Technological advancement since the 1960s makes these computations effortless in laboratory environments, but the percentile and threshold schedules mentioned above present significant challenges to the manipulation of variability in the natural environment (that is, the treatment setting). In addition, if the delivery of reinforcers becomes too infrequent too soon, as is possible under the differential-reinforcement-of-novel-responses schedule, varied responding might undergo ratio strain and cease to occur (Skinner, 1953).

Lag $x$ reinforcement schedules, however, do not require complex calculations, in that the current response is compared to the preceding $x$ responses. In applied settings (where continuous coding, categorization, and establishment of a response threshold for variability is difficult to accomplish before the occurrence of the next response) the simplicity of the lag $x$ schedule may be appealing. In addition, because only the most recent instances of behavior are used for comparison (see below), it is unlikely that ratio strain will occur.

Under a lag $x$ schedule, a response is reinforced if it differs from $x$ prior responses on some dimension. For example, assume that the behavior of interest is a sequence of four lever presses, and that the dimension along which variability is measured is how responses are allocated to the left and right levers. A Lag 5 schedule would arrange for the delivery of a reinforcer if the left (L) and right (R) presses in the current four-response sequence (e.g., RRLR) differ from the five preceding sequences of left and right presses (e.g., RLLR, LLRR, LRRL, 
LLLR, RRRL). Lag $x$ schedules have been used successfully to increase variability in both basic and applied settings (see, Lee et al., 2007; Neuringer, 2002, 2004, 2009, for reviews).

If the schedule on which an existing behavior is reinforced is beyond direct environmental control (as in the case of sensory-maintained behavior), the response-reinforcer relation can neither be terminated nor made intermittent (see Lovaas et al., 1987, for a review). Instead, delivery of other identified reinforcers (e.g., edible items, tokens, praise, leisure items) for varied responding may be the most viable approach for increasing variability in a repetitive response repertoire (e.g., Rozenblat et al., 2009; Taylor et al., 2005).

\section{Increasing Vocal Variability in Autism Spectrum Disorders}

Vocalizations in several species of animals are amenable to control by contingencies. Several aspects of vocalizations, including the rate (Hake \& Mabry, 1979; Lane, 1961; Leander, Milan, Jasper, \& Heaton, 1972; Reeve, Reeve, Brown, Brown, \& Poulson, 1992; Reeve, Reeve, \& Poulson, 1993; Salzinger \& Waller, 1962; Weiss, Boyer, Colwick, \& Moran, 1971), duration (Lane, Kopp, Sheppard, Anderson, \& Carlson, 1967; Molliver, 1963), volume (Fleece et al., 1981), and topography (Johnston \& Johnston, 1972; Moerk, 1983, 1990) are modifiable. Most relevant among these are studies that demonstrated control of vocal variability by consequences (Manabe, Staddon, \& Cleaveland, 1997; Schusterman \& Reichmuth, 2008). Manabe et al. (1997) demonstrated that the call frequency of budgerigars (a species of parakeet) could be made variable when reinforced on a modified lag schedule. Under this reinforcement contingency, new call types occurred that were created from features of pre-existing call types. Similarly, Schusterman and Reichmuth (2008) found that the variability of vocal productions by the Pacific walrus could be increased under a Lag 1 schedule. The two subjects engaged in varied behavior both under and above water. Both walruses had lived in captivity from two weeks of age, and the 
authors claimed that the subjects produced vocalizations never observed before by staff. Indeed, frequency analysis showed that, under reinforcement, both subjects vocalized in ways more similar to wild walruses than in baseline.

Repetitive responding in individuals with ASD can be reduced and variability can be increased through reinforcement (Miller \& Neuringer, 2000; Napolitano, Smith, Zarcone, Goodkin, \& McAdam, 2010; Newman, Reinecke, \& Meinberg, 2000). Particularly relevant to the current studies, vocal variability can be increased in participants with ASD using direct reinforcement (Esch, Esch, \& Love, 2009; Heldt \& Schlinger, in press; Lee, McComas, \& Jawor, 2002; Lee \& Sturmey, 2006; Susa \& Schlinger, in press). To date, research indicates that variability in intraverbal responses (i.e., answers to social questions; Lee et al., 2002; Lee \& Sturmey, 2006; Susa \& Schlinger, in press), in tacting (i.e., labeling; Heldt \& Schlinger, in press), and in echoics (i.e., responses that topographically match a model; Esch et al., 2009) can be increased.

Using a combination Lag 1/differential-reinforcement-of-appropriate-responses (DRA) schedule of reinforcement, Lee et al. (2002) increased the variability with which two participants with autism responded to the question, "What do you like to do?" For a third participant, the question, "How are you?" was presented but response variability did not increase under Lag 1/DRA. For the two participants for whom variability did increase, responses were comprised mostly of items present in the participant's field of vision. Therefore, it was unclear if variability would have increased without these stimuli present (i.e., with reinforcement alone), or if the stimuli controlled responding (i.e., reinforcement was unnecessary). In a follow-up study, Lee and Sturmey (2006) demonstrated that stimuli alone did not control varied responding, and that Lag 1 reinforcement was the operant mechanism of behavior change for two of three participants 
(variability did not increase for the third participant). It should be noted that in both studies, at least one participant met the reinforcement contingency (i.e., earned all available reinforcers) by simply switching between two response alternatives. This pattern, which has been referred to as higher-order stereotypy (Lee et al., 2007; Page \& Neuringer, 1985), can occur as an inadvertent effect of lag schedules. Susa and Schlinger (in press) addressed this concern by exposing the behavior of one participant with ASD to a Lag 3 schedule in a systematic replication of Lee et al. (2002). Here, more varied responses were produced by the participant as schedule requirements increased from Lag 1 to Lag 3. Heldt and Schlinger (in press) also showed that higher-order stereotypy could be avoided by programming a higher lag value during tact training.

In each of these studies, participants with ASD demonstrated pre-existing production of words. The results are certainly relevant to reducing inappropriate repetitive responses and increasing varied vocal behavior in individuals with ASD. The above findings, however, do not demonstrate that variability can be increased in individuals without functional speech or individuals with sensory maintained vocal stereotypy. Esch et al. (2009) attempted to address this problem. Here, two participants with autism (who did not use words and who did not engage in vocal imitation) were exposed to a Lag 1 schedule of reinforcement for topographically different vocalizations. On each of ten trials, a vocal model was presented, and a reinforcer was delivered if the participant's response was different (i.e., contained more or fewer phonemes, these being the smallest unit of speech sounds) from the previous response, regardless of the model. Both participants produced vocalizations that differed from trial to trial under the reinforcement contingency, but variability did not maintain when reinforcers were withheld. The authors also pointed out that variability, as defined in their study resulted, in recombinations of existing sounds but that new phonemes were few or were not observed. The findings of Esch et 
al. (2009) are encouraging, but more work is needed to identify how vocal variability, and especially the occurrence of new but developmentally appropriate speech sounds, can be increased.

\section{Objectives of the Present Research}

Reinforcement typically is provided for a response class (e.g., the vocal repertoire) rather than one class member. Reinforcing stereotypy limits the range of behaviors in the class, whereas reinforcing variability expands the range of the class, allowing for the later reinforcement of a greater variety of responses (Ross \& Neuringer, 2002). Indeed, higher levels of variability lead to faster target response acquisition (Grunow \& Neuringer, 2002; Neuringer, 1993; Neuringer, Deiss, \& Olson, 2000) and to better response generalization to new tasks (Stokes, Lai, Holtz, Rigsbee, \& Cherrick, 2008). On the other hand, reinforcement for a single behavior within a response class can impede learning of new responses (e.g., Schroeder \& Baer, 1972). If stereotypy is viewed as behavior that frequently contacts reinforcing contingencies (i.e., through its own sensory consequences), then greater response strength is developed with each response (Lovaas et al., 1987). Instead, by arranging for the reinforcement of varied behaviors, better clinical outcomes and better skill acquisition in individuals with ASD may be achieved. When applied to communication training, increased vocal variability could mean the addition of novel phonemes to the vocal repertoire, and therefore the availability of more speech sounds for shaping into functional words.

There were three main objectives of the current set of studies. After identifying the characteristics of vocal behavior of children with ASD with limited vocal repertoires, an intervention to increase vocal variability was investigated, followed by the assessment of a simplified procedure for maintaining variability gains. The first objective was to conduct a 
descriptive analysis of the novelty of vocalizations and phoneme repertoires of children diagnosed with ASD who were not imitating vocalizations nor engaging in word use. The second objective was to determine if, and to what extent, reinforcement for variability would increase production of varied vocalizations and of novel phonemes. The third objective was to examine how vocal variability, once developed, could be maintained under alternative schedules of reinforcement.

Objective 1. Young children with autism who are not using vocal forms of communication frequently engage in vocal play (e.g., babbling). To date, however, most research aims to decrease vocal stereotypy without always documenting improvements in appropriate communication (e.g., Ahearn et al., 2007). Studies that provide an analysis of the phonemes in the existing vocal repertoire, or of the ways in which these phonemes are combined into vocalizations, are lacking in the literature (but see, McCleery, Tully, Slevc, \& Schreibman, 2006, for an exception). Study 1 was designed to collect information about the vocal repertoires of children with ASD who were not using words to communicate. These findings provided data on the existing variability of vocalizations, as well as on the ways in which individual speech sounds (i.e., phonemes) were combined as sub-units of larger responses (i.e., vocalizations).

Objective 2. Although vocal stereotypy itself can impede the development of appropriate vocal behavior (Lovaas et al., 1987; Koegel \& Covert, 1972; Koegel et al., 1974; Matson et al., 1997), reduction of stereotypy should not result in the elimination of all speech sounds. One previous study attempted to apply variability contingencies to the repetitive vocal repertoires of nonverbal children with autism (Esch et al., 2009). The study used a lenient definition of variability (e.g., "ba" and "baba" both were considered novel vocalizations) and investigated the effects of one variability contingency (i.e., a Lag 1 schedule of reinforcement). It is unclear if 
this procedure would be effective for most children (only two children participated in that study with limited gains reported). To that end, participants with low baseline vocal variability (i.e., high levels of repetitive vocalizations) as evidenced by Study 1 were exposed to two lag schedules of reinforcement in Study 2. Data collected under these conditions provided information about the impact of reinforced variability on the phoneme repertoire and the production of novel vocalizations.

Objective 3. Although increases in vocal variability can be attained under rigorous schedules of reinforcement, behavioral literature suggests that these gains can be lost when the original schedule is discontinued (i.e., extinction; e.g., Esch et al., 2009) or when the contingency for earning reinforcers changes (i.e., reinforcer delivery is no longer dependent on variability; e.g., Page \& Neuringer, 1985). If, however, a behavioral intervention contains many components, parents or caregivers may be unable to implement the procedure with fidelity (Gresham, 2009). That is, they may not be able to implement the behavior plan as written, resulting in a degradation of the variability-reinforcer contingency. Study 3 was designed to determine the conditions under which vocal variability is maintained after the removal of a lag schedule of reinforcement. If an alternative, less rigorous reinforcement schedule maintains vocal variability, it may be possible to develop a technology of maintenance whereby behavior analysts target acquisition of variability, and caregivers or other service providers (e.g., teachers, speech-language pathologists) maintain it. 


\section{General Methods}

\section{Participants}

Ten children participated in the set of three studies. All ten children participated in Study 1, five participated in Study 2, and one participated in Study 3. Prior to the study, each participant had been previously diagnosed with an autism spectrum disorder by a professional involved with that child's care. Participants were recruited through public elementary schools, local intervention service providers, or a major hospital system that provides a wide range of services for individuals with disabilities. Each participant was referred to the study because they engaged in vocal play, such as babbling speech sounds, and demonstrated a lack of functional speech (i.e., speech sounds were not directed toward an object or individual, and no words were

vocalized). Participant characteristics are summarized in Table 1; additional details are provided below.

Nadia was a 2-year-old White female diagnosed with autistic disorder. She was a fraternal twin and her brother also was diagnosed with an autism spectrum disorder. At the beginning of the study, Nadia received weekly in-home speech therapy, occupational therapy, and behavioral consultation through state-funded Birth-to-Three (BTT) early intervention services. The BTT behavioral service provider referred her for study participation. Therapy documentation indicated that Nadia did not demonstrate vocal imitative skills; a brief imitative probe at intake was consistent with the documentation in that she did not engage in these skills. During the intake meeting, Nadia made repetitive vocal sounds while staring at her hands or at the wall.

Nathan was a 7-year-old White male, diagnosed with autistic disorder and encephalopathy; his family had immigrated to the United States from the Middle East shortly 
after his birth. He was referred by his public school teacher and was observed in his classroom during the regular school day and during speech therapy sessions. Speech therapy targeted picture communication, but Nathan did not to exchange pictures independently when observed by research staff. He vocalized throughout the school day while looking at his fingers or at a tabletop.

Kali was a 3-year-old White female diagnosed with autistic disorder and global developmental delay. At the time of study enrollment, she received weekly in-home speech therapy, occupational therapy, and behavioral consultation through BTT. Kali was referred by her BTT behavioral service provider. Documentation of Kali's skills by the service providers indicated that she neither engaged in vocal imitation nor independent picture exchange. Initial observations were consistent with the documentation. Kali was observed to vocalize various speech sounds while manipulating play items and while moving about the room; however, her vocalizations were unintelligible and were not directed toward other people.

Dillon was a 14-year-old Black male diagnosed with autistic disorder whose family had immigrated to the United States from Africa after his birth. At the time of the study, Dillon was hospitalized for the assessment and treatment of severe aggressive and self-injurious behavior (these behaviors did not occur during any study sessions). An analog functional analysis (Iwata, Dorsey, Slifer, Bauman, \& Richman, 1994) indicated that Dillon's aggressive and self-injurious behaviors were maintained by escape from work, access to preferred activities, and access to preferred foods. Although school-based speech and in-home respite care providers attempted to teach picture-based communication, Dillon used neither picture-based communication nor words to communicate his needs during his inpatient admission. Specifically, Dillon was observed to vocalize a range of sounds during leisure times on the hospital unit; however, these vocalizations 
were directed primarily at his hands or were voiced with his eyes closed.

Nicholas was a 2-year-old White male diagnosed with autistic disorder. At the beginning of the study, he received weekly in-home speech therapy, occupational therapy, and behavioral consultation through BTT. The service providers documented that Nicholas did not demonstrate vocal imitative skills. A brief imitative probe at intake was consistent with the report of the service providers. At the intake meeting, Nicholas sat alone and vocalized while rocking.

Kristopher was an 8-year-old White male diagnosed with autistic disorder and seizure disorder. He was referred by his public school teacher and was observed by research staff in the classroom during the regular school day and during speech therapy sessions. Although speech therapy targeted picture communication, Kristopher did not to exchange pictures independently when observed by research staff. In the classroom, he vocalized throughout the school day with his eyes closed or while looking at his fingers.

Owen was a 6-year-old Black male diagnosed with autistic disorder. He was referred by his public school teacher and was observed by research staff in the classroom during the regular school day and during speech therapy sessions. Speech therapy sessions targeted picture communication, but independent communication did not occur. In the classroom, Owen vocalized primarily while engaging in gross motor activity (e.g., running, swinging).

Remy was a 2-year-old White male diagnosed with autistic disorder. At the time of the study, he received speech therapy, occupational therapy, and behavioral consultative services through BTT. Remy's mother sought more intensive behavioral services through a local clinic and was contacted about study participation when her son was placed on the clinic's waiting list. Remy's mother reported that he did not communicate his wants or needs vocally; an initial probe showed that he did not imitate sounds either. Remy vocalized while engaging in gross motor 
activities (e.g., running, spinning) and while manipulating play items; such vocalizations were not directed toward other people.

Nelson was a 6-year-old Black male diagnosed with pervasive developmental disorder, gross motor delays, and congenital encephalopathy. At the time of the study, he was hospitalized for the assessment and treatment of severe self-injurious behavior. These behaviors were found to be maintained by access to edibles and attention, and to produce sensory stimulation via a pairwise functional analysis (Iwata, Duncan, Zarcone, Lerman, \& Shore, 1994). During the study sessions, self-injurious behavior was gently blocked to prevent tissue damage to his hands, wrists, face, and head. Sessions were terminated for the day if tantrum behavior that included self-injury occurred (this happened twice over the course of the study). School documentation indicated that Nelson did not communicate his wants or needs vocally, nor through any alternative modality. During leisure times on the hospital unit, he vocalized repetitive speech sounds while rocking and rhythmically tapping his arms and hands on surfaces.

Isabel was a 4-year-old White female diagnosed with autistic disorder. Over the course of the study she developed a seizure disorder. Isabel was referred to a school-based behavior team for the assessment and treatment of elopement from activities in her classroom (this behavior did not occur during study sessions). Isabel received speech and occupational therapy services through her inclusive preschool placement, and applied behavior analytic therapy through a local consultative clinic; however, she was not observed to communicate independently. During the intake meeting, Isabel vocalized speech sounds while engaged in gross motor activities (e.g., running, spinning) and while seated and rocking. 


\section{Setting and Materials}

For all participants, study sessions were conducted in designated areas with a table, chairs, and some form of visual barrier (e.g., door to room, room partitions) from any existing distractions. Writing materials and preferred edible items (e.g., juice, small chips, candy) were located on the table out of reach of the participants. A digital video camera and tripod positioned on the table recorded sessions for later transcription. Table 1 contains a summary of session setting information; additional details are provided below.

Sessions with Nadia and Remy were conducted in a cubicle at an intensive services clinic near their hometown. The cubicle contained a set of child-sized table and chairs and a set of rolling drawers that contained various toys (unavailable during study sessions). Throughout the study, other clients served by the clinic received services in adjacent cubicles; a movable partition blocked the entrance of the study cubicle and reduced both visual and auditory distractions.

Sessions were conducted in a small portion of the public school classroom that served Nathan, Kristopher, and Owen. A partition blocked off an area that contained a locked storage closet and a table and chairs. As with the intensive clinic, students received services in other parts of the classroom throughout the study.

Study sessions with Kali and Isabel were conducted in a room in a university-based laboratory. A table, chairs, adult-sized desk, and a container of toys (unavailable during sessions) were present in the room. Nicholas started the study in the laboratory; complications with his mother's health and access to transportation required that sessions be moved to a bedroom in his home. This change occurred during baseline, and stable responding was achieved during these home-based sessions. The bedroom contained a child-sized bed and chair, two chests of drawers, 
and various toys and books (unavailable during study sessions).

The study sessions conducted with Dillon and Nelson occurred on the hospital unit in a treatment room with padded walls. A one-way mirror was located on one wall of the room.

\section{Defining Vocalizations and Novelty}

Vocalizations. The target response for all participants throughout the series of studies was vocalizations. A vocalization was defined as an orally emitted phoneme, or series of phonemes, separated from the previously emitted vocalization by $0.5 \mathrm{~s}$ or more. Exceptions not included as vocalizations were sounds attributable to chewing, blowing "raspberries," heavy breathing, grunting, coughing, and growling. Phonemes uttered above or below conversational volume (e.g., shouting or whispering), or that occurred simultaneous with aggressive or selfinjurious behavior, were not scored as vocalizations. Trained research assistants transcribed vocalizations from digital video after each session.

Novel vocalizations. The primary focus of these studies was to analyze and increase the production of novel vocalizations by the participants. A novel vocalization was defined as a vocalization that was more than one unique (i.e., not repeated) phoneme different from all prior vocalizations within that session. For example, the vocalization "bŏ-bŏ-bŏ" would not be different from "bŏ" because there are no unique phonemes contained in the former as compared to the latter; this is simply a repetition of the same sound. Similarly, "bŏ-bŏ-bŏ" would not be scored as novel when compared to "bŏ-/d/" as only one phoneme is different between the two vocalizations (/d/). However, "bŏ-bŏ-bŏ" would be considered novel when compared to "bŏ-dā" because the latter contains two phonemes that the former does not $(/ \mathrm{d} /$ and $\overline{\mathrm{a}})$. In this instance, "bŏ-bŏ-bŏ” would be scored as a novel vocalization. 


\section{Dependent Measures}

Percentage of novel vocalizations. The percentage of novel vocalizations was determined from session transcripts. The first vocalization within a session was always coded as novel because there were no prior vocalizations to which it could be compared (i.e., it was novel compared to not having previously vocalized in that session). The remaining vocalizations within a session were compared to all preceding vocalizations; that is, the second vocalization was compared to the first, the third vocalization was compared to the first and second, and so forth. The percentage of vocalizations scored as novel was calculated for each session by dividing the number of novel vocalizations by the total number of vocalizations during that session and multiplying by $100 \%$.

Cumulative novel vocalizations. Transcripts were also scored for cumulative novel vocalizations across sessions within an experimental phase (as opposed to within sessions). A vocalization was coded as novel if it differed by more than one phoneme from all prior vocalizations within the current experimental condition. Similar to percentage of novel vocalizations, the first vocalization within the first session of a condition was scored as novel. The remaining vocalizations within a condition were compared to all preceding vocalizations across all sessions within that condition. Following this rule, the first vocalization of the second session was compared to all vocalizations from the first session, and the last vocalization of the last session was compared to all vocalizations within all sessions in the condition. Cumulative records were created by adding the number of novel vocalizations produced in a session to the number of novel vocalizations from prior sessions in the phase. The slope of the resulting line provides an index of the extent to which vocalizations were variable or stereotyped over sessions (the steeper the slope, the more novel vocalizations per session of that condition). This measure 
of novel vocalizations is a more conservative analysis than within session novelty in that variability was assessed over a larger set of vocalizations over an extended period of time (one $v s$. multiple sessions).

Frequency of phonemes. Multiple dimensions of a response can be affected simultaneously by placing contingencies on variability (Ross \& Neuringer, 2002). Although the percentage of novel vocalizations provides a general description of how different vocalizations are from each other within a session, it is unclear whether the differences are due to the recombination of a small set of phonemes or to the creation of novel vocalizations from a larger set of phonemes. Further, because each vocalization could potentially be comprised of an unlimited number of phonemes, an analysis of the phonemic sub-units within a vocalization provides a fine-grained examination. Thus, the frequency of each individual phoneme was counted to allow an analysis of response sub-units.

The transcripts from the final six sessions of each phase (i.e., when percentage of novel vocalizations per session had stabilized) were analyzed for the frequency of phonemes. The number of times each phoneme occurred within the six stable sessions was counted, and a frequency bar graph was created. However, only the first instance of a phoneme within each vocalization was counted. That is, only the unique, within-vocalization occurrence of a phoneme was scored. For example, a vocalization transcribed as "bŏ-bŏ-bŏ" was scored as one occurrence of /b/ and one occurrence of $\breve{~ o . ~ T h u s, ~ n o ~ p h o n e m e ~ c o u l d ~ b e ~ s c o r e d ~ a s ~ o c c u r r i n g ~ m o r e ~ o f t e n ~ t h a n ~}$ the total number of vocalizations (e.g., one vocalization and one count of $/ \mathrm{b} /$ ), preventing the repetition of a sound within one vocalization from inflating its proportional representation in the vocal repertoire. This measure provided an across-vocalization examination of phoneme stereotypy instead of a within-vocalization assessment. 
Proportion of phonemes. Because vocalizations could be comprised of an unlimited number of phonemes, the gross measure of frequency complicates an across-participant comparison of the distribution of phonemes produced. Calculating the proportion of each phoneme produced provides a standardized measure to compare stereotypy across the phoneme repertoires of multiple participants, or across conditions within participant, during the final six sessions of a phase. Therefore, the number of times a given phoneme was uttered was divided by the total number of phonemes to derive a proportion.

Proportion of vocalizations. The above method for counting phonemes allowed for another measure to be derived. Calculating the proportion of vocalizations containing a particular phoneme allowed for an analysis of stereotypy across vocalizations rather than within the phoneme repertoire (i.e., proportion of phonemes). Here, the frequency of each phoneme was divided by the total number of vocalizations occurring in the last six sessions of a condition.

\section{Interobserver Agreement}

Eight undergraduate students served as research assistants (RAs) for this series of studies. The RAs were trained to identify and record phonemes and to determine vocalizations and novel vocalizations. Prior to transcribing the digital video recordings of a specific participant, an RA was trained to $90 \%$ or better interobserver agreement (IOA) for that participant, the criterion being the transcriptions of an experienced observer (the primary investigator). The RA would then transcribe a participant's recordings and calculate key measures (novel vocalizations and frequency of phonemes). A second RA, also trained to criterion for that participant, would independently review the transcriptions and calculate the key measures. The primary investigator then compared the results from the two RAs to determine IOA.

To determine IOA for novel vocalizations, the results from the two independent 
observers were compared by dividing the smaller number of novel vocalizations coded for a session by the larger number of novel vocalizations coded for that session. The resulting value was multiplied by $100 \%$ to give percentage agreement. Percentage agreement scores were then averaged across sessions for that participant. Similarly, IOA for frequency of phonemes was calculated by dividing the smaller count for a given phoneme in a session by the larger count for that phoneme in that session. Percentage agreement for that phoneme was calculated by multiplying the result by $100 \%$. Phoneme agreement scores were then averaged across all phonemes within a session, and then averaged across all stable sessions for each participant.

\section{General Procedures}

Preference assessment. Prior to intervention, a paired-choice preference assessment (PCPA) was conducted with each participant to select an item for use as a reinforcer (Fisher et al., 1992). Preference assessments are standardized procedures to identify highly preferred items that will likely serve as reinforcers for the individual. In a PCPA, two items are presented on each trial, with each item paired with every other item at least once. Items used in the assessment were nominated by a parent or caregiver, and up to eight items were assessed for each participant. The item selected by the participant the greatest percentage of opportunities was used as a reinforcer during the study. For some participants, more than one item was selected more than $70 \%$ of opportunities; in these cases, the participant was given the opportunity to select one item at the beginning of each session throughout the study. Table 1 shows the most preferred items for each participant.

Structure of study sessions. Study appointments lasted 1 to 2 hours, and were scheduled between 1 and 3 times weekly. Between 3 and 8 sessions were conducted during each appointment, with brief breaks for play ( 2 to $3 \mathrm{~min}$ ) between each session. During sessions, the 
participant was seated in a chair directly opposite the investigator. A table was positioned to either side of the two chairs such that a pen and paper were close to the investigator. No prompts or instructions were given to the participant. The investigator used a hand-held device to count vocalizations. Individual sessions lasted until the participant emitted 20 vocalizations.

Participants were exposed to each condition for a minimum of 20 sessions. Pilot data suggested that 20 sessions per condition provided sufficient exposure to contingencies to produce stable behavioral performance in percentage of novel vocalizations. Stability criteria were established such that, over six consecutive sessions of a condition, there could be no more than $5 \%$ variability between the mean of the first three and the mean of the second three sessions from the grand mean of the six sessions. Conditions were terminated when behavior met stability criteria or when a total of 40 sessions were conducted in the condition.

Procedural fidelity. Procedural fidelity is defined as the accurate implementation of a specified procedure. To ensure that sessions were terminated after 20 vocalizations, the number of vocalizations within a session was counted by the RA transcribing the session. To calculate procedural fidelity for session termination, the smaller of the two values was divided by the larger of the two, and multiplied by $100 \%$ to yield a procedural fidelity score. Fidelity scores for session termination were averaged across all sessions in each condition for each participant.

To ensure that reinforcement procedures were implemented with fidelity, sessions in which reinforcers were given (Studies 2 and 3) were scored for the appropriate delivery of those items. The RA transcribing a session placed a mark next to a vocalization if a reinforcer was delivered following the vocalization. The RA then determined whether each vocalization in a session should have been reinforced according to the schedule of reinforcement in effect. If a reinforcer should have been delivered and was actually delivered, or if a reinforcer should not 
have been delivered and was not actually delivered, procedural implementation was coded as correct. If a reinforcer should have been delivered but was not, or if a reinforcer should not have been delivered but was, procedural implementation was coded as incorrect. A fidelity score was calculated by counting corrects, dividing by corrects plus incorrects, and multiplying by $100 \%$ to yield a fidelity score for reinforcer delivery. Fidelity scores for reinforcer delivery were averaged across at least $25 \%$ of sessions in each condition for each participant. Fidelity of session termination and reinforcer delivery will be reported separately for each study.

\section{Study 1}

\section{Methods}

Participants. All ten of the children described above (see also Table 1) participated in Study 1.

Procedures. The purpose of Study 1 was to collect descriptive information about the vocal repertoire of language-delayed children with an autism spectrum diagnosis. To examine the existing level of stereotypy, sessions in which no environmental contingencies were programmed for vocalizations were conducted.

Baseline. Sessions were conducted in the settings described above (see also Table 1), with the participant seated across from the investigator and distractions minimized. Sessions were structured as noted above, being terminated after the participant produced 20 vocalizations. During the baseline condition, no reinforcers were delivered for vocalizations, although one preferred item identified via PCPA was located on the adjacent table and was visible (but out of reach) to the participant during all sessions.

Procedural fidelity. Across all sessions in Study 1, the procedure for session termination (20 vocalizations) was implemented with greater that $95 \%$ fidelity for eight of the participants: 
95.9\% for Nadia (range: $80-100 \%$ ), 96.4\% for Remy (range: 85-100\%), 96.7\% for Kali (range: 85-100\%), 96.7\% for Kristopher (range: 90-100\%), 97.2\% for Isabel (range: 83.3-100\%), 97.6\% for Nicholas (range: 90-100\%), 97.8\% for Dillon (range: 90-100\%), and 100\% for Nelson. Fidelity was slightly lower, but above $91 \%$ for the other two participants: $91.5 \%$ for Owen (range: $83.3 \%-95.2 \%$ ), and $93.7 \%$ for Nathan (range: $90.9-95.2 \%$ ).

Interobserver agreement. Interobserver agreement for each raw dependent measure (novel vocalizations and frequency of phonemes) is reported separately.

Novel vocalizations. IOA for novel vocalizations was $100 \%$ for three participants: Nadia, Nelson, and Nicholas (calculated across 35\%, 36\%, and 35\% of their sessions, respectively). The average agreement was above $96 \%$ for four other participants: (a) Nathan: $96.7 \%$ (range: 86.7 100\%, 33\% of sessions), (b) Kali: $96.8 \%$ (range: $82.4-100 \%, 36 \%$ of sessions), (c) Dillon: $96.9 \%$ (range: $85.7-100 \%$, across $35 \%$ of sessions), and (d) Owen: $98 \%$ (range: $90-100 \%$, 50\% of sessions). Average agreement for novel vocalizations was between $92 \%$ and $95 \%$ for the other three participants: (a) Isabel: $92.7 \%$ (range: $80-100 \%$, across $40 \%$ of sessions), (b) Kristopher: 93.1\% (range: $87.5-100 \%, 48 \%$ of sessions), and (c) Remy: $94.2 \%$ (range: $80-100 \%, 35 \%$ of sessions).

Frequency of phonemes. IOA for frequency of phonemes was above $96 \%$ for all ten participants. The percentage agreement (and range) for each participant was: $96.2 \%$ for Nadia (range: $75-100 \%), 97.3 \%$ for Kali (range: $84.7-100 \%), 97.7 \%$ for Isabel $(77.8-100 \%), 98.0 \%$ for Nathan (range: $85.7-100 \%$ ), 98.8\% for Nelson (range: 93.3-100\%), and 99.8\% for both Dillon and Nicholas (range: 97.6-100\%); agreement for Kristopher, Owen, and Remy was 100\%.

\section{Results}

The descriptive data for each of the ten children participating in Study 1 are next 
presented. First, analyses of novel vocalizations are provided for the last six sessions of baseline (when stability criteria were met), followed by analyses of cumulative responding across the entire condition. Then, detailed analyses of the phonemes that each participant emitted are provided.

Novel vocalizations. Figure 1 displays the percentage of novel vocalizations during the final six baseline sessions for each participant. The last six sessions of baseline are depicted along the $x$-axis, and percentage of novel vocalizations are presented along the $y$-axis. The panels in the first column present data for four participants who engaged in more than $50 \%$ average novel vocalizations at the point of stability and include Nadia, Nathan, Kali, and Dillon. These participants are classified as engaging in a high level of vocal variability. The panels in the second column display data for four participants who engaged in 30-50\% novel vocalizations and include Nicholas, Kristopher, Owen, and Remy. These participants are classified as engaging in a moderate level of vocal variability. The two panels in the third column depict data for two participants who engaged in less than $30 \%$ novel vocalizations and include Nelson and Isabel. These participants are classified as engaging in low vocal variability. The average percentage of novel vocalizations, as well as the range of percentages across the last six sessions, are presented in Table 2.

Cumulative novel vocalizations. Figures 2 shows cumulative novel vocalizations across all baseline sessions for each participant. Sessions are depicted along the $x$-axis, and cumulative novel vocalizations are displayed along the $y$-axis. The open circles represent the total vocalizations emitted during a session, cumulatively summed across sessions; the closed circles represent the novel vocalizations emitted during a session, cumulated across sessions. Figure 3 displays these data as the percent of vocalizations that were novel (out of all vocalizations) 
during the baseline sessions (top panel), and as the average number of novel vocalizations per session during baseline (bottom panel). The number of total vocalizations, the percentage that were novel, and the average number of novel vocalizations per sessions are summarized in Table 2 as well.

The panels in the first column of Figure 2 present cumulative data across all baseline sessions for the four participants who engaged in high vocal variability. Together, these participants emitted more than $20 \%$ novel vocalizations across all baseline sessions. The panels in the second column display data for the four participants who engaged in moderate vocal variability. Here, participants produced $8-25 \%$ novel vocalizations during baseline. The panels in the third column depicted data for the low variability participants, each of whom responded with less than $6 \%$ vocal variability across sessions.

Frequency of phonemes. Data on the frequency of phonemes produced during the last six sessions of baseline are presented in Figures 4 through 8. Frequency is depicted along the $x$ axis and the phonemes produced are listed along the $y$-axis. Table 3 lists the individual phonemes at each frequency level for each participant. Figure 4 shows the data for two of the four high vocal variability participants, Nadia (top panel) and Nathan (lower panel). Nadia used 30 distinct phonemes to create 129 vocalizations during the last six sessions of baseline, while Nathan produced 22 phonemes in 124 vocalizations. Figure 5 shows the data for the remaining two high vocal variability participants, Kali (upper panel) and Dillon (lower panel). Kali’s 126 vocalizations were comprised of 28 unique phonemes. Dillon used 19 distinct phonemes to create 117 vocalizations. Figure 6 displays the data for two of four moderate vocal variability participants, Nicholas (upper panel) and Kristopher (lower panel). Nicholas produced 122 vocalizations during these sessions, using16 unique phonemes to create these vocalizations. 
Kristopher used 14 distinct phonemes to create 104 vocalizations. Figure 7 displays the data for the remaining two moderate vocal variability participants, Owen (upper panel) and Remy (lower panel). Owen engaged in 132 vocalizations, using 16 unique phonemes to create these vocalizations. Remy's 117 vocalizations were comprised of 13 distinct phonemes. Figure 8 displays the data for Nelson (upper panel) and Isabel (lower panel), the two low vocal variability participants. Nelson produced 113 vocalizations, using nine unique phonemes to create these responses. Isabel's vocalizations were comprised of 11 unique phonemes.

Proportion of phonemes. Data on the proportional distribution of phonemes (out of all phonemes produced) during the last six sessions of baseline are presented in Figures 9 through 13. Proportion is depicted along the $x$-axis and the phonemes produced are listed along the $y$ axis. Figure 9 shows the data for Nadia (top panel) and Nathan (lower panel). Of the 30 phonemes Nadia vocalized, no one phoneme accounted for more than 0.10 of all phonemes emitted, but 21 phonemes each accounted for 0.01 to 0.09 of all phonemes produced (/h/, ě, /d/,

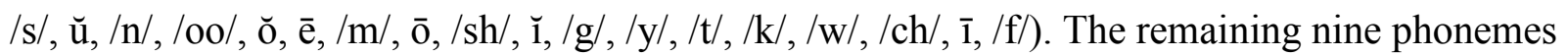
each accounted for less than 0.01 of all phonemes produced (/th/, /b/, /j/, /ow/, ā, /r/, /p/, /oy/, /1/). For Nathan, two of the 22 phonemes he produced accounted for more than 0.10 of all phonemes (ă, ē). Fourteen phonemes accounted for 0.01 to 0.09 of all those emitted(/y/, /h/, ŭ, /w/, /m/, /1/, /oo/, $\overline{\mathrm{a}}, / \mathrm{d} /, / \mathrm{n} /, \overline{\mathrm{o}}, / \mathrm{b} /, / \mathrm{g} /, \mathrm{e})$, while six phonemes made up less than 0.01 of all phonemes that he produced $(/ \mathrm{v} /, \overline{1}, / \mathrm{t} /, / \mathrm{p} /, / \mathrm{k} /, / \mathrm{ch} /)$.

Figure 10 displays the data for Kali (top panel) and Dillon (lower panel) during the last six sessions of baseline. Three phonemes of the 28 that Kali produced accounted for more than 0.10 of all phonemes vocalized ( $\breve{\mathrm{u}}, / \mathrm{g} /, / \mathrm{h} /)$, while 17 phonemes each accounted for between 0.01

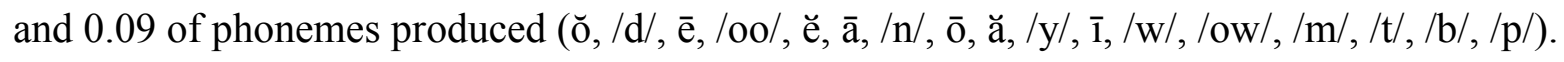


Eight phonemes made up less than 0.01 of all phonemes (/ng/, /ew/, /z/, /th/, , , /k/, /oy/, /1/).

Likewise for Dillon, three of the 19 phonemes he vocalized each accounted for more than 0.10 of all phonemes $(/ \mathrm{h} /, / \mathrm{n} /, \breve{\mathrm{u}})$, while 12 phonemes each comprised between 0.01 and 0.09 of all

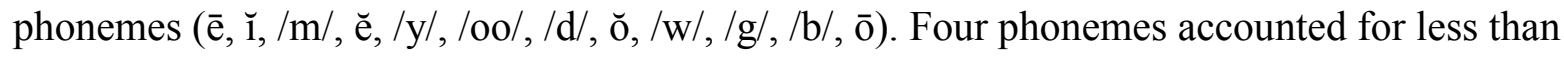
0.01 of all the phonemes he produced ( $\overline{1}, / \mathrm{oy} /, / \mathrm{th} /$, /ow/).

Figure 11 presents the stable baseline data for Nicholas (top panel) and Kristopher (lower panel). Four of Nicholas' 16 phonemes each accounted for more than 0.10 of all phonemes produced ( $\breve{\mathrm{u}}, / \mathrm{h} /, / \mathrm{m} /, \overline{\mathrm{e}})$. Nine phonemes each accounted for 0.01 to 0.09 of all phonemes ( $\breve{\mathrm{a}}, / \mathrm{d} /$, /g/, ĕ, /n/, /b/, à, /y/, /w/), and three phonemes each accounted for less than 0.01 of all phonemes that occurred (/l/, /ow/, /k/). Similarly, four phonemes of the 14 produced by Kristopher each accounted for greater than 0.10 of all phonemes $(/ \mathrm{m} /, \mathrm{a}, / \mathrm{h} /, / \mathrm{y} /)$, while the remaining 10 phonemes each comprised between 0.01 and 0.09 of all those emitted ( $\breve{\mathrm{u}}, / \mathrm{oo} /, \overline{\mathrm{e}}, \overline{\mathrm{a}}, / \mathrm{n} /, / \mathrm{b} /, / \mathrm{d} /$, $/ \mathrm{w} /, / \mathrm{r} /, / \mathrm{p} /)$.

Figure 12 shows the data for Owen (top panel) and Remy (lower panel) during the six stable baseline sessions. One of the 16 phonemes produced by Owen accounted for more than 0.30 of all phonemes $(/ \mathrm{m} /)$, and one other accounted for over 0.10 of all phonemes $(\overline{\mathrm{e}})$. Twelve phonemes each accounted for 0.01 to 0.09 of all phonemes that were produced (/d/, ă, $\breve{u}, / \mathrm{h} /, / \mathrm{g} /$, $\overline{\mathrm{a}}, / \mathrm{y} /, / \mathrm{oo} /, / \mathrm{b} /, \overline{\mathrm{o}}, \mathrm{1}, / \mathrm{w} /)$, while two each comprised less than 0.01 of all phonemes $(/ \mathrm{n} /$, ĕ). Of the 13 phonemes that Remy produced, four each accounted for more than 0.10 of all phonemes $(/ \mathrm{h} /$, $\overline{\mathrm{e}}, / \mathrm{y} /, \breve{\mathrm{o}})$. Five phonemes each accounted for 0.01 to 0.09 of all phonemes $(/ \mathrm{n} /, \overline{1}, \breve{e}, / \mathrm{oo} /, \breve{\mathrm{u}})$, and four phonemes each accounted for less than 0.01 of all phonemes that occurred $(/ \mathrm{m} /, \overline{\mathrm{o}}, / \mathrm{sh} /, \overline{1})$.

Figure 13 displays the data from the last six baseline sessions for Nelson (top panel) and Isabel (lower panel). One of the nine phonemes that Nelson vocalized accounted for over 0.30 of 


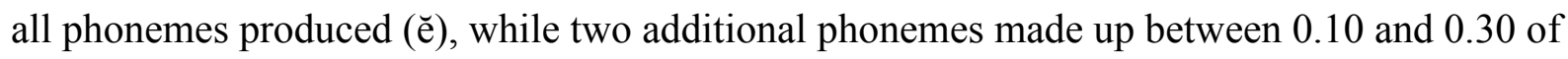
phonemes that occurred ( $\breve{\mathrm{u}}, \breve{o})$. Five phonemes accounted for 0.01 to 0.09 of all phonemes ( $\breve{a}$, $\overline{\mathrm{a}}$, $/ \mathrm{m} /, / \mathrm{h} /, \breve{1})$, and the one remaining accounted for less than 0.01 of all phonemes that Nelson produced $(/ \mathrm{n} /)$. Of the 11 phonemes that Isabel produced, one accounted for greater than 0.30 of all phonemes $(/ \mathrm{h} /)$, while three each made up between 0.10 and 0.30 of phonemes $(/ \mathrm{n} /, \breve{a}$, $\breve{\mathrm{e}})$. Three other phonemes each accounted for 0.01 to 0.09 of all phonemes that occurred ( $\breve{\mathrm{u}}, \overline{\mathrm{e}}, / \mathrm{d} /)$; the remaining four accounted for less than 0.01 of all phonemes produced $(/ \mathrm{y} /, / \mathrm{g} /, \overline{\mathrm{a}}, / \mathrm{r} /)$.

Proportion of vocalizations. Data on the proportional distribution of phonemes, out of all vocalizations produced, during the last six sessions of baseline are presented in Figures 14 through 18. Proportion is depicted along the $x$-axis and the phonemes emitted are listed along the $y$-axis. Figure 14 presents the data for Nadia (top panel) and Nathan (lower panel). At stability, greater than 0.25 of Nadia's vocalizations contained eight distinct phonemes $(/ \mathrm{h} /, \breve{\mathrm{e}}, / \mathrm{d} /, / \mathrm{s} /, \breve{\mathrm{u}}, / \mathrm{n} /$, /oo/, ŏ). Between 0.10 and 0.25 of vocalizations contained the same ten phonemes $(\overline{\mathrm{e}}, / \mathrm{m} /, \overline{\mathrm{o}}, / \mathrm{sh} /$, $\breve{1}, / \mathrm{g} /, / \mathrm{y} /, / \mathrm{t} /, / \mathrm{k} /, / \mathrm{w} /)$, while fewer than 0.10 of vocalizations contained 12 phonemes $(/ \mathrm{ch} /, \overline{1}, / \mathrm{f} /$, /th/, /b/, /j/, /ow/, ā,/r/, /p/, /oy/, /l/). Nathan produced one phoneme that was contained in over 0.70 of all vocalizations at stability $(\breve{a})$; four other phonemes were contained in greater than 0.25 of vocalizations $(\overline{\mathrm{e}}, / \mathrm{y} /, / \mathrm{h} /, \mathrm{u})$. Between 0.10 and 0.25 of vocalizations included eight distinct phonemes $(/ \mathrm{w} /, / \mathrm{m} /, / 1 /, / \mathrm{oo} /, \overline{\mathrm{a}}, / \mathrm{d} /, / \mathrm{n} /, \overline{\mathrm{o}})$, and less than 0.10 of vocalizations contained each of nine phonemes (/b/, /g/, è, /v/, , , /y/, /p/,/k/,/ch/).

Figure 15 shows the data for Kali (top panel) and Dillon (lower panel) during the final six baseline sessions. One phoneme occurred in almost half of Kali's vocalizations $(\breve{\mathrm{u}})$; three other phonemes occurred in over 0.25 of her vocalizations $(/ \mathrm{g} /, / \mathrm{h} /, \breve{\mathrm{o}})$. Six phonemes were contained in 0.10 to 0.25 of vocalizations $(/ \mathrm{d} /, \overline{\mathrm{e}}, / \mathrm{oo} /, \mathrm{e}, \overline{\mathrm{a}}, / \mathrm{n} /)$, and 18 additional phonemes occurred in 
less than 0.10 of all vocalizations ( $\overline{\mathrm{o}}, \mathrm{a}, / \mathrm{y} /, \overline{1}, / \mathrm{w} /, / \mathrm{ow} /, / \mathrm{m} /, / \mathrm{t} /, / \mathrm{b} /, / \mathrm{p} /, / \mathrm{ng} /, / \mathrm{ew} /, / \mathrm{z} /, / \mathrm{th} /, \breve{1}, / \mathrm{k} /$, /oy/, /l/). For Dillon, one phoneme was contained in over half of all vocalizations produced (/h/); two other phonemes were contained in over 0.25 of all vocalizations $(/ \mathrm{n} /, \breve{\mathrm{u}})$. Five phonemes occurred in 0.10 to 0.25 of vocalizations $(\overline{\mathrm{e}}, \breve{\mathrm{l}}, / \mathrm{m} /, \mathrm{e}, / \mathrm{y} /)$, and 11 phonemes each were contained in less than 0.10 of vocalizations (/oo/, /d/, ŏ, /w/, /g/, /b/, ō, , , /oy/, /th/, /ow/).

Figure 16 displays the data for Nicholas (top panel) and Kristopher (lower panel) during the stable baseline sessions. Greater than 0.25 of Nicholas's stable vocalizations contained four distinct phonemes $(\breve{\mathrm{u}}, / \mathrm{h} /, / \mathrm{m} /, \overline{\mathrm{e}})$. Between 0.10 and 0.25 of vocalizations contained the same

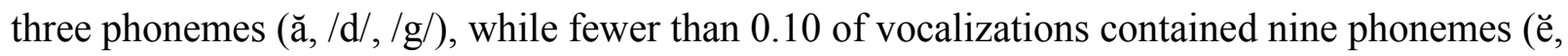
/n, /b/, ā, /y/, /w/, /1/, /ow/, /k/). For Kristopher, two phonemes were contained in greater than 0.25 of vocalizations $(/ \mathrm{m} /$, ă), while four phonemes each were contained in 0.10 to 0.25 of vocalizations (/h/,/y/, ŭ, /oo/). Eight phonemes each were contained within fewer than 0.10 of vocalizations ( $\overline{\mathrm{e}}, \overline{\mathrm{a}}, / \mathrm{n} /, / \mathrm{b} /, / \mathrm{d} /, / \mathrm{w} /, / \mathrm{r} /, / \mathrm{p} /)$.

Figure 17 presents the stable baseline data for Owen (top panel) and Remy (lower panel). Of all vocalizations Owen produced, over half contained the phoneme $/ \mathrm{m} /$. Seven other phonemes were contained in 0.10 to 0.25 of vocalizations $(\overline{\mathrm{e}}, / \mathrm{d} /, \breve{a}, \breve{\mathrm{u}}, / \mathrm{h} /, / \mathrm{g} /, \overline{\mathrm{a}})$, while the remaining eight phonemes that he uttered occurred in less than 0.10 of vocalizations $(/ \mathrm{y} /$, /oo/, /b/, $\overline{\mathrm{o}}, \breve{1}, / \mathrm{w} /, / \mathrm{n} /, \mathrm{e})$. More than half of Remy's vocalizations contained four distinct phonemes (/h/, è, $/ \mathrm{y} /, \breve{\mathrm{o}})$. Between 0.10 and 0.25 of vocalizations contained the same three phonemes $(/ \mathrm{n} /, \breve{1}$, ě), while less than 0.10 of vocalizations contained six phonemes (/oo/, ŭ, /sh/, /m/, $\overline{1}, \bar{o})$.

Figure 18 shows the stability sessions for Nelson (top panel) and Isabel (lower panel). Over 0.25 of the vocalizations produced by Nelson contained each of two phonemes $(\breve{\mathrm{e}}, \breve{\mathrm{u}})$, while 0.10 to 0.25 of vocalizations contained each of two different phonemes ( $\breve{o}, \breve{a})$. The five remaining 
phonemes each were contained in less than 0.10 of vocalizations $(\overline{\mathrm{a}}, / \mathrm{m} /, / \mathrm{h} /, \mathrm{i}, / \mathrm{n} /)$. Of all vocalizations produced by Isabel, almost three-fourths contained the phoneme $/ \mathrm{h} /$, and over half contained $/ \mathrm{n} /$. Two additional phonemes were contained in over 0.25 of vocalizations $(\breve{\mathrm{a}}, \breve{\mathrm{e}})$, while the remaining seven phonemes were contained in less than 0.10 vocalizations ( $\breve{\mathrm{u}}, \overline{\mathrm{e}}, / \mathrm{d} /, / \mathrm{y} /$, $/ \mathrm{g} /, \overline{\mathrm{a}}, / \mathrm{r} /)$.

\section{Discussion}

The analysis of novel vocalizations (i.e., how different vocalizations are from each other within a session) shows that this group of children with ASD did not present with a uniform vocal profile. At least three profiles of variable responding emerged from the present analysis: high variability, moderate variability, and low variability. Moreover, there was considerable heterogeneity in the phoneme production of children in each of these variability groups. These findings suggest that the language deficits seen in individuals with ASD are not likely uniform across participants.

The participants considered to be highly variable engaged in $50 \%$ or greater novel vocalizations during sessions and produced $20 \%$ or greater novel vocalizations when these responses were examined across sessions in the cumulative analysis. They used 19 or more phonemes to create vocalizations and no one phoneme accounted for more than 0.25 of the entire phoneme repertoire for any of these participants. In general, the more phonemes present in the repertoire, the more novel vocalizations that were produced.

Participants in the moderate variability category produced between 30 and $50 \%$ novel vocalizations. They composed a less consistent profile of cumulative novel vocalizations and phoneme production than either of the other two groups. These participants used between 13 and 16 phonemes to create vocalizations, but one of these participants (Owen) emitted one phoneme 
that accounted for over 0.25 of his phoneme repertoire. For some of these participants, novel vocalizations were comprised of more phonemes, while for the other participants, novel vocalizations were created from recombinations of a smaller set of phonemes.

Low-variability participants engaged in less than $30 \%$ novel vocalizations and less than $6 \%$ novel vocalizations across sessions in the cumulative analysis. They used 11 or fewer phonemes to create vocalizations, and both participants produced two phonemes that accounted for greater than 0.25 of the phonemes repertoire. The same pattern of repetitive use of phonemes across vocalizations was evident, as well. These data suggest that the fewer novel vocalizations that are produced, the fewer phonemes that are in the repertoire, and the more stereotypic the emission of sounds from that repertoire.

Collectively, the data in Study 1 provide a heterogeneous vocal profile of children with ASD referred for vocal stereotypy and the absence of functional speech. Knowing the existing vocal repertoire of a child referred for these reasons can assist in the development of a more targeted behavioral intervention for both vocal stereotypy and vocal communication training. Indeed, the data suggest that different interventions should be designed for participants based on existing variability. For the participants with more baseline variability, shaping procedures can be used to target speech sounds already in the repertoire and increase word approximations with or without imitation of a model. Anecdotally, both Nadia and Kali began imitating sounds and words within one month of discharge from the study; Kali began to produce words independently (i.e., with no model) shortly thereafter. For the participants who engaged in moderate to low levels of vocal variability, investigation of additional intervention procedures is necessary. Because they engaged in moderate to low levels of vocal variability and proportionally greater repetition of phonemes at baseline, Nicholas, Remy, and Isabel were selected for participation in 
Study 2 .

\section{Study 2}

\section{Methods}

Participants. Three of the children from Study 1 (Nicholas, Remy, and Isabel) participated in Study 2.

Procedures. To determine whether reinforcers delivered contingent on novel vocalizations would increase vocal variability, behavior under two different schedules of reinforcement was compared with behavior at baseline.

Baseline. The data from Study 1 served as the baseline condition for Study 2.

Lag 1. During this condition, participants were exposed to a Lag 1 schedule of reinforcement. A lag schedule of reinforcement programs the delivery of a reinforcer for a behavior if it is different, on some dimension, from previous behavior. On a Lag 1 schedule, a reinforcer is delivered if the current response is different from the immediately preceding response. In the current study, reinforcers were delivered contingent on the occurrence of a vocalization that was topographically different from the immediately preceding vocalization. A vocalization was reinforced if it differed from the preceding vocalization by more than one phoneme. For example, a reinforcer would not be delivered for the vocalization "bŏ" if the immediately preceding vocalization was "bŏ-/d/" as there is only one phoneme difference between the former and the latter (/d/). However, "bŏ-bŏ-bŏ" would be different from "bŏ-dā" (a two phoneme difference: /d/ and $\bar{a})$, and would therefore be reinforced.

Because no comparison could be made to a preceding vocalization, the first vocalization of each session in the Lag 1 condition was reinforced. This procedure allowed for a maximum of 20 reinforcers to be earned during each session (because 20 vocalizations occurred in each 
session); however, the actual number of reinforcers earned from session to session varied depending on the participant's behavior.

Lag 3. During this condition, participants were exposed to a Lag 3 schedule of reinforcement. On a Lag 3 schedule, a reinforcer was delivered if the current vocalization was different from the three immediately preceding vocalizations by more than one phoneme. As in the Lag 1 condition, the first vocalization in a session was always reinforced. From here, responses were compared to preceding responses until the Lag 3 schedule could be implemented. That is, the second response was compared to the first response to determine whether a reinforcer should be delivered (Lag 1), and the third response was compared to the first and second responses (Lag 2). By the fourth response, three vocalizations preceded this vocalization and a Lag 3 schedule could be implemented for the remainder of vocalizations in the session. This procedure is similar to the one used by Stokes and Harrison (2002) and allows for an equal number of reinforcers to be earned across lag conditions.

Consider the following sample of vocalizations:

$$
\begin{array}{ll}
\text { V1. } & \text { bŏ-/d/ } \\
\text { V2. } & \text { bŏ } \\
\text { V3. bŏ-bŏ-bŏ } \\
\text { V4. bŏ-dā-dē } \\
\text { V5. bŏ-dī } \\
\text { V6. ē-yē }
\end{array}
$$

Using the procedure outlined above, Vocalization 1 (V1) would be reinforced as the first behavior in the session. Because V2 differs from V1 by only one phoneme (/d/), it would not be reinforced. Similarly, V3 is a repetition of V2 and differs from V1 by one phoneme, so it would 
not be reinforced. Because there is more than one phoneme difference between V4 and V1 (/d/, $\overline{\mathrm{a}}, \overline{\mathrm{e}}), \mathrm{V} 2(\overline{\mathrm{a}}, \overline{\mathrm{e}})$, and V3 (/d/, a,$\overline{\mathrm{e}})$, this vocalization would be reinforced. When compared to the three preceding responses, more than one phoneme difference is present in each comparison to V5 (V2: /d/, i ; V3: /d/, $\overline{1} ; \mathrm{V} 4: \overline{1}, \bar{a}, \bar{e})$, so this vocalization would be reinforced. Finally, V6 differs

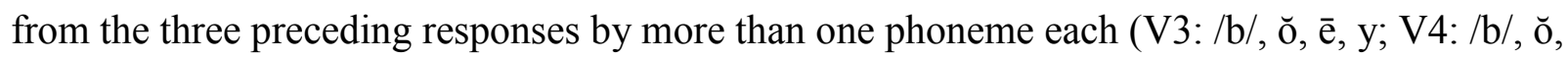
/d/, à, /y/; V5: /b/, ŏ, /d/, $1, \bar{e}, y)$, and would be reinforced. In sum, four vocalizations of the six produced in this sample would be reinforced (V1, V4, V5, V6) under a Lag 3 reinforcement schedule.

Lag 5. During this condition, participants were exposed to a Lag 5 schedule of reinforcement. On a Lag 5 schedule, a reinforcer was delivered if the current vocalization was different from the five immediately preceding vocalizations by more than one phoneme. As in the other lag conditions, the first vocalization in a session was always reinforced. As in the Lag 3 condition, responses were compared to preceding responses until the Lag 5 schedule could be implemented. By the sixth response, five vocalizations preceded this vocalization and a Lag 5 schedule could be implemented for the remainder of vocalizations in the session.

Consider the following sample of vocalizations:

$$
\begin{aligned}
& \text { V1. bŏ-/d/ } \\
& \text { V2. bŏ } \\
& \text { V3. bŏ-bŏ-bŏ } \\
& \text { V4. bŏ-dā-dē } \\
& \text { V5. bŏ-dī } \\
& \text { V6. } \bar{e}-y \bar{e}
\end{aligned}
$$

Using the procedure outlined above, V1 would be reinforced as the first behavior in the 
session. Because V2 differs from V1 by only one phoneme (/d/), it would not be reinforced. Similarly, V3 is a repetition of V2 and differs from V1 by one phoneme, so it would not be reinforced. Because there is more than one phoneme difference between V4 and V1 (/d/, à, è), V2 $(\overline{\mathrm{a}}, \overline{\mathrm{e}})$, and V3 $(/ \mathrm{d} /, \overline{\mathrm{a}}, \overline{\mathrm{e}})$, this vocalization would be reinforced. When compared to the four preceding responses, V5 is different from V1 by one phoneme (ī) and would not be reinforced. Finally, V6 differs from the five preceding responses by more than one phoneme each (V1: /b/,

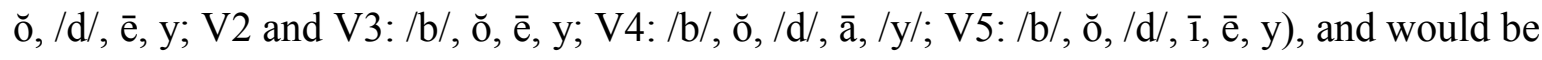
reinforced. In sum, three vocalizations of the six produced in this sample would be reinforced (V1, V4, V6) under a Lag 5 reinforcement schedule.

Experimental design. Table 4 provides the sequence of conditions for the three participants, which followed an A-B-C research design. All participants first were exposed to baseline (see Study 1) and then to one of two lag schedules. Once stability was met under the first lag schedule (see General Methods), a lag schedule of higher value (i.e., with a more stringent variability criterion) was implemented. Isabel and Nicholas each began with Lag 1 schedule of reinforcement and were increased to Lag 3. A decision was made to begin Remy on a Lag 3 schedule due to mixed results for Isabel and Nicholas on Lag 1.

\section{Procedural fidelity.}

Fidelity of session termination. The fidelity of session termination (20 vocalizations) was calculated for each condition (baseline and the two lag conditions) of Study 2, by participant. (Recall that Study 1 represents the baseline condition for Study 2; as such, the procedural fidelity data for that condition were reported in Study 1.) The procedures for session termination were followed with greater than $97 \%$ fidelity for two of the three participants: (a) Nicholas: $97.6 \%$ during the Lag 1 condition (range: 95-100\%), and 97.2\% during the Lag 3 condition (range: 90- 
100\%); and (b) Remy: $97.5 \%$ for the Lag 3 condition (range: 90-100\%), and 97.6\% during the Lag 5 condition (range: 87.0-100\%). Fidelity was slightly lower for Isabel, with $96.3 \%$ fidelity for the Lag 1 condition (range: 83.3-100\%), and 91.0\% fidelity for the Lag 3 condition (range: 69.0-100\%).

Fidelity of reinforcer delivery. Reinforcers were not delivered during baseline and therefore no fidelity data are reported for this condition. The fidelity of reinforcer delivery for the Lag 1 condition was $98 \%$ for Nicholas (range: $95-100 \%$, across $25 \%$ of sessions), and $95 \%$ for Isabel (range: $92-100 \%$, across $22 \%$ of sessions). Fidelity of reinforcer delivery was somewhat lower under the Lag 3 condition, being $89.3 \%$ for Nicholas (range: $85-100 \%, 29 \%$ of sessions), $85.3 \%$ for Remy (range: $80-95 \%, 27 \%$ of sessions), and $88.2 \%$ for Isabel (range: $82-95 \%$, across $30 \%$ of sessions). Lastly, reinforcer delivery fidelity was at $93.3 \%$ for Remy under the Lag 5 condition (range: $90-100 \% ; 26 \%$ of sessions).

\section{Interobserver agreement.}

Novel vocalizations. Interobserver agreement for novel vocalizations was above $90 \%$ for all three participants under each of the lag conditions (IOA for the baseline condition is reported under Study 1). Under Lag 1, IOA for novel vocalizations was 91.2\% for Nicholas (range: 80$100 \%$, across $35 \%$ of sessions), and $95.3 \%$ for Isabel (range: $75-100 \%, 36 \%$ of sessions). Under the Lag 3 condition, IOA was $94.1 \%$ for Remy (range: $80-100 \%$, 66\% of sessions), $95.8 \%$ for Nicholas (range: $80-100 \%, 52 \%$ of sessions), and $97.4 \%$ for Isabel (range: $80-100 \%, 35 \%$ of sessions). Finally, fidelity was at $98.5 \%$ for Remy under the Lag 5 condition (range: $90-100 \%$, $34 \%$ of sessions).

Frequency of phonemes. IOA was calculated for frequency of phonemes (during the final six sessions) for each participant, under each condition (IOA for the baseline condition is 
reported under Study 1). IOA for Nicholas was $100 \%$ during both the Lag 1 and Lag 3 conditions. For Remy, agreement was 100\% during the last 6 sessions of the Lag 3 condition, and $95.6 \%$ under the Lag 5 condition (range 83.3-100\%). Agreement for frequency of phonemes was 99.2\% under Lag 1 (range: 93.3-100\%), and 97.0\% under Lag 3 (range: $75-100 \%$ ) for Isabel.

\section{Results}

The descriptive data for each of the three children participating in Study 2 are next presented. First, analyses of novel vocalizations are provided for the last six sessions of each condition (the baseline and lag schedules), followed by analyses of cumulative responding across each condition. Then, detailed analyses of the phonemes that each participant emitted are provided for each condition.

Percentage of novel vocalizations. Figure 19 displays percentage of novel vocalizations during the last six sessions of each condition for all three participants. Sessions are depicted along the $x$-axis, and percentage of novel vocalizations are presented along the $y$-axis.

Nicholas. Data for Nicholas are presented in the upper panel of Figure 19. His baseline percentage of novel vocalizations averaged $48.4 \%$ (as reported in Study 1). Nicholas was exposed to 20 sessions with reinforcement for vocalizations on a Lag 1 schedule. At stability, percentage of novel vocalizations averaged 44\% (range: 35-52.4\%). Vocalizations then were exposed to a Lag 3 schedule of reinforcement for 21 sessions; novelty averaged $40.6 \%$ (range: 31.6-50\%). No change in vocal variability was demonstrated across conditions by this measure for Nicholas. However, the Lag 3 condition could not be run to stability because his mother withdrew him from the study due to her personal health concerns.

Remy. Data for Remy are presented in the middle panel of Figure 19. He engaged in an 
average of $36.2 \%$ novel vocalizations across the last six sessions in baseline (Study 1). Remy was exposed to 35 sessions under Lag 3 contingencies; at stability the percentage of novel vocalizations averaged 35.3\% (range: $30-40 \%$ ). After 38 sessions under a Lag 5 schedule of reinforcement, novel vocalizations averaged $41.9 \%$ at stability (range: $35-45 \%$ ). A slight increase is evident in average percentage novel vocalizations, although this change is difficult to interpret from visual inspection of the data presented in Figure 23 alone.

Isabel. Data for Isabel are presented in the lower panel of Figure 19. At baseline, she averaged $23 \%$ novel vocalizations across the last six sessions (Study 1). A Lag 1 schedule of reinforcement was in place for 22 sessions and percentage of novel vocalizations averaged $29.7 \%$ at stability (range: $27.3-35 \%$ ). With the implementation of a Lag 3 schedule for 40 sessions, novel vocalizations averaged $68.6 \%$ across the last six sessions (range: $57.1-85 \%$ ). The Lag 3 phase was terminated when the maximum number of sessions was conducted. For Isabel, a clear and significant increase in percentage of novel vocalizations is evident from both baseline and Lag 1 responding to behavior under the Lag 3 schedule.

Cumulative novel vocalizations. Figure 20 displays cumulative total vocalizations (open circles) and cumulative novel vocalizations (closed circles) across all sessions of baseline and the lag conditions for all three participants. Sessions are depicted along the $x$-axis, and cumulative vocalizations are presented along the $y$-axis. Summary data for percentage of novel vocalizations (top panel) and for average novel vocalizations (bottom panel) across all sessions of each condition are presented in Figure 21. Participants are listed across each $x$-axis. Baseline data are represented by the black bars, Lag 1 data are represented by the white bars (Nicholas and Isabel only), Lag 3 data are represented by light gray bars, and Lag 5 data are represented by the dark gray bars (Remy only). 
Nicholas. Data for Nicholas are presented in the upper panel of Figure 20. Visual inspection of the graph shows that the slope of the cumulative data paths under baseline (leftmost lines), Lag 1 (center lines), and Lag 3 (rightmost lines) are not different, indicating that the introduction of reinforcers for variability did not result in increased novel vocalizations across sessions. Summary data for Nicholas are depicted by the leftmost set of bars in both panels of Figures 21. During baseline (Study 1), he produced 129 novel vocalizations out of a total of 802 vocalizations during that condition (16.1\% novelty). Each session, an average of 3.2 novel vocalizations was produced (range: 0-7). Under a Lag 1 schedule, Nicholas produced 50 novel vocalizations out of 404 total vocalizations (12.4\% novelty), with an average of 2.5 novel vocalizations per session (range: 1-6). With the implementation of a Lag 3 schedule, he produced 70 novel vocalizations out of 391 total vocalizations (17.9\% novelty), with an average of 3.3 novel vocalizations per session (range: 0-12). A rather modest increase in percentage of novel vocalizations and in average novel vocalizations is evident between baseline and Lag 3 conditions. However, both measures show a clear decrease under the Lag 1 schedule of reinforcement.

Remy. Data for Remy are presented in the middle panel of Figure 20. Visual inspection of the graph shows that slope of the cumulative data paths under baseline (leftmost lines), Lag 3 (center lines), and Lag 5 (rightmost lines) are not noticeably different, indicating that the introduction of reinforcers for variability did not result in increased novel vocalizations across sessions. Summary data for Remy are represented by the middle set of bars in both panels of Figure 21. During baseline sessions (Study 1), 61 of Remy’s 747 vocalizations were different from all other vocalizations (8.2\% novelty), with an average of 1.7 novel vocalizations per session (range: 0-6). With the implementation of the Lag 3 schedule, Remy produced 54 novel 
vocalizations out of 700 total responses ( $7.7 \%$ novelty), for an average of 1.5 novel vocalizations per session (range: 0-10). Under Lag 5 contingencies, 70 of 775 vocalizations were scored as novel (9\%), with an average of 1.8 novel vocalizations per session (range: $0-7)$. Similar to the pattern for Nicholas, a slight increase in percentage of novel vocalizations and average novel vocalizations is evident between baseline and Lag 5 conditions. However, both measures again show a decrease under the Lag 3 schedule of reinforcement.

Isabel. Data for Isabel are presented in the lower panel of Figure 20. Visual inspection of the graph shows that the slope of the cumulative data paths under baseline (leftmost lines) and Lag 1 (center lines) are not different, indicating that the introduction of reinforcers for variability did not result in increased novel vocalizations across sessions. However, with the delivery of reinforcers on a Lag 3 schedule (rightmost lines), a noticeable increase in the slope of the cumulative data path is evident, indicating that more novel vocalizations occurred per session. The slope of the line for the Lag 3 condition is stable over time; that is, the increase in novel vocalizations per session continued across all sessions in the condition. Summary data for Isabel are represented by the rightmost set of bars in both panels of Figure 21 . When no programmed contingencies were provided in baseline (Study 1), 39 of Isabel's 654 vocalizations were scored as being different from all other vocalizations (6\% novelty), and an average of 1.2 novel vocalizations were produced per session (range: 0-8). Under a Lag 1 schedule, Isabel produced 456 total vocalizations; 36 of those met criteria for being scored as novel (7.9\%) with a session average of 1.6 novel vocalizations (range: $0-8$ ). With the implementation of a Lag 3 schedule, 211 of 856 vocalizations were coded as novel (24.7\%), with an average of 5.3 novel vocalizations occurring per session (range: 1-12). An increase in both measures corresponding to the increased stringency of the reinforcement schedules is evident. That is, a greater portion of 
Isabel's vocalizations were novel, and more novel vocalizations were produced per session, with the introduction of both the Lag 1 and Lag 3 schedules.

Frequency of phonemes. Data on the frequency of phonemes are presented in Figures 22,23 , and 24. Frequency is shown along the $x$-axis and the phonemes vocalized by each participant are listed along the $y$-axis. Baseline data are represented by the black bars, the initial lag schedule is represented by the white bars (Lag 1 for Nicholas and Isabel, Lag 3 for Remy), and the second lag schedule is represented by the gray bars (Lag 3 for Nicholas and Isabel, Lag 5 for Remy).

Nicholas. Figure 22 shows phoneme frequency data for Nicholas. As reported in Study 1, Nicholas engaged in 122 vocalizations during the last six sessions under baseline conditions, producing 16 unique phonemes and an average of 2.2 distinct phonemes per vocalization. Across 121 vocalizations at stability in the Lag 1 condition, the number of phonemes combined to create vocalizations increased to 19 , with an average of 1.8 unique phonemes per vocalization (range: 1.4-2.3). Six of these phonemes had not been produced during the baseline condition (/oo/, $\overline{1}, \overline{\mathrm{o}}$, $/ \mathrm{r} /, \breve{1}, / \mathrm{p} /)$. However, three infrequent phonemes documented in baseline did not occur under Lag 1 (/k/, /l/, /ow/). Nicholas emitted 16 phonemes to create 109 vocalizations over the last six sessions of the Lag 3 condition, with an average of 1.9 unique phonemes per vocalization (range: 1.6-2.2). One of the 16 phonemes had not been produced in either of the two previous conditions

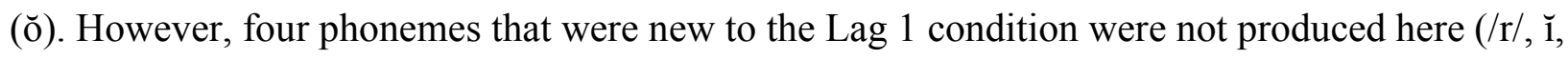
$/ \mathrm{p} /)$, nor were four of the phonemes documented in baseline (/d/, /k/, /l/, /ow/).

At baseline, Nicholas produced four phonemes more than 30 times each $(\breve{\mathrm{u}}, / \mathrm{h} /, / \mathrm{m} /, \overline{\mathrm{e}})$. Three phonemes were emitted between 10 and 30 times each ( $\breve{a}, / d /, / g /)$, and he produced nine phonemes less than 10 times each (ĕ, /n, /b/, ā,/y/, /w/, /1/,/ow/,/k/). When Lag 1 contingencies 
were applied to vocal variability, one phoneme increased to 75 occurrences during the last six sessions $(/ \mathrm{m} /)$. Six phonemes were emitted between 10 and 30 times each (/h/, ŭ, ă, ě, è, /y/), and 12 phonemes were vocalized less than 10 times each (/b/, /n/, /w/, /d/, /oo/, /g/, à, $\overline{1}, \overline{\mathrm{o}}, / \mathrm{r} /, \mathrm{1}, / \mathrm{p} /)$. Although one high-frequency phoneme from baseline increased further with reinforcement for variability, the frequency of the remaining 18 phonemes in this phase were more evenly distributed. During the last six sessions of the Lag 3 condition, two phonemes each occurred more than 30 times $(\breve{\mathrm{u}}, / \mathrm{m} /)$, while four phonemes occurred between 10 and 30 times each $(\overline{1}$,

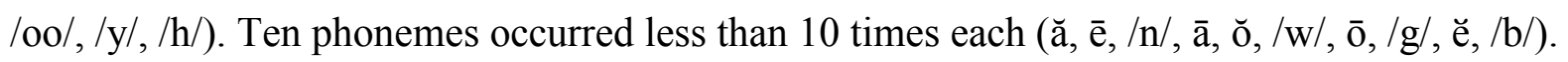
Again, although two high-frequency baseline phonemes continued to dominate the repertoire, a more even distribution of the remaining 14 phonemes is evident from Figure 26.

Remy. Figure 23 shows the phoneme frequency data for Remy. As reported in Study 1, Remy engaged in 117 vocalizations during the last six sessions of the condition and he emitted 13 unique phonemes to create these responses. Baseline vocalizations contained an average of 2.9 distinct phonemes (range: $2.3-3.6$ ). Across 122 vocalizations during the last six sessions in the Lag 3 condition, 13 phonemes were emitted to create vocalizations as well. Vocalizations contained an average of 2.0 unique phonemes (range: 1.8-2.3). Although the number of phonemes in this condition is equal to the number of unique phonemes produced in baseline, three of the phonemes had not been documented previously (ă, /b/, /w/). Three phonemes from baseline, two of which were infrequent, did not occur in the stable vocalizations in the Lag 3 condition $(\breve{1}, / s /, \overline{1})$. During the last six sessions under the Lag 5 schedule, Remy produced 16 phonemes to create 124 vocalizations. Vocalizations averaged 2.0 unique phonemes during the last six sessions of the Lag 5 condition (range: 1.3-3.3). The three new phonemes produced in the previous phase were maintained under the more stringent reinforcement schedule, and three 
additional phonemes were produced $(\overline{\mathrm{a}}, / \mathrm{t} /, / \mathrm{p} /)$. One infrequent phoneme from baseline and the Lag 3 conditions did not occur in the Lag 5 condition, although one phoneme from baseline lost in the Lag 3 condition returned under Lag 5 ()ㅜ.

Remy emitted four phonemes over 50 times each in 117 vocalizations (/h/, è, /y/, ŏ). He vocalized three phonemes between 10 and 30 times each $(/ \mathrm{n} /, \breve{1}, \breve{e})$, and he vocalized six phonemes fewer than 10 times each (/oo/, ŭ, /sh/, /m/, $\overline{1}, \overline{\mathrm{o}})$. When Lag 3 contingencies were applied, only one phoneme occurred more than 50 times ( $\breve{o})$, while 3 other phonemes were vocalized more than 30 times each $(\breve{\mathrm{u}}, \overline{\mathrm{e}}, / \mathrm{h} /)$. Three phonemes occurred between 10 and 30 times each $(/ \mathrm{oo} /, / \mathrm{m} /, / \mathrm{n} /)$, and six phonemes were vocalized less than 10 times each $(/ \mathrm{y} /$, ĕ, ō, ă, /w/, /b/). Although one frequent baseline phoneme continued to be frequent under Lag 3, the frequency of the remaining 12 phonemes shifted such that less frequent ones increased in occurrence and more frequent phonemes decreased in occurrence. Under the Lag 5 condition, no phonemes occurred more than 50 times. Three phonemes occurred more than 30 times each (/h/, $\breve{\mathrm{o}}, / \mathrm{oo} /$ ), while six phonemes each occurred between 10 and 30 times ( $\breve{\mathrm{u}}, \breve{a}, \overline{\mathrm{e}}, / \mathrm{n} /, / \mathrm{y} /, / \mathrm{b} /)$. Seven phonemes were emitted less than 10 times each ( $\mathrm{i}, \mathrm{e}, / \mathrm{w} /, \overline{\mathrm{a}}, / \mathrm{m} /, / \mathrm{th} /, / \mathrm{p} /)$. Again, phoneme frequency became more evenly distributed during this condition than observed in the previous conditions.

Isabel. Figure 24 shows the phoneme frequency data for Isabel. As reported in Study 1, the 126 vocalizations she produced during the last six sessions were comprised of 11 unique phonemes. Baseline vocalizations contained an average of 2.3 unique phonemes (range: 1.8-2.6). Across 125 vocalizations at stability in Lag 1, 14 phonemes were emitted, and vocalizations contained an average of 2.2 unique phonemes per response (range: 1.8-2.9). Four new phonemes were documented during this condition $(/ \mathrm{b} /, / \mathrm{m} /, \overline{1}, \overline{\mathrm{o}})$, although one infrequent phoneme from 
baseline was not evident (/d/). Under the Lag 3 schedule, Isabel produced 22 phonemes to create 117 vocalizations. Here, vocalizations averaged 4.0 phonemes (range: 3.2-5.2). Eight new phonemes were produced during this condition ( $(\breve{\mathrm{l}}, \breve{\mathrm{o}}, / \mathrm{oo} /, / \mathrm{ow} /, / \mathrm{w} /, / \mathrm{ng} /, / 1 /, / \mathrm{p} /)$, and the baseline phoneme lost in the Lag 1 condition recovered under Lag 3. One phoneme that occurred infrequently in both baseline and Lag 1 conditions was not produced under Lag 5 (/r/).

In the last six sessions of baseline, Isabel vocalized two phonemes more than 70 times

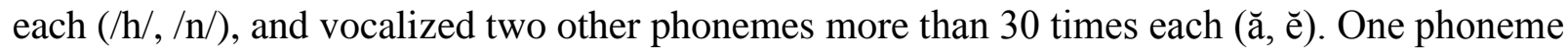
was produced between 10 and 30 times $(\breve{\mathrm{u}})$, while Isabel vocalized 6 phonemes less than 10 times each $(\overline{\mathrm{e}}, / \mathrm{d} /, / \mathrm{y} /, / \mathrm{g} /, \overline{\mathrm{a}}, / \mathrm{r} /)$. When Lag 1 contingencies were applied, one phoneme occurred more than 80 times $(/ \mathrm{n} /)$, while two others were emitted more than 30 times each $(/ \mathrm{h} /, \mathrm{c})$. Four phonemes occurred between 10 and 30 times each ( $\breve{\mathrm{e}}, / \mathrm{b} /, \breve{\mathrm{u}}, / \mathrm{m} /)$, and seven phonemes were vocalized less than 10 times each $(/ \mathrm{y} /, / \mathrm{g} /, \overline{\mathrm{a}}, / \mathrm{r} /, \overline{\mathrm{i}}, \overline{\mathrm{o}})$. Under the Lag 3 schedule of reinforcement, one phoneme occurred 90 times $(/ \mathrm{h} /)$. Six phonemes were vocalized more than 30 times each (/n/, ŭ, $\breve{\mathrm{i}}, / \mathrm{y} /, / \mathrm{m} /, \breve{\mathrm{e}})$, while four phonemes each occurred between 10 and 30 times $(/ \mathrm{d} /, / \mathrm{b} /, \bar{e}, \overline{1})$. Eleven phonemes occurred less than 10 times each ( $\overline{\mathrm{a}}, \breve{\mathrm{o}}, / \mathrm{g} /, \overline{\mathrm{o}}$, /oo/, /ow/, ă, /w/, /ng/, /l/, /p/). For Isabel, the most frequent phonemes under the baseline condition continued to dominate the phoneme repertoire under both lag conditions, while the frequency of other phonemes increased under these reinforcement schedules.

Proportion of phonemes. Data on the proportional distribution of phonemes, out of all phonemes produced, are presented in Figures 25, 26, and 27. Proportion is shown along the $x$-axis and the phonemes emitted by each participant are listed along the $y$-axis. Baseline data are represented by the black bars, the initial lag schedule is represented by the white bars (Lag 1 for Nicholas and Isabel, Lag 3 for Remy), and the second lag schedule is represented by the gray 
bars (Lag 3 for Nicholas and Isabel, Lag 5 for Remy).

Nicholas. Figure 25 displays Nicholas’ proportional phoneme production. During the last six sessions of baseline, four phonemes each accounted for more than 0.10 of all those emitted ( $\breve{\mathrm{u}}, / \mathrm{h} /, / \mathrm{m} /, \overline{\mathrm{e}})$. Nine phonemes each accounted for 0.01 to 0.09 of all phonemes ( $\mathrm{a}, / \mathrm{d} /, / \mathrm{g} /, \mathrm{e}, / \mathrm{n} /$, /b/, $\bar{a}, / y /, / w /)$, and three phonemes each accounted for less than 0.01 of all phonemes (/1/, /ow/, $/ \mathrm{k} /$ ). With the introduction of the Lag 1 condition, three of the four phonemes prominent in baseline continued to comprise more than 0.10 of all phonemes $(/ \mathrm{m} /, / \mathrm{h} /, \breve{\mathrm{u}})$, as did one additional

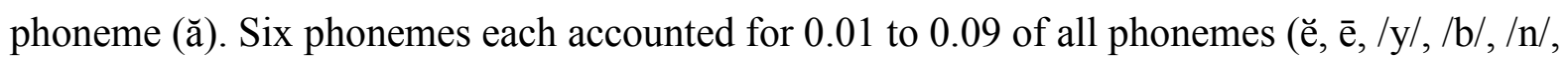
/w/), and nine phonemes each accounted for less than 0.01 of all phonemes (/d/, /oo/, /g/, ā, $\overline{1}, \overline{\mathrm{o}}$, $/ \mathrm{r} /, \breve{1}, / \mathrm{p} /$ ). When analyzed proportionally, the distribution of phoneme production indicates that phonemes dominant in baseline continued to dominate, or even increased in occurrence with the introduction of reinforcement for variability. Although some new phonemes were added to the repertoire, they were proportionally infrequent to the previously documented phonemes. During the last six sessions of the Lag 3 condition, only two phonemes each comprised greater than 0.10 of phonemes $(\breve{\mathrm{u}}, / \mathrm{m} /)$. Each of 11 phonemes accounted for 0.01 to 0.09 of phonemes ( $\overline{1}, / \mathrm{oo} /, / \mathrm{y} /$, /h/, ă, $\bar{e}, / \mathrm{n} /, \overline{\mathrm{a}}, \breve{\mathrm{o}}, / \mathrm{w} /, \overline{\mathrm{o}}$ ), and three others each accounted for less than 0.01 of all phonemes vocalized (/g/, ĕ, /b/). Again, although the distribution of phonemes shifted with the changing reinforcement criteria in this condition, previously produced phonemes continued to dominate Nicholas' phoneme repertoire.

Remy. Figure 26 displays the proportional phoneme production of Remy. At baseline, four phonemes each accounted for more than 0.10 of all those emitted (/h/, ê, /y/, ŏ). Five phonemes each accounted for 0.01 to 0.09 of all phonemes $(/ \mathrm{n} /, \overline{1}, \mathrm{e}, / \mathrm{oo} /, \breve{\mathrm{u}})$, and four phonemes each accounted for less than 0.01 of all phonemes $(/ \mathrm{m} /, \overline{\mathrm{o}}, / \mathrm{sh} /, \overline{1})$. With the introduction of a Lag 
3 reinforcement schedule, three of the four phonemes prominent in baseline continued to comprise more than 0.10 of all phonemes $(\breve{\mathrm{o}}, \overline{\mathrm{e}}, / \mathrm{h} /)$, as did one additional phoneme ( $\breve{\mathrm{u}})$. Five phonemes each accounted for 0.01 to 0.09 of all phonemes (/oo/, /m/, /n/, /y/, ě), and four phonemes each accounted for less than 0.01 of all phonemes ( $\overline{\mathrm{o}}, \breve{a}, / \mathrm{w} /, / \mathrm{b} /)$. As noted with Nicholas, the distribution of phoneme production indicates that phonemes dominant in baseline continued to be prominent, or increase in occurrence with the introduction of reinforcement for variability. While some new phonemes were added to the repertoire in this condition, they were proportionally infrequent relative to previously documented phonemes. It should be noted, however, that some phonemes did increase in use relative to baseline. During the last six sessions of the Lag 5 condition, two of the most frequent baseline phonemes continued to comprise greater than 0.10 of phonemes emitted $(/ \mathrm{h} /, \breve{o})$, as did a third phoneme prominent in Lag $3(\breve{\mathrm{u}})$. An additional phoneme increased to greater than 0.10 of all phonemes (/oo/). Each of nine phonemes accounted for 0.01 to 0.09 of all those produced ( $\breve{a}, \bar{e}, / n /, / y /, / b /, \breve{1}$, è, /w/, à), and two other phonemes each accounted for less than 0.01 of all phonemes (/th/, /p/). Under the Lag 5 schedule, although some frequently produced phonemes continued to be relatively more common than others, new and less common phonemes increased relative to previous conditions.

Isabel. Figure 27 displays Isabel's proportional phoneme production. At baseline, one phoneme accounted for greater than 0.30 of all phonemes $(/ \mathrm{h} /)$, while three others each made up between 0.10 and 0.30 of phonemes $(/ \mathrm{n} /, \breve{a}, \breve{e})$. Three phonemes each accounted for 0.01 to 0.09 of all phonemes ( $\breve{\mathrm{u}}, \overline{\mathrm{e}}, / \mathrm{d} /)$, and the remaining four phonemes accounted for less than 0.01 of all those produced $(/ \mathrm{y} /, / \mathrm{g} /, \overline{\mathrm{a}}, / \mathrm{r} /)$. During the last six sessions of the Lag 1 condition, three of the four most prominent phonemes in baseline continued to comprise the majority of Isabel's phonemes. One phoneme accounted for greater than 0.30 of all phonemes $(/ \mathrm{n} /)$, while two others 
each accounted for 0.10 to 0.30 of all phonemes produced $(/ \mathrm{h} /, \breve{a})$. Five phonemes each made up between 0.01 and 0.09 of all phonemes ( $\breve{\mathrm{e}}, / \mathrm{b} /, \breve{\mathrm{u}}, / \mathrm{m} /, / \mathrm{y} /)$, and the remaining phonemes each accounted for less than 0.01 of all phonemes $(\overline{\mathrm{e}}, / \mathrm{g} /, \overline{\mathrm{a}}, / \mathrm{r} /, \overline{1}, \overline{\mathrm{o}})$. During this condition, Isabel's phonemic repertoire remained relatively stable when compared to baseline. With the implementation of Lag 3 reinforcement, two of the most prominent phonemes continued to dominate Isabel's repertoire, although not to the same extent as previously identified. Along with a third phoneme, these phonemes each accounted for 0.10 to 0.30 of all those produced at stability $(/ \mathrm{h} /, / \mathrm{n} /, \breve{\mathrm{u}})$. Eleven phonemes each accounted for 0.01 to 0.09 of all phonemes $(\breve{1}, / \mathrm{y} /$, /m/, è , /d/, /b/, è, $\overline{1}, \bar{a}, \breve{o}, / g /)$, while eight phonemes each accounted for less than 0.01 of all those emitted ( $\overline{\mathrm{o}}, / \mathrm{oo} /, / \mathrm{ow} /, \mathrm{a}, / \mathrm{w} /, / \mathrm{ng} /, / 1 /, / \mathrm{p} /)$. A noticeable shift in the distribution of phoneme production occurred with the implementation of more stringent variability criteria: phonemes that were dominant in the previous conditions became relatively less common here, and, although produced less often, new phonemes accounted for over half of those that occurred.

Proportion of vocalizations. Data on the proportional distribution of phonemes, out of all vocalizations produced, are presented in Figures 28, 29, and 30. Proportion is shown along the $x$-axis and the phonemes vocalized by each participant are listed along the $y$-axis. Baseline data are represented by the black bars, the initial lag schedule is represented by the white bars (Lag 1 for Nicholas and Isabel, Lag 3 for Remy), and the second lag schedule is represented by the gray bars (Lag 3 for Nicholas and Isabel, Lag 5 for Remy).

Nicholas. Figure 28 displays Nicholas' proportional phoneme use across vocalizations. During the last six sessions of baseline, greater than 0.25 of his vocalizations contained four distinct phonemes $(\breve{\mathrm{u}}, / \mathrm{h} /, / \mathrm{m} /, \overline{\mathrm{e}})$. Between 0.10 and 0.25 of vocalizations contained the same three phonemes $(\breve{\mathrm{a}}, / \mathrm{d} /, / \mathrm{g} /)$, while fewer than 0.10 vocalizations contained nine phonemes (ĕ, /n, 
/b/, a, /y/, /w/, /1/, /ow/, /k/). Under the Lag 1 condition, more than half (0.50) of the vocalizations at stability contained the single phoneme $/ \mathrm{m} /$. Five other phonemes occurred in 0.10 to 0.25 of vocalizations $(/ \mathrm{h} /, \breve{\mathrm{u}}, \breve{a}, \breve{e}, \overline{\mathrm{e}})$, and 13 phonemes occurred in less than 0.10 of vocalizations $(/ \mathrm{y} /$, /b/, /n/, /w/, /d/, /oo/, /g/, a, , $, \overline{\mathrm{o}}, / \mathrm{r} /, \mathrm{1}, / \mathrm{p} /)$. The contingencies in this condition increased the production of vocalizations containing a phoneme that was prominent in baseline. However, the remaining prevalent phonemes occurred in fewer vocalizations in this condition than in baseline. With the implementation of a Lag 3 condition, two phonemes occurred in more than 0.25 of vocalizations ( $\breve{\mathrm{u}}, / \mathrm{m} /)$. Between 0.10 and 0.25 of vocalizations contained 3 distinct phonemes $(\overline{1}$,

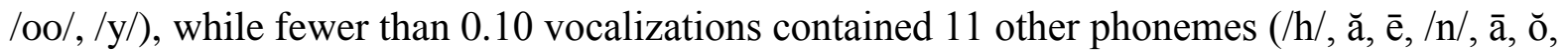
/w/, ō, /g/, è, /b/). During this condition, although two phonemes continued to occur in a larger proportion of vocalizations, the remaining phonemes became more evenly distributed across vocalizations than in either baseline or in the previous lag condition.

Remy. Figure 29 shows data on the distribution of phonemes across vocalizations during the last six sessions of each condition for Remy. At baseline, greater than 0.50 of Remy's stable vocalizations contained four distinct phonemes $(/ \mathrm{h} /, \overline{\mathrm{e}}, / \mathrm{y} /, \breve{\mathrm{o}})$. Between 0.10 and 0.25 of vocalizations contained the same three phonemes $(/ \mathrm{n} /, \breve{1}, \breve{e})$, while less than 0.10 of vocalizations contained six phonemes $(/ \mathrm{oo} /, \breve{\mathrm{u}}, / \mathrm{sh} /, / \mathrm{m} /, \overline{1}, \overline{\mathrm{o}})$. Under the Lag 3 condition, four phonemes occurred in greater than 0.25 of vocalizations ( $\breve{\mathrm{o}}, \breve{\mathrm{u}}, \overline{\mathrm{e}}, / \mathrm{h} /)$, but no phoneme occurred in over half of the vocalizations as observed in baseline. Three phonemes occurred in 0.10 to 0.25 of vocalizations $(/ \mathrm{oo} /, / \mathrm{m} /, / \mathrm{n} /)$, and six phonemes occurred in less than 0.10 of vocalizations $(/ \mathrm{y} /$, ĕ, $\overline{\mathrm{o}}, \mathrm{a}, / \mathrm{w} /, / \mathrm{b} /$ ). Phoneme inclusion across vocalizations approximated a more even distribution under these contingencies. With the implementation of the Lag 5 condition, three phonemes occurred in more than 0.25 of vocalizations $(/ \mathrm{h} /, \breve{\mathrm{o}}, / \mathrm{oo} /)$. Between 0.10 and 0.25 of vocalizations 
contained four distinct phonemes ( $\breve{\mathrm{u}}, \breve{a}, \overline{\mathrm{e}}, / \mathrm{n} /$ ), while fewer than 0.10 of vocalizations contained nine phonemes $(/ \mathrm{y} /, / \mathrm{b} /, \breve{1}, \mathrm{e}, / \mathrm{w} /, \overline{\mathrm{a}}, / \mathrm{m} /, / \mathrm{th} /, / \mathrm{p} /)$. The increased stringency of reinforcement criteria under this condition led to a more even distribution of phoneme occurrence within vocalizations than observed in either of the two previous conditions.

Isabel. Figure 30 presents data for the proportional use of phonemes across stable vocalizations for Isabel. Of her vocalizations during the last six sessions in baseline, almost three-fourths contained the same phoneme $(/ \mathrm{h} /)$, and over half contained another $(/ \mathrm{n} /)$. Two additional phonemes were contained in over 0.25 of vocalizations ( $\breve{a}, \breve{e})$, while the remaining seven phonemes were contained in less than 0.10 vocalizations ( $\breve{\mathrm{u}}, \overline{\mathrm{e}}, / \mathrm{d} /, / \mathrm{y} /, / \mathrm{g} /, \overline{\mathrm{a}}, / \mathrm{r} /)$. During the Lag 1 condition, over half of the vocalizations contained each of two phonemes $(/ \mathrm{n} /, / \mathrm{h} /)$. A third phoneme was contained in over 0.25 of vocalizations $(\breve{\mathrm{a}})$. Two phonemes occurred in 0.10 to 0.25 of vocalizations $(\breve{\mathrm{e}}, / \mathrm{b} /)$, while nine phonemes occurred in less than 0.10 of vocalizations ( $\breve{\mathrm{u}}, / \mathrm{m} /, / \mathrm{y} /, \overline{\mathrm{e}}, / \mathrm{g} /, \overline{\mathrm{a}}, / \mathrm{r} /, \overline{\mathrm{i}}, \overline{\mathrm{o}})$. Phoneme distribution in baseline was skewed, with four of 11 phonemes occurring in a large proportion of vocalizations and the remaining phonemes occurring rarely. With the introduction of contingencies for variability, the dominant baseline phonemes continued to be dominant, but less so. In addition, the distribution of phoneme inclusion across vocalizations became more even with two phonemes occurring in the mid-range of proportional values (0.10-0.25). With the implementation of the Lag 3 condition, one phoneme occurred in over three-fourths of vocalizations $(/ \mathrm{h} /)$, while one other phoneme was contained in over half of all vocalizations $(/ \mathrm{n} /)$. Five phonemes occurred in greater than 0.25 of vocalizations ( $\breve{\mathrm{u}}, \breve{\mathrm{l}}, / \mathrm{y} /, / \mathrm{m} /, \breve{\mathrm{e}})$, four phonemes occurred in 0.10 to 0.25 of vocalizations $(/ \mathrm{d} /, / \mathrm{b} /$, $\overline{\mathrm{e}}, \overline{\mathrm{1}})$, and 11 phonemes occurred in less than 0.10 of vocalizations $(\overline{\mathrm{a}}, \breve{\mathrm{o}}, / \mathrm{g} /, \overline{\mathrm{o}}, / \mathrm{oo} /$, /ow/, ă, /w/, /ng/, /l/, /p/). Again, previously dominant phonemes continued to occur in a large proportion of 
vocalizations. However, the inclusion of the other existing and new phonemes across vocalizations once again approximated a more even distribution.

\section{Discussion}

The application of lag reinforcement for varied vocalizations produced changes in the phoneme repertoires of all three participants. Nicholas, Remy, and Isabel all emitted more phonemes during the lag schedule conditions, and for each participant, more new phonemes were produced when the stringency of the lag criteria were increased. However, the production of novel phonemes did not lead to the production of more novel vocalizations across conditions. An analysis of the distribution of phoneme use provides an explanation for these findings.

For Nicholas and Remy, the addition of new phonemes under reinforcement-forvariability conditions did not result in increased production of novel vocalizations. Although Nicholas and Remy produced seven and six new phonemes, respectively, these new sounds were not combined with existing sounds in a manner that met criteria for novelty. The analysis of unique phonemes per vocalization and the proportional production of phonemes across vocalizations support this conclusion. Moreover, production of these new phonemes failed to result in large shifts in the overall production of existing phonemes. It did, however, result in a shift in the general distribution of phonemes, as evidenced by the analysis of proportional phoneme production. Taken together, these data suggest that contingencies for variability did, in fact, alter the substrate of sub-units (i.e., phonemes) that make up responses (i.e., vocalizations). However, to increase variability further, reinforcement may need to be made contingent on vocalizations that are different and that do not contain dominant sounds. In addition, shaping could be initiated such that the new sounds would be targeted for reinforcement and increased separate from or in combination with other sounds to create word approximations. 
For Isabel, the effects of lag contingencies on vocal variability were different from the effects for Nicholas and Remy. The emergence of 12 new phonemes led to a large increase in the production of novel vocalizations under the most stringent lag schedule to which she was exposed (i.e., Lag 3). Although the most prominent phonemes from baseline continued to occur in a large proportion of vocalizations, the increase in average unique phonemes per vocalization from 2.3 at baseline to 4.0 in the Lag 3 condition indicates that novel vocalizations were created by combining new and existing phonemes in such a way that met criteria for reinforcement. Indeed, the emergence of new phonemes resulted in a shift in the proportional production of phonemes overall.

Although at acceptable levels, procedural fidelity for reinforcer delivery in the Lag 3 condition was lower in the Lag 1 condition in the current study. The complexity of the procedure might hinder successful implementation by caregivers. To determine whether an alternative (and simpler to implement) system of reinforcer delivery could maintain the gains achieved here, maintenance was assessed with Isabel in Study 3.

\section{Study 3}

\section{Methods}

Participant. Isabel was the only participant in Study 3.

Procedures. The procedures in this study were designed to determine whether reinforcers delivered on a schedule yoked to the delivery of reinforcers on a variability schedule but delivered contingent on any vocalization (i.e., regardless of variability) would maintain vocal variability. To investigate this question, Isabel was exposed to baseline, Lag 3, and yokedcontrol conditions.

EXT baseline. Data from Study 1 served as the initial baseline for the current study. The 
same baseline procedures were implemented for a reversal to baseline (extinction) phase.

Lag 3. Data from Study 2 served as the initial Lag 3 condition for the current study. The same Lag 3 procedures from Study 2 were implemented for a reversal to Lag 3 in Study 3.

Yoked-control. In the yoked-control condition, reinforcers were delivered after the occurrence of a pre-determined number of responses, regardless of variability. Using the procedure outlined by Page and Neuringer (1985), the last 6 sessions of the preceding Lag 3 condition (i.e., the point at which responding became stable) were used to create a schedule of reinforcer delivery. During the yoked-control condition, reinforcers were delivered for the occurrence of a vocalization according to this schedule. For example, if vocalizations 2, 7, 12, and 19 met the variability criterion in a stable session of the Lag 3 condition, then vocalizations $2,7,12$, and 19 would be reinforced in a yoked-control session, regardless of variability. In this way, reinforcer frequency and dependency on the occurrence of behavior was held constant across phases; only the contingency on variability differed.

Experimental design. A reversal design was used to study the circumstances under which vocal variability was or was not maintained. The conditions described above were implemented and withdrawn sequentially in A-B-C-A-B-C format $(\mathrm{A}=$ baseline, $\mathrm{B}=\mathrm{Lag} 3, \mathrm{C}=$ yokedcontrol).

\section{Procedural fidelity.}

Fidelity of session termination. Fidelity scores were provided for the initial baseline and Lag 3 conditions in Studies 1 and 2, respectively. In the current study, session termination procedures were implemented with greater than $96 \%$ fidelity across all conditions: $96.6 \%$ for the first yoked-control condition (range: $83.3-100 \%), 96.6 \%$ for the reversal to baseline (87-100\%), 98.1\% for the replication of the Lag 3 condition (range: $90.9-100 \%$ ), and $99.4 \%$ for the 
replication of the yoked-control condition (range: 95-100\%).

Fidelity of reinforcement procedures. Fidelity of reinforcer delivery for the initial Lag 3 condition was reported in Study 2. During the first yoked-control condition, reinforcers were delivered with $100 \%$ fidelity across $25 \%$ of sessions in that phase. Reinforcement procedures during the replication of the Lag 3 phase were implemented with 89.2 fidelity across $27 \%$ of sessions in that phase (range: $83-100 \%$ ), and with $100 \%$ fidelity across $25 \%$ of sessions in the replication of the yoked-control condition.

\section{Interobserver agreement.}

Novel vocalizations. Agreement for the initial baseline and Lag 3 conditions were reported in Studies 1 and 2, respectively. IOA for the remaining conditions in Study 3 averaged above 94\%: $97.1 \%$ across $35 \%$ of sessions in the first yoked-control condition (range: 87.5$100 \%$ ), $100 \%$ across $35 \%$ of sessions in the reversal to baseline, $94.8 \%$ across $33 \%$ of sessions during the replication of the Lag 3 condition (range: $77.8-100 \%$ ), and $95.5 \%$ for 35\% of sessions during the replication of the yoked-control condition (range: 83.3-100\%).

Frequency of phonemes. Phoneme agreement for the initial baseline and Lag 3 conditions were reported in Studies 1 and 2, respectively. IOA averaged greater than 99\% across all phonemes in the last six sessions in each of the remaining conditions for this study: $99.6 \%$ in the first yoked-control condition (range: 94.3-100\%), 99.3\% in the reversal to baseline (range: 95-100\%), 99.1\% in the Lag 3 condition (range: $88.3-100 \%$ ), and 99.7\% in the replication of the yoked-control condition (range: 97.9-100\%).

\section{Results}

Percentage of novel vocalizations. Figure 31 displays percentage of novel vocalizations across all six conditions. Sessions are depicted along the $x$-axis, and percentage novel 
vocalizations are presented along the $y$-axis.

Recall that in baseline, Isabel averaged $23 \%$ novel vocalizations (Study 1) and that delivery of reinforcers on a Lag 3 schedule increased variability to an average of $68.6 \%$ novel vocalizations (Study 2). A clear and significant increase in percentage novel vocalizations occurred from the baseline to the Lag 3 condition. These conditions were followed by the initial yoked-control condition, which was implemented for 20 sessions. Percentage novel vocalizations averaged $68.4 \%$ across the last six sessions of this condition (range: $60-80 \%$ ). That is, the variability generated with the application of contingencies for variability was maintained when those contingencies were removed. Under extinction in the reversal to baseline, average percentage novel vocalizations decreased to $45.4 \%$ (range: $38.9-50 \%$ ). Although not as low as in the original baseline condition, average variability here was markedly lower than in either of the conditions with reinforcers (Lag 3 and yoked). Reintroduction of the Lag 3 condition again increased percentage novel vocalizations, this time to an average of $65.3 \%$ (range: $55-75 \%$ ), and these gains were maintained again with the replication of the yoked condition $(M=63.3 \%$; range: $55-75 \%)$.

Cumulative novel vocalizations. Figure 32 displays cumulative total vocalizations (open circles) and cumulative novel vocalizations (closed circles) across all sessions for all conditions. Sessions are depicted along the $x$-axis, and cumulative vocalizations are presented along the $y$ axis. Summary data for percentage of novel vocalizations (upper panel) and for average novel vocalizations per session (lower panel) are presented in Figure 33. The first presentation of each condition is shown in the leftmost set of bars, and the second replication of each condition is shown in the rightmost set of bars. Baseline data are represented by the black bars, Lag 3 data are represented by the light gray bars, and yoked-control data are represented by the dark gray bars. 
Recall from Study 2 that implementation of the Lag 3 condition led to an increase in the slope of the line created by graphing cumulative novel vocalizations per session, indicating that reinforcement for variability not only increased the production of novel vocalizations within sessions but also across sessions. The slope of the line remained steeper during the yoked-control condition as well, indicating that the gains in production of novel vocalizations in Lag 3 were maintained even though the contingency for variability was removed. However, this pattern was not observed when the three conditions were replicated. Visual inspection of the line when vocalizations were under extinction in the reversal to baseline shows that the slope is highly variable across sessions. With the re-introduction of the Lag 3 condition, although the slope is steep at the beginning of the condition, the production of novel vocalizations begins to decrease across sessions toward the end of the condition. In the final yoked condition, the slope of the line more closely approximates the original baseline cumulative graph than either of the lines generated by Lag 3 data. Here, fewer novel vocalizations were emitted across sessions, although reinforcers were still being earned for variability within sessions (see above section).

Summary data for Isabel are provided in Figure 33. Recall from Study 1 that in baseline, 39 of Isabel's 654 vocalizations were scored as being different from all other vocalizations (6\%), and that in each session, an average of 1.2 novel vocalizations were produced (range: $0-8$ ). Recall from Study 2 that in the Lag 3 condition, 211 of 856 vocalizations were coded as novel (24.7\%), with 5.3 different vocalizations occurring per session (range: 1 -12). When yokedcontrol reinforcement was delivered, 138 of Isabel's 413 total vocalizations were novel (33.4\%). Each session, an average of 6.9 novel vocalizations was produced (0-17). The yoked condition not only maintained the pattern of increased novel vocalization production, but also increased these responses further. 
However, responding was not similar to this pattern during the replication of the three conditions. When baseline conditions were reinstated, Isabel emitted 128 novel vocalizations out of the 529 total vocalizations she produced $(24.2 \%)$. Here, an average 4.9 novel vocalizations occurred each session (0-15). While novel vocalizations decreased relative to the previous phase, re-introduction of the Lag 3 condition did not result in a substantial increase in either measure: 155 of 608 total vocalizations were scored as novel (25.5\%), with an average of 5.2 novel vocalizations per session (1-12). During the second yoked-control condition, 87 of 461 total vocalizations were novel (18.9\%), and an average of 3.8 novel vocalizations were emitted per session (0-10).

Frequency of phonemes. Data on the frequency of phonemes across the last six sessions in the first three conditions are presented in Figure 34 and in the last three conditions in Figure 35. Frequency is shown along the $x$-axis and the phonemes are listed along the $y$-axis. Baseline data are represented by the black bars, the Lag 3 condition is represented by the dark gray bars, and the yoked-control condition is represented by the light gray bars.

At baseline, the 126 vocalizations Isabel produced during the last six sessions of baseline consisted of 11 unique phonemes, with an average of 2.3 unique phonemes produced per vocalization (Study 1). Initial implementation of a Lag 3 reinforcement schedule resulted in the production of 22 different phonemes across 117 vocalizations, with an average of 4.0 unique phonemes per vocalizations (Study 2). During the yoked ratio condition, Isabel used 23 phonemes to create 123 vocalizations, including two phonemes that had not been coded in previous conditions (/oy/, /v/). One phoneme produced in both the baseline and Lag 3 conditions was not observed during the yoked condition (ă). In this condition, there was an average of 3.9 different phonemes per vocalization (range: $3.4-4.2$ ). 
When extinction was implemented during the reversal to baseline, 123 vocalizations in the last six sessions of the condition were comprised of 17 different phonemes. Each of these had occurred during a previous condition; that is, no new phonemes were produced. Some phonemes that had occurred in the original baseline were not observed here $(\overline{\mathrm{e}}, / \mathrm{r} /)$, while phonemes produced with variability contingencies were also absent (/oo/, /ow/, /ng/, /1/). Unique phonemes per vocalization decreased to an average of 2.7 during this condition (range: $2.1-3.0$ ). Replication of the Lag 3 condition resulted in the production of 24 unique phonemes to create 121 vocalizations, including one phoneme that had not been produced in previous phases (/ew/). Only two phonemes previously recorded did not occur during this condition: one from the initial Lag 3 condition $(/ \mathrm{p} /)$ and one from the initial yoked condition (/oy/). During this condition, there was an average of 3.8 phonemes per vocalization (range: 3.6-4.3). In the final yoked-control condition, 14 phonemes were produced across 120 vocalizations, with no novel phonemes being produced. Several phonemes identified previously did not occur during this condition: two from the original set of baseline phonemes $(\breve{\mathrm{a}}, / \mathrm{r} /)$, seven from the initial Lag 3 condition ( $\overline{\mathrm{o}}$, /oo/, /ow/, /w/, /ng/, /1/, /p/), two from the initial yoked condition (/oy/, /v/), and one from the reversal to Lag 3 (/ew/). These phonemes were absent regardless of the fact that all but two (/p/, /oy/) had been produced in the immediately preceding Lag 3 condition. Replication of the yoked-control condition yielded an average of 4.0 unique phonemes per vocalization (range: $3.8-4.3$ ).

Recall from Study 2 that dominant baseline phonemes continued to occur with a high frequency when the Lag 3 condition was implemented. However, some previously infrequent phonemes also increased in production, as did new phonemes. When reinforcers were delivered on a yoked-control schedule, two phonemes occurred more than 70 times each $(/ \mathrm{n} /, / \mathrm{h} /)$, while four phonemes occurred more than 30 times each $(/ \mathrm{m} /$, e $, \breve{u}, / y /)$. These six phonemes were 
similarly dominant in the two prior conditions. Four phonemes were produced between 10 and 30 times each $(/ \mathrm{d} /, / \mathrm{b} /, \breve{1}, / \mathrm{g} /)$, and 13 phonemes were produced less than 10 times each $(\overline{\mathrm{e}}, \overline{1}, / \mathrm{w} /$, $\breve{\mathrm{o}}, / \mathrm{oo} /, \overline{\mathrm{a}}, / \mathrm{r} /, \overline{\mathrm{o}}, / \mathrm{ow} /, / \mathrm{ng} /, / \mathrm{l} /, / \mathrm{oy} /, / \mathrm{v} /$ ). The majority of new phonemes from the Lag 3 condition were maintained under the yoked condition, and some of these increased in frequency with the delivery of yoked reinforcers.

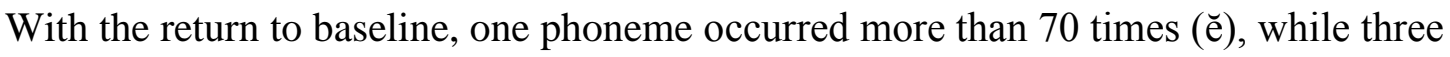
additional phonemes were produced more than 30 times each $(/ \mathrm{h} /, / \mathrm{n} /, \breve{a})$. Again, it was noted that the same phonemes continued to be prominent in the repertoire. Five phonemes were emitted between 10 and 30 times $(/ \mathrm{b} /, / \mathrm{y} /, / \mathrm{m} /, \overline{1}, \breve{\mathrm{u}})$, while eight occurred less than 10 times each $(\overline{\mathrm{o}}, \breve{\mathrm{o}}$, $/ \mathrm{d} /, \breve{1}, / \mathrm{g} /, \overline{\mathrm{a}}, / \mathrm{p} /)$. Only phonemes produced in the preceding yoked condition occurred during extinction; many new phonemes from the Lag 3 condition did not occur under extinction. When the Lag 3 schedule of reinforcement was re-implemented, one phoneme occurred more than 70 times $(/ \mathrm{n} /)$, and five phonemes were produced more than 30 times each $(\breve{\mathrm{e}}, / \mathrm{h} /, \breve{\mathrm{u}}, / \mathrm{m} /, / \mathrm{y} /)$. Five phonemes were emitted between 10 and 30 times each $(/ d /, \overline{1}, \breve{1}, \breve{o}, \bar{a})$. The remaining 11 phonemes produced in this condition occurred less than 10 times each $(/ \mathrm{g} /, / \mathrm{b} /, / 1 /, \overline{\mathrm{o}}, / \mathrm{w} /, / \mathrm{ow} /$, /ng/, /ew/, ă, è, /r/, /oo/, /v/). Finally, when reinforcer delivery was yoked to the previous condition, but was no longer contingent on variability, two phonemes were produced more than 100 times each $(/ \mathrm{h} /, / \mathrm{n} /)$. Four phonemes occurred more than 30 times each $(\breve{\mathrm{u}}, \breve{e}, / \mathrm{y} /, / \mathrm{m} /)$, four occurred between 10 and 30 times each $(/ \mathrm{d} /, / \mathrm{g} /, \breve{1}, \breve{o})$ and four other phonemes occurred less than 10 times each $(\overline{1}, \bar{a}, / b /, \bar{e})$. In contrast with the previous yoked condition, phonemes produced for the first time under the Lag 3 condition were not maintained here, no new phonemes were produced, and baseline phonemes dominated the phoneme repertoire, even above and beyond previous prominence. 
Proportion of phonemes. Data on the proportional distribution of phonemes, out of all phonemes produced, are presented in Figures 36 and 37. Proportion is shown along the $x$-axis and the phonemes produced are listed along the $y$-axis. Baseline data are represented by the black bars, the Lag 3 condition is represented by the dark gray bars, and the yoked-control condition is represented by the light gray bars.

Recall from the description of the relative distribution of phonemes in Study 2 that introduction of the Lag 3 condition resulted in a more even distribution of phoneme production, with dominant phonemes becoming less pervasive in the phoneme repertoire and relatively rare phonemes occurring more often. When yoked-control reinforcement was introduced, no phonemes accounted for more than a quarter of the phoneme repertoire. That is, all phonemes accounted for less than 0.25 of all those produced. Five phonemes each accounted for 0.10 to 0.25 of phonemes $(/ \mathrm{n} /, / \mathrm{h} /, / \mathrm{m} /, \breve{\mathrm{e}}, \breve{\mathrm{u}})$, while eight other phonemes each accounted for 0.01 to 0.09 of all phonemes $(/ \mathrm{y} /, / \mathrm{d} /, / \mathrm{b} /, \overline{1}, / \mathrm{g} /, \overline{\mathrm{e}}, \overline{1}, / \mathrm{w} /)$. The remaining ten phonemes made up less than 0.01 of all phoneme production ( $\breve{\mathrm{o}}, / \mathrm{oo} /, \overline{\mathrm{a}}, / \mathrm{r} /, \overline{\mathrm{o}}, / \mathrm{ow} /, / \mathrm{ng} /, / 1 /, / \mathrm{oy} /, / \mathrm{v} /)$. The more even distribution of phoneme production that occurred under Lag 3 reinforcement was maintained when reinforcers were no longer contingent on variability.

When baseline conditions were reinstated, the relative distribution of phonemes identified in the Lag 3 and yoked conditions was maintained: no one phoneme accounted for greater than 0.25 of the phoneme repertoire. Here, four phonemes accounted for 0.10 to 0.25 of all phonemes

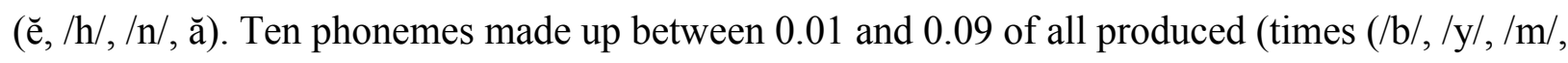
$\overline{1}, \breve{\mathrm{u}}, \overline{\mathrm{o}}, \breve{\mathrm{o}}, / \mathrm{d} /, \breve{1}, / \mathrm{W} /$ ), while three phonemes accounted for less than 0.01 of all phonemes produced $(/ \mathrm{g} /, \overline{\mathrm{a}}, / \mathrm{p} /)$. Although several phonemes were not produced during this condition (see discussion under Frequency of Phonemes), no phonemes entirely dominated the repertoire to the 
extent identified in the original baseline. With the re-introduction of the Lag 3 condition, four phonemes accounted for 0.10 to 0.25 of all those produced $(/ \mathrm{n} /, \breve{\mathrm{e}}, / \mathrm{h} /, \breve{\mathrm{u}})$, eight made up 0.01 to 0.09 of all emitted (/m/, /y/, /d/, $, \breve{1}, \breve{o}, \bar{a}, / g /)$, and 12 phonemes accounted for less than 0.01 of all phonemes (/b/, /1/, , , /w/, /ow/, /ng/, /ew/, ă, ē,/r/, /oo/, /v/). Again, the relative distribution of phonemes achieved under the initial Lag 3 condition was maintained here and in the final yokedcontrol condition. Under yoked reinforcement, three phonemes made up between 0.10 and 0.25 of all phonemes $(/ \mathrm{h} /, / \mathrm{n} /, \breve{\mathrm{u}})$. Eight phonemes each accounted for 0.01 to 0.09 of all phonemes produced $(\breve{\mathrm{e}}, / \mathrm{y} /, / \mathrm{m} /, / \mathrm{d} /, / \mathrm{g} /, \breve{1}, \breve{\mathrm{o}}, \overline{1})$, and three others each made up less than 0.01 of all phonemes $(\overline{\mathrm{a}}, / \mathrm{b} /, \overline{\mathrm{e}})$.

Proportion of vocalizations. Data on the proportional distribution of phonemes, out of all vocalizations produced, are presented in Figures 38 and 39. Proportion is shown along the $x$ axis and the phonemes produced are listed along the $y$-axis. Baseline data are represented by the black bars, the Lag 3 condition is represented by the dark gray bars, and the yoked-control condition is represented by the light gray bars.

As discussed in Study 2, implementation of the Lag 3 condition resulted in the continued prevalence of dominant baseline phonemes across a large proportion of vocalizations. However, the inclusion of the other existing and new phonemes across vocalizations approximated a more even distribution. When reinforcers were no longer contingent on variability in the yoked condition, four phonemes were contained in over half of all vocalizations $(/ \mathrm{n} /, / \mathrm{h} /, / \mathrm{m} /$, ě), and two additional phonemes occurred in greater than 0.25 of vocalizations ( $\breve{\mathrm{u}}, / \mathrm{y} /)$. Three phonemes were each contained in 0.10 to 0.25 of all vocalizations $(/ \mathrm{d} /, / \mathrm{b} /, \breve{1})$, and the remaining 14 phonemes occurred in less than 0.10 of vocalizations (/g/, è, $\overline{1}, / w /, \breve{o}, / o o /, \bar{a}, / r /, \bar{o}, / o w /, / n g /, / 1 /$, /oy/, /v/). The distribution of phonemes across vocalizations continued to be skewed in this 
condition toward previously dominant phonemes, with a greater difference in occurrence between the most common and least common phonemes.

With implementation of extinction in the return to baseline, one phoneme occurred in

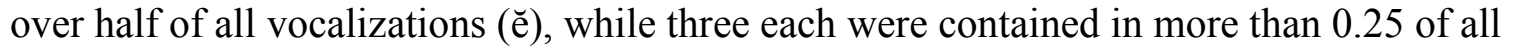
vocalizations $(/ \mathrm{h} /, / \mathrm{n} /, \breve{a})$. Four phonemes occurred in 0.10 to 0.25 of vocalizations $(/ \mathrm{b} /, / \mathrm{y} /, / \mathrm{m} /$, $\overline{1})$, and nine were contained in less than 0.10 of vocalizations ( $\breve{\mathrm{u}}, \overline{\mathrm{o}}, \breve{\mathrm{o}}, / \mathrm{d} /, \breve{1}, / \mathrm{w} /, / \mathrm{g} /, \overline{\mathrm{a}}, / \mathrm{p} /)$. Here, the prevalence of phonemes across vocalizations decreased. That is, phonemes that were dominant across vocalizations decreased relative to production in all previous conditions. A reversal to the Lag 3 condition resulted in an increase in the proportion of vocalizations containing the most dominant phonemes: three occurred in over half of all vocalizations (/n/, ĕ, $/ \mathrm{h} /$ ), and two others occurred in greater than 0.25 of all vocalizations ( $\breve{\mathrm{u}}, / \mathrm{m} /)$. Six phonemes were each contained in 0.10 to 0.25 of vocalizations $(/ y /, / d /, \overline{1}, \breve{1}, \breve{o}, \bar{a})$, while the remaining 13 occurred in less than 0.10 of vocalizations (/g/, /b/, /1/, ō, /w/, /ow/, /ng/, /ew/, ă, ē, /r/, /oo/, /v/). Removal of the contingency on variability in the yoked condition resulted in three phonemes occurring in over half of vocalizations $(/ \mathrm{h} /, / \mathrm{n} /, \breve{\mathrm{u}}, / \mathrm{m} /)$. Three additional phonemes occurred in more than 0.25 of all vocalizations ( $\breve{\mathrm{e}}, / \mathrm{y} /, / \mathrm{d} /)$, four occurred in 0.10 to 0.25 of vocalizations $(/ \mathrm{g} /$, $\breve{1}, \breve{o}, \overline{1})$, and three phonemes occurred in less than 0.10 of vocalizations $(\overline{\mathrm{a}}, / \mathrm{b} /, \overline{\mathrm{e}})$. The most prominent phonemes that increased proportionally within vocalizations under the second Lag 3 condition remained prevalent here as well.

\section{Discussion}

During the first Lag 3 condition, Isabel produced more phonemes, and as a result, a greater percent of her vocalizations were novel. When reinforcer delivery in the maintenance condition was yoked to the delivery of reinforcers in the Lag 3 condition, variability was 
sustained. These conclusions were strengthened when the pattern of increased variability and maintenance was replicated across conditions. Indeed, when extinction was implemented in the reversal to baseline, novel vocalizations decreased but not to levels observed in the first condition (23\% as compared to $45.4 \%$ ). This finding might be explained by the fact that variable behavior tends to be more resistant to change than repetitive behavior (Cohen, Neuringer, \& Rhodes, 1990; Doughty \& Lattal, 2001). It is also possible that novel vocalizations contacted reinforcement in the natural environment (i.e., attention from her parents) between sessions during this time (cf., Baer \& Wolf, 1970). In fact, her mother reported that Isabel was trying to "say more" around the house and that she and Isabel's father were praising her for each attempt. Additionally, Isabel's in-home tutors reported that she began imitating single and combined phonemes, and approximating words under echoic control during the final phase of the study. Although phonemes that emerged during reinforcement for variability continued to be produced during the first maintenance condition and were produced again during the second Lag 3 condition, these finding were not replicated in the last phase of the study. That is, repeated exposure to reinforcement for vocalizations independent of variability led to increased repetition of existing phonemes. This finding is consistent with results from basic research that indicate that when a choice between responding variably or repetitively is available, behaving variably is selected less often implying that it requires increased effort (Abreu-Rodrigues, Lattal, Dos Santos, \& Matos, 2005).

These findings, taken together, suggest that although novel vocalizations can be maintained with yoked reinforcement, long-term exposure to reinforcement independent of a variability contingency would result in stereotypy of the phoneme repertoire over time. Exposure to variability booster sessions weekly may prevent this from occurring. It should be noted that 
Isabel began to imitate speech sounds and to emit word approximations independently shortly after the completion of this study.

\section{General Discussion}

Skinner (1981) reasoned that selection by consequences required variation in behavior, thereby creating a metaphorical relation between evolutionary processes (i.e., phylogeny) and behavioral processes (i.e., ontogeny). The study of behavioral variability, which includes such domains as novelty and creativity, is one research area that links the evolutionary process of natural selection and the reinforcement process of behavioral selection (Neuringer, 2002, 2004, 2009). Research on variable behavior has the potential to lead to new and innovative interventions for problems characterized by repetition, sameness, and stereotypy, as in the case of autism spectrum diagnoses. Sameness in behavior precludes the possibility of reinforcing new responses, which in turn hinders learning and generalization. To engineer appropriate and effective interventions for individuals with ASD, ways to develop variable behavioral repertoires must be considered.

In Study 1, data were collected on the existing vocal repertoires of children with autism. A heterogeneous profile of phoneme production was identified. This wide range of vocal skills is consistent with previous research in children with ASD (e.g., McCleery et al., 2006), even though the current data set represents individuals at the lower end of vocal functioning. For the present study, data were collected in a manner that differs from typical speech and language research in which participants are required to attempt to produce words containing each speech sound, either through labeling or imitation (e.g., Prather, Hedrick, \& Kern, 1975; Stoel-Gammon, 1991). Here, the participants were unable to imitate or independently produce words as a condition of enrollment. Therefore, a free-operant procedure was arranged, whereby participants 
produced a sample of 20 vocalizations in a limited environment without additional stimuli or prompts. Structuring sessions in this way allowed for an analysis of phonemes involved in stereotypic vocalizing that was likely maintained by its sensory consequences (i.e., extended ignore sessions; Vollmer, Marcus, Ringdahl, \& Roane, 1995). In addition, only phonemes produced when vocalizations achieved stability were used to conduct this analysis, providing a safeguard that very low frequency sounds (ones that were unlikely at mastery) would be scored. As a result, it is unclear if phonemes absent from the current vocal samples (over 100 vocalizations per participant) represent phonemes the participants were not producing or were unable to produce, or if the environment was not arranged to elicit the behavior. In either case, future research should investigate procedural arrangements that ensure a full range of behaviors in the participant's current vocal repertoire can occur during observation.

Application of reinforcement for variability of vocalizations in Study 2 led to mixed results, with all participants producing more phonemes than in baseline, but with only one participant using these new sounds to create significantly more novel vocalizations within and across sessions (Isabel). A failure to increase the behavior of interest, novel vocalizations, could be attributed to two reasons. First, although steps were taken to ensure that highly preferred items were delivered contingent on variability, it could be the case that these items did not function as reinforcers for varied vocalizations for Nicholas and Remy. Review of session videos, however, suggests otherwise: both participants frequently reached out for or attempted to grab the items from the therapist when they were not delivered for repetitive vocalizations. An analysis of reinforcers earned during lag schedule conditions could shed light on the observed behavior, as well. If the participants earned the majority of the reinforcers available for varied vocalizations during session, then the observed level of novelty was sufficient to meet the 
arranged contingencies (e.g., Page \& Neuringer, 1985). That is, participants maximized behavior by meeting the arranged contingencies with the least effort necessary (i.e., by recombining existing phonemes or repeating vocalizations). It is possible that more stringent variability criteria (i.e., higher lag schedule values) could have resulted in increased novel vocalizations for these participants.

The reversal arrangement in Study 3 provided additional empirical support that increases in vocal variability were attributable to the experimental manipulation (i.e., the lag schedule of reinforcement). In addition, this variability was maintained under less stringent reinforcement criteria once the contingency for variability was removed (i.e., the yoked-control condition). However, long-term exposure to reinforcement for vocalizations independent of variability may result in deterioration of these gains over time. These conclusions are made with caution, however, in that only one participant was exposed to the conditions. Future research should systematically replicate that study. As mentioned previously, an examination of the frequency of variability intervention during maintenance that would prevent these losses could also be conducted. Investigation of training parents to implement the maintenance procedures also is warranted.

\section{Developmental Implications}

Although for some participants over half of the vocalizations produced in a session were different from all other vocalizations in that session, none of the children had acquired use of vocalizations to communicate prior to study enrollment and previous attempts to teach communication had failed. The question then turns to how these phoneme repertoires compare to those of typically developing children. Figures 40 (vowels) and 41 (consonants) display data on typical phoneme development, as well as on the phonemes present in the phoneme repertoires of 
study participants. In each figure, phonemes are listed in the far left column, and the International Phonetic Alphabet (IPA) code for each sound is in the column to the right of that. Speech pathologists additionally code phoneme production based on the manner in which the sound is articulated with the tongue, lips, and teeth. The far right column lists these articulation categories, with each category, sound, and IPA code similarly shaded for ease of interpretation. Age (in months) is displayed along the top of the charts, with each vertical line corresponding to the beginning of a four-month interval. For the bar associated with each phoneme, the leftmost boundary indicates the age at which the sound has been first recorded in typically developing children. The rightmost boundary specifies the age at which the majority of typically developing children have mastered production of that sound at the beginning, middle, and end of words (see Prather et al., 1975; Stoel-Gammon, 1991, for reviews). Although the participants in the current study could not be tested in the traditional manner used by speech-language researchers (e.g., imitation, picture labeling), their spontaneous vocalizations could be analyzed for any occurrence of specific sounds. The names of those participants who produced the target sound at any time during the last six sessions of baseline are listed within each bar. More than 100 vocalizations per participant were analyzed.

All vowels (Figure 40) are typically mastered by 36 months of age, with the exception of r-colored vowels, which are not typically mastered until the sixth year. At least $50 \%$ of all participants produced monopthong vowels, while at least 50\% produced three of five diphthongs. The remaining two diphthongs were produced by highly variable (Nadia, Kali, Dillon) and moderately variable (Nicholas) participants. None of the participants produced r-colored vowels. One of the youngest participants (Nadia, two years of age) was also one of the most variable; her vowel production mirrors typical development. For the other two-year-old participant (Remy, 
moderately variable), it is unclear whether absence of some phonemes reflects typical development or skill deficit. However, for the remaining participants, aged 3 to 14 years, absence of these vowels marks speech delay; analysis of consonant production should indicate if the pattern of phoneme development in these participants is following typical, though delayed, phonemic progression.

With consonant production (Figure 41), nasals, plosives, and glides are typically produced before fricatives, affricates, and liquids. All participants, except one (Isabel, low variability), produced both early-onset nasals (/n/, /m/, mastered by 36 months). Only one participant (Kali, high variability) produced the late-onset nasal (/ng/, mastered after 48 months). The six sounds within the plosive articulation group, regardless of age of onset, were produced by the majority of highly variable participants and by some moderately variable participants; two of these sounds were produced by one low variability participant (/d/, /g/, Isabel). The earlyonset fricative (/h/, mastered by 36 months) was produced by all participants, but the remaining six fricatives were only produced by highly variable participants, with the exception of one moderately variable participant producing one of these sounds (/sh/, Remy). Sounds with onset after 32 months, including all liquids and affricates, were primarily produced by highly variable participants, with the exception that two moderately variable participants produced one sound each (/l/, Nicholas; /sh/, Remy). In general, the pattern of consonant production for the most variable participants was consistent with the pattern observed in typically developing children; that is, more early-onset phonemes were produced than late-onset phonemes. For the moderate variability group, the same is true with a few exceptions: both Nicholas and Remy produced sounds late-onset phonemes that do not typically emerge before the absent early-onset phonemes (/l/, /sh/). In the low variability group, Nelson only produced consonants that are typically 
mastered by 36 months of age; combined with his vowel production, this pattern reflects typical although severely delayed speech development. Isabel, on the other hand, did not produce some early-onset phonemes $(/ \mathrm{m} /, / \mathrm{p} /, / \mathrm{b} /)$ but did produce phonemes that typically develop later (/y/, /r/). Her pattern of phoneme development may reflect not only speech delay but also a co-morbid speech disorder. An analysis of the kind presented here may assist in diagnostic evaluation in the future.

Figures 42 through 47 show the developmental charts of Study 2 participants with shading of the phoneme bars according to the condition in each was documented (if a phoneme was not observed, it was shaded black). For all three participants (Figures 42, 44, and 46), reinforcement for variability in either lag condition resulted in production of the majority of early-onset vowels. Analysis of the consonant production (Figures 43, 45, and 47) shows that reinforcement also resulted in production of missing early-onset but not later-onset phonemes for all three participants. That is, under lag schedules of reinforcement, all new phonemes were ones that typically develop before 36 months of age; no participant produced new sounds that typically develop after 36 months. Further, with replication of the Lag 3 condition in Study 3 , Isabel eventually produced all phonemes (vowels and consonants) that are typically mastered by 36 months, and all but two phonemes that are typically mastered by 48 months (Figures 48 and 49). Taken together, these data suggest that the behaviors that emerge with increased variability occur in a developmentally appropriate sequence.

\section{Future Directions}

Although the current set of studies provides valuable information regarding the vocal patterns of children with ASD who do not vocally imitate nor use functional vocal communication, additional questions arise. Future research could investigate the effects of higher 
lag values when variability does not increase at a less stringent criterion. In addition, it is unclear at what level of variability vocal imitation training could begin. A systematic replication of Study 2 could include more stringent lag schedules as well as probes for vocal imitation across all conditions to answer this question.

It is possible that an assessment of the sort conducted as baseline (Study 1) could inform diagnostic evaluation and may provide clinicians with additional information when designing intervention. If clients present with few phonemes in the vocal repertoire, vocal variability interventions should be recommended. In addition, identifying the baseline phonemic repertoire could suggest phoneme targets for decelerative intervention (i.e., for those sounds that compose an excessive proportion of the repertoire) or for accelerative intervention (i.e., for those sounds that occur but are at low frequency).

In the current set of studies, social validity was not assessed. It is unclear if parents or other professionals would find the procedures or behavioral outcomes acceptable. If not, it is unlikely that they would maintain the intervention in the absence of a behavioral professional. Future research could investigate the components necessary to train parents to implement the variability and maintenance procedures set forth here.

In general, more work is needed to understand the ways in which features of ASD interact with the social environment to develop individual behavioral repertoires. For example, research suggests that there may be a critical or optimal period for learning to respond variably (Stokes, 1999; Stokes \& Balsam, 2001; Stokes \& Harrison, 2002; Stokes, Lai, Holtz, Rigsbee, \& Cherrick, 2008). In light of the MacDonald et al. (2007) findings that differences between typically developing children and children with ASD, it may be possible to significantly impact the development of stereotyped repertoires if intervention begins early (e.g., at two or three year 
of age), but it is unclear how effective variability training would be later in development. 


\section{References}

Aase, H. \& Sagvolden, T. (2006). Infrequent, but not frequent, reinforcers produce more variable responding and deficient sustained attention in young children with attentiondeficit/hyperactivity disorder (ADHD). Journal of Child Psychology and Psychiatry, 47, 457-471.

Abreu-Rodrigues, J., Lattal, K. A., Dos Santos, C. V., \& Matos, R. A. (2005). Variation, repetition, and choice. Journal of the Experimental Analysis of Behavior, 83, 147-168.

Ahearn, W. H., Clark, K. M., MacDonald, R. P. F., \& Chung, B. I. (2007). Assessing and treating vocal stereotypy in children with autism. Journal of Applied Behavior Analysis, 40, 263-275.

Ahrens, E.N., Lerman, D.C., Kodak, T., Worsdell, A.S., \& Keegan, C. (2011). Further evaluation of response interruption and redirection as treatment for stereotypy. Journal of Applied Behavior Analysis, 44, 95-108.

American Psychiatric Association (2000). Diagnostic and statistical manual of mental disorders ( $4^{\text {th }}$ edition). Washington, D.C.: Author.

American Speech-Language-Hearing Association (2012). Augmentative and Alternative Communication (AAC). Retrieved from http://www.asha.org/public/speech/disorders/aac.htm

Anderson, J., \& Le, D.D. (2011). Abatement of intractable vocal stereotypy using an overcorrection procedure. Behavioral Interventions, 26, 134-146.

Antonitis, J. J., (1951). Response variability in the white rat during conditioning, extinction, and reconditioning. Journal of Experimental Psychology, 42, 273-281.

Athens, E. S., Vollmer, T. R., Sloman, K. N., \& St. Peter Pipkin, C. (2008). An analysis of vocal stereotypy and therapist fading. Journal of Applied Behavior Analysis, 41, 291-297. 
Ayllon, T., \& Kelly, K. (1974). Reinstating verbal behavior in a functionally mute retardate. Professional Psychology, 5, 385-393.

Baer, D., \& Wolf, M. (1970). The entry into natural communities of reinforcement. In R. Ulrich, T. Stachnik, \& J. Mabry (Eds.), Control of human behavior (319-324). Glenview, IL: Scott, Foresman.

Bartman, S., \& Freeman, N. (2003). Teaching language to a two-year-old with autism. Journal of Developmental Disabilities, 10, 47-52.

Baumann, A. A., Abreu-Rodrigues, J., \& da Silva Souza, A. (2009). Rules and self-rules: Effects of variation upon behavioral sensitivity to change. The Psychological Record, 59, 641670.

Betz, A.M., Higbee, T.S., Kelley, K.N., Sellers, T.P., \& Pollard, J.S. (2011). Increasing response variability of mand frames with script training and extinction. Journal of Applied Behavior Analysis, 44, 357-362.

Blough, D.S. (1966). The reinforcement of least-frequent interresponse times. Journal of the Experimental Analysis of Behavior, 9, 581-591.

Bodfish, J. W., Symons, F. J., Parker, D. E., \& Lewis, M. H. (2000). Varieties of repetitive behavior in autism: Comparisons to mental retardation. Journal of Autism and Developmental Disorders, 30, 237-243.

Bondy, A., \& Frost, L. (2001). The Picture Exchange Communication System. Behavior Modification, 25, 725-744.

Boren, J. J., Moerschbaecher, J. M., \& Whyte, A. A. (1978). Variability of response location on fixed-ratio and fixed-interval schedules of reinforcement. Journal of the Experimental Analysis of Behavior, 30, 63-67. 
Brigham, T. A., \& Sherman, J. A. (1968). An experimental analysis of verbal imitation in preschool children. Journal of Applied Behavior Analysis, 1, 151-158.

Bryant, D., \& Church, R. M. (1974). The determinants of random choice. Animal Learning \& Behavior, 2, 245-248.

Cammilleri, A. P., \& Hanley, G. P. (2005). Use of a lag differential reinforcement contingency to increase varied selections of classroom activities. Journal of Applied Behavior Analysis, 38, 111-115.

Carr, E.G., \& Durand, V.M. (1985). Reducing behavior problems through functional communication training. Journal of Applied Behavior Analysis, 18, 111-126.

Carroll, R.A., \& Klatt, K.P. (2008). Using stimulus-stimulus pairing and direct reinforcement to teach vocal verbal behavior to young children with autism. The Analysis of Verbal Behavior, 24, 135-146.

Cassella, M.D., Sidener, T.M., Sidener, D.W., \& Progar, P.R. (2011). Response interruption and redirection for vocal stereotypy in children with autism: A systematic replication. Journal of Applied Behavior Analysis, 44, 169-173.

Catania, A. C., Ono, K., \& de Souza, D. (2000). Sources of novel behavior: Stimulus control arranged for different response dimensions. European Journal of Behavior Analysis, 1, 23-32.

Charlop-Christy, M. H., Carpenter, M., Le, L., LeBlanc, L. A., \& Kellet, K. (2002). Using the Picture Exchange Communication System (PECS) with children with autism: Assessment of PECS acquisition, speech, social-communicative behavior, and problem behavior. Journal of Applied Behavior Analysis, 35, 213-231.

Cohen, L., Neuringer, A., \& Rhodes, D. (1990). Effects of ethanol on reinforced variations and 
repetitions by rats under a multiple schedule. Journal of the Experimental Analysis of Behavior, 54, 1-12.

Cunningham, A. B., \& Schreibman, L. (2008). Stereotypy in autism: The importance of function. Research in Autism Spectrum Disorders, 2, 469-479.

Denney, J., \& Neuringer, A. (1998). Behavioral variability is controlled by discriminative stimuli. Animal Learning \& Behavior, 26, 154-162.

DeThorne, L. S., Johnson, C. J., Walder, L., and Mahurin-Smith, J. (2009). When "Simon Says" doesn't work: Alternatives to imitation for facilitating early speech development. American Journal of Speech-Language Pathology, 18, 133-145.

Doughty, A. H., \& Lattal, K. A. (2001). Resistance to change of operant variation and repetition. Journal of the Experimental Analysis of Behavior, 76, 195-215.

Duker, P. C., \& van Lent, C. (1991). Inducing variability in communicative gestures used by severely retarded individuals. Journal of Applied Behavior Analysis, 24, 379-386.

Eckerman, D. A., \& Lanson, R. N. (1969). Variability of response location for pigeons responding under continuous reinforcement, intermittent reinforcement, and extinction. Journal of the Experimental Analysis of Behavior, 12, 73-80.

Esch, B. E., Carr, J. E., \& Grow, L. L. (2009). Evaluation of an enhanced stimulus-stimulus pairing procedure to increase early vocalizations of children with autism. Journal of Applied Behavior Analysis, 42, 225-441.

Esch, B. E., Carr, J. E., \& Michael, J. (2005). Evaluating stimulus-stimulus pairing and direct reinforcement in the establishment of an echoic repertoire of children diagnosed with autism. The Analysis of Verbal Behavior, 21, 43-58.

Esch, J. W., Esch, B. E., \& Love, J. R. (2009). Increasing vocal variability in children with 
autism using a lag schedule of reinforcement. The Analysis of Verbal Behavior, 25, 7378.

Falcomata, T. S., Roane, H. S., Hovanetz, A. N., Kettering, T. L., \& Keeney, K. M. (2004). An evaluation of response cost in the treatment of inappropriate vocalizations maintained by automatic reinforcement. Journal Applied Behavior Analysis, 37, 83-87.

Fisher, W., Piazza, C. C., Bowman, L. G., Hagopian, L. P., Owens, J. C., \& Slevin, I. (1992). A comparison of two approaches for identifying reinforcers for persons with severe and profound disabilities. Journal of Applied Behavior Analysis, 25, 491-498.

Fleece, L., Gross, A., O’Brien, T., Kistner, J., Rothblum, E., \& Drabman, R. (1981). Elevation of voice volume in young developmentally delayed children via an operant shaping procedure. Journal of Applied Behavior Analysis, 14, 351-355.

Ganz, J. B., Heath, A. K., Rispoli, M. J., \& Earles-Vollrath, T. L. (2010). Impact of AAC versus modeling on verbal imitation, picture discrimination, and related speech: A pilot investigation. Journal of Developmental and Physical Disabilities, 22, 179-196.

Ganz, J. B., \& Simpson, R. L. (2004). Effects on communicative requesting and speech development of the Picture Exchange Communication System in children with characteristic of autism. Journal of Autism and Developmental Disorders, 34, 395-409.

Goetz, E. M., \& Baer, D. M. (1973). Social control of form diversity and the emergence of new forms in children's blockbuilding. Journal of Applied Behavior Analysis, 6, 209-217.

Goldman, S., Wang, C., Salgado, M. W., Greene, P. E., Kim, M., \& Rapin, I. (2008). Motor stereotypies in children with autism and other developmental disorders. Developmental Medicine \& Child Neurology, 51, 30-38.

Gregory, M. K., DeLeon, I. G., \& Richman, D. M. (2009). The influence of matching and motor- 
imitation abilities on rapid acquisition of manual signs and exchange-based communication responses. Journal of Applied Behavior Analysis, 42, 399-404.

Gresham, F. M. (2009). Evolution of the treatment integrity concept: Current status and suture directions. School Psychology Review, 38, 533-540.

Grow, L. L., Kelley, M. E., Roane, H. S., \& Shillingsburg, M. A. (2008). Utility of extinctioninduced variability for the selection of mands. Journal of Applied Behavior Analysis, 41, $15-24$.

Grunow, A., \& Neuringer, A. (2002). Learning to vary and varying to learn. Psychonomic Bulletin \& Review, 9, 250-258.

Hagopian, L. P., Contrucci Kuhn, S. A., Long, E. S., \& Rush, K. S. (2005). Schedule thinning following communication training: Using competing stimuli to enhance tolerance to decrements in reinforcer density. Journal of Applied Behavior Analysis, 38, 177-193.

Hake, D. F., \& Mabry, J. (1979). Operant and nonoperant vocal responding in the mynah: Complex schedule control and deprivation-induced responding. Journal of the Experimental Analysis of Behavior, 32, 305-321.

Haley, J.L., Heick, P.F., \& Luiselli, J.K. (2010). Use of an antecedent intervention to decrease vocal stereotypy of a student with autism in the general education classroom. Child \& Family Behavior Therapy, 32, 311-321.

Hanley, G.P., Iwata, B.A., \& McCord, B.E. (2003). Functional analysis of problem behavior: A review. Journal of Applied Behavior Analysis, 36, 147-185.

Harding, J. W., Wacker, D. P., Berg, W. K., Rick, G., \& Lee, J. F. (2004). Promoting response variability and stimulus generalization in martial arts training. Journal of Applied Behavior Analysis, 37, 185-195. 
Harris, S. L. (1975). Teaching language to nonverbal children-With emphasis on problems of generalization. Psychological Bulletin, 82, 565-580.

Heldt, J., \& Schlinger Jr., H.D. (in press). Increased variability in tacting under a Lag-3 schedule of reinforcement. The Analysis of Verbal Behavior.

Hernandez, E., Hanley, G. P., Ingvarsson, E. T., \& Tiger, J. H. (2007). A preliminary evaluation of the emergence of novel mand forms. Journal of Applied Behavior Analysis, 40, 137156.

Hopkinson, J., \& Neuringer, A. (2003). Modifying behavioral variability in moderately depressed students. Behavior Modification, 27, 251-264.

Hunziker, M. H. L., Saldana, R. L., \& Neuringer, A. (1996). Behavioral variability in SHR and WKY rats as a function of rearing environment and reinforcement contingency. Journal of the Experimental Analysis of Behavior, 65, 129-144.

Iwata, B.A., Dorsey, M.F., Slifer, K.J., Bauman, K.E., \& Richman, G.S. (1994). Toward a functional analysis of self-injury. Journal of Applied Behavior Analysis, 27, 197-209.

Iwata, B.A., Duncan, B.A., Zarcone, J.R., Lerman, D.C., \& Shore, B.A. (1994). A sequential, test-control methodology for conducting functional analyses of self-injurious behavior. Behavior Modification, 18, 289-306.

Johansen, E. B., Killeen, P. R., \& Sagvolden, T. (2007). Behavioral variability, elimination of responses, and delay-of-reinforcement gradients in SHR and WKY rats. Behavioral and Brain Functions, 3, ArtID 60.

Johnston, J. M., \& Johnston, G. T. (1972). Modification of consonant speech-sound articulation in young children. Journal of Applied Behavior Analysis, 5, 233-246.

Joyce, J. H., \& Chase, P. N. (1990). Effects of response variability on the sensitivity of rule- 
governed behavior. Journal of the Experimental Analysis of Behavior, 54, 251-262.

Kennedy, C. H., Meyer, K. A., Knowles, T., \& Shukla, S. (2000). Analyzing the multiple functions of stereotypical behavior for students with autism: Implications for assessment and treatment. Journal of Applied Behavior Analysis, 33, 559-571.

Kinloch, J.M., Foster, T. M., \& McEwan, J. S. A. (2009). Extinction-induced variability in human behavior. The Psychological Record, 59, 347-370.

Koegel, R. L., \& Covert, A. (1972). The relationship of self-stimulation to learning in autistic children. Journal of Applied Behavior Analysis, 5, 381-387.

Koegel, R. L., Firestone, P. B., Kramme, K. W., \& Dunlap, G. (1974). Increasing spontaneous play by suppressing self-stimulation in autistic children. Journal of Applied Behavior Analysis, 7, 521-528.

Kurtz, P.F., Boelter, E.W., Jarmolowicz, D.P., Chin, M.D., \& Hagopian, L.P. (2011). An analysis of functional communications training as an empirically supported treatment for problem behavior displayed by individuals with intellectual disabilities. Research in Developmental Disabilities, 32, 2935-2942.

Lalli, J. S., Zanolli, K., \& Wohn, T. (1994). Using extinction to promote response variability in toy play. Journal of Applied Behavior Analysis, 27, 735-736.

Lancioni, G. E., O’Reilly, M. F., Cuvo, A. J., Singh, N. N., Sigafoos, J., \& Didden, R. (2007). PECS and VOCAS to enable students with developmental disabilities to make requests: An overview of the literature. Research in Developmental Disabilities, 28, 468-488.

Lane, H. (1961). Operant control of vocalizing in the chicken. Journal of the Experimental Analysis of Behavior, 4, 171-177.

Lane, H., Kopp, J., Sheppard, W., Anderson, T., \& Carlson, D. (1967). Acquisition, 
maintenance, and retention in the differential reinforcement of vocal duration. Journal of Experimental Psychology, 74, 1-16.

Lane, H. L., \& Shinkman P.G. (1963). Methods and findings in an analysis of a vocal operant. Journal of the Experimental Analysis of Behavior, 6, 179-188.

Lanovaz, M.J., Fletcher, S.E., \& Rapp, J.T. (2009). Identifying stimuli that alter immediate and subsequent levels of vocal stereotypy. Behavior Modification, 33, 682-704.

Lanovaz, M.J., \& Sladeczek, I.E. (2011). Vocal stereotypy in children with autism: Structural characteristics, variability, and effects of auditory stimulation. Research in Autism Spectrum Disorders, 5, 1159-1168.

Lanovaz, M.J., \& Sladeczek, I.E. (2012). Vocal stereotypy in individuals with autism spectrum disorders: A review of behavioral interventions. Behavior Modification, 36, 146-164.

Leander, J. D., Milan, M. A., Jasper, K. B., \& Heaton, K. L. (1972). Schedule control of the vocal behavior of Cebus monkeys. Journal of the Experimental Analysis of Behavior, 17, 229-235.

LeBlanc, L. A., Esch, J., Sidener, T. M., \& Firth, A. M. (2006). Behavior language interventions for children with autism: Comparing applied verbal behavior and naturalistic teaching approaches. The Analysis of Verbal Behavior, 22, 49-60.

Lee, R., McComas, J. J., \& Jawor, J. (2002). The effects of differential and lag reinforcement schedules on varied responding by individuals with autism. Journal of Applied Behavior Analysis, 35, 391-402.

Lee, R., \& Sturmey, P. (2006). The effects of lag schedules and preferred materials on variable responding in students with autism. Journal of Autism and Developmental Disorders, 36, 421-428. 
Lee, R., Sturmey, P., \& Fields, L. (2007). Schedule-induced and operant mechanisms that influence response variability: A review and implications for future investigations. The Psychological Record, 57, 429-455.

Lee, V. L. (1999). Human latencies under differential reinforcement, yoked ratio reinforcement, and continuous reinforcement. The Psychological Record, 49, 645-662.

Liu-Gitz, L., \& Banda, D. R. (2010). A replication of the RIRD strategy to decrease vocal stereotypy in a student with autism. Behavioral Interventions, 25, 77-87.

Lopatto, D. E., \& Brown, B. M. (1994). The effects of schedules of reinforcement on operant sequential stereotypy in humans. Psychological Record, 44, 185-207.

Lovaas, O. I., Berberich, J. P., Perloff, B. F., \& Schaeffer, B. (1966). Acquisition of imitative speech by schizophrenic children. Science, 151, 705-707.

Lovaas, O.I., Newsom, C., \& Hickman, C. (1987). Self-stimulatory behavior and perceptual reinforcement. Journal of Applied Behavior Analysis, 20, 45-68.

Lovaas, O. I., Varni, J. W., Koegel, R. L., \& Lorsch, N. (1977). Some observations on the nonextinguishability of children's speech. Child Development, 48, 1121-1127.

MacDonald, R., Green, G., Mansfield, R., Geckeler, A., Gardenier, N., Anderson, J., Holcomb, W., \& Sanchez, J. (2007). Stereotypy in young children with autism and typically developing children. Research in Developmental Disabilities, 28, 266-277.

Machado, A. (1989). Operant conditioning of behavioral variability using a percentile reinforcement schedule. Journal of the Experimental Analysis of Behavior, 52, 155-166.

Machado, A. (1992). Behavioral variability and frequency-dependent selection. Journal of the Experimental Analysis of Behavior, 58, 241-263.

Machado, A. (1993). Learning variable and stereotypical sequences of responses: Some data and 
a new model. Behavioural Processes, 30, 103-130.

Madelain, L., Champrenaut, L., \& Chauvin, A. (2007). Control of sensorimotor variability by consequences. Journal of Neurophysiology, 98, 2255-2265.

Maes, J. H. R. (2003). Response stability and variability induced in humans by different feedback contingencies. Learning \& Behavior, 31, 332-348.

Maes, J. H. R., \& van der Goot, M. (2006). Human operant learning under concurrent reinforcement of response variability. Learning and Motivation, 37, 79-92.

Manabe, K., Staddon, J. E. R., \& Cleaveland, J. M. (1997). Control of vocal repertoire by reward in Budgerigars. Journal of Comparative Psychology, 111, 50-62.

Matson, J. L., Kiely, S. L., \& Bamburg, J. W. (1997). The effect of stereotypies on adaptive skills as assessed with the DASH-II and Vineland Adaptive Behavior Scales. Research in Developmental Disabilities, 18, 471-476.

McCleery, J. P., Tully, L., Slevc, L. R., \& Schreibman, L. (2006). Consonant production patterns of young severely language-delayed children with autism. Journal of Communication Disorders, 39, 217-231.

Metz, J. R. (1965). Conditioning generalized imitation in autistic children. Journal of Experimental Child Psychology, 2, 389-399.

Miguel, C. F., Carr, J. E., \& Michael, J. (2002). The effects of a stimulus-stimulus pairing procedure on the vocal behavior of children diagnosed with autism. The Analysis of Verbal Behavior, 18, 3-13.

Miguel, C.F., Clark, K., Tereshko, L., \& Ahearn, W.H. (2009). The effects of response interruption and redirection and sertraline on vocal stereotypy. Journal of Applied Behavior Analysis, 42, 883-888. 
Miller, N., \& Neuringer, A. (2000). Reinforcing variability in adolescents with autism. Journal of Applied Behavior Analysis, 33, 151-165.

Mirenda, P. (2003). Toward functional augmentative and alternative communication for students with autism: Manual signs, graphic symbols, and voice output communication aids. Language, Speech, and Hearing Services in Schools, 34, 203-216.

Moerk, E. L. (1983). A behavioral analysis of controversial topics in first language acquisition: Reinforcements, corrections, modeling, input frequencies, and the three-term contingency pattern. Journal of Psycholinguistic Research, 12, 129-155.

Moerk, E. (1990). Three-term contingency patterns I mother-child verbal interactions during first-language acquisition. Journal of the Experimental Analysis of Behavior, 54, 293305.

Molliver, M. E. (1963). Operant control of vocal behavior in the cat. Journal of the Experimental Analysis of Behavior, 6, 197-202.

Morgan, D. L., \& Lee, K. (1996). Extinction-induced response variability in humans. Psychological Record, 46, 145-160.

Morgan, L., \& Neuringer, A. (1990). Behavioral variability as a function of response topography and reinforcement contingency. Animal Learning \& Behavior, 18, 257-263.

Morris, C. J. (1987). The operant conditioning of response variability: Free-operant versus discrete-response procedures. Journal of the Experimental Analysis of Behavior, 47, 273277.

Mullins, M., \& Rincover, A. (1985). Comparing autistic and normal children along the dimensions of reinforcement maximization, stimulus sampling, and responsiveness to extinction. Journal of Experimental Child Psychology, 40, 350-374. 
Napolitano, D.A., Smith, T., Zarcone, J.R., Goodkin, K., \& McAdam, D.B. (2010). Increasing response diversity in children with autism. Journal of Applied Behavior Analysis, 43, 265-271.

Neuringer, A. (1986). Can people behave "randomly?": The role of feedback. Journal of Experimental Psychology: General, 115, 62-75.

Neuringer, A. (1993). Reinforced variation and selection. Animal Learning \& Behavior, 21, 83-

91.

Neuringer, A. (2002). Operant variability: Evidence, functions, and theory. Psychonomic Bulletin \& Review, 9, 672-705.

Neuringer, A. (2004). Reinforced variability in animals and people: Implications for adaptive action. American Psychologist, 59, 891-906.

Neuringer, A. (2009). Operant variability and the power of reinforcement. The Behavior Analyst Today, 10, 319-343.

Neuringer, A., Deiss, C., \& Imig, S. (2000). Comparing choices and variations in people and rats: Two teaching experiments. Behavior Research Methods, Instruments, \& Computers, 32, 407-416.

Neuringer, A., Deiss, C., \& Olson, G. (2000). Reinforced variability and operant learning. Journal of Experimental Psychology: Animal Behavior Processes, 26, 98-111.

Neuringer, A., Kornell, N., \& Olufs, M. (2001). Stability and variability in extinction. Journal of Experimental Psychology: Animal Behavior Processes, 27, 79-94.

Newman, B., Reinecke, D. R., \& Meinberg, D. L. (2000). Self-management of varied responding in three students with autism. Behavioral Interventions, 15, 145-151.

Newman, B., Reinecke, D., \& Ramos, M. (2009). Is a reasonable attempt reasonable? Shaping 
versus reinforcing verbal attempts of preschoolers with autism. The Analysis of Verbal Behavior, 25, 67-72.

Normand, M. P., \& Knoll, M. L. (2006). The effects of a stimulus-stimulus pairing procedure on the unprompted vocalizations of a young child diagnosed with autism. The Analysis of Verbal Behavior, 22, 81-85.

O’Connor, A.S., Prieto, J., Hoffman, B., DeQuinzio, J.A., \& Taylor, B.A. (2011). A stimulus control procedure to decrease motor and vocal stereotypy. Behavioral Interventions, 26, 231-242.

Odum, A. L., Ward, R. D., Barnes, C. A., and Burke, K. A. (2006). The effects of delayed reinforcement on variability and repetition of response sequences. Journal of the Experimental Analysis of behavior, 86, 159-179.

Olive, M. L., Lang, R. B., \& Davis, T. N. (2008). An analysis of the effects of functional communication and a voice output communication aid for a child with autism spectrum disorder. Research in Autism Spectrum Disorders, 2, 223-236.

Page, J., \& Boucher, J. (1998). Motor impairments in children with autistic disorder. Child Language Teaching and Therapy, 14, 233-259.

Page, S., \& Neuringer, A. (1985). Variability is an operant. Journal of Experimental Psychology: Animal Behavior Processes, 11, 429-452.

Petursdottir, A.I., Carp, C.L., Matthies, D.W., \& Esch, B.E. (2011). Analyzing stimulus-stimulus pairing effects on preferences for speech sounds. The Analysis of Verbal Behavior, 27, 45-60.

Prather, E.M., Hedrick, D.L., \& Kern, C.A. (1975). Articulation development in children aged two to four years. Journal of Speech and Hearing Disorders, 40, 179-191. 
Pryor, K. W., Haag, R., \& O’Reilly, J. (1969). The creative porpoise: Training for novel behavior. Journal of the Experimental Analysis of Behavior, 12, 653-661.

Rapp, J.T. (2007). Further evaluation of methods to identify matched stimulation. Journal of Applied Behavior Analysis, 40, 73-88.

Rapp, J. T., Patel, M. R., Ghezzi, P. M., O’Flaherty, C. H., \& Titterington, C. J. (2009). Establishing stimulus control of vocal stereotypy displayed by young children with autism. Behavioral Interventions, 24, 85-105.

Reeve, L., Reeve, K. F., Brown, A. K., Brown, J. L., \& Poulson, C. L. (1992). Effects of delayed reinforcement on infant vocalization rate. Journal of the Experimental Analysis of Behavior, 58, 1-8.

Reeve, L., Reeve, K. F., \& Poulson, C. L. (1993). A parametric variation of delayed reinforcement in infants. Journal of the Experimental Analysis of Behavior, 60, 515-527.

Richler, J., Bishop, S.L., Kleinke, J.R., \& Lord, C. (2007). Restricted and repetitive behaviors in young children with autism spectrum disorders. Journal of Autism and Developmental Disorders, 37, 73-85.

Richler, J., Huerta, M., Bishop, S. L., \& Lord, C. (2010). Developmental trajectories of restricted and repetitive behaviors and interests in children with autism spectrum disorders. Development and Psychopathology, 22, 55-69.

Risley, T. R., \& Wolf, M. M. (1967). Establishing functional speech in echolalic children. Behavior Research and Therapy, 5, 73-88.

Rogers, S. J., Hepburn, S. L., Stackhouse, T., \& Wehner, E. (2003). Imitation performance in toddlers with autism and those with other developmental disorders. Journal of Child Psychology and Psychiatry, 44, 763-781. 
Ross, C., \& Neuringer, A. (2002). Reinforcement of variations and repetitions along three independent response dimensions. Behavioural Processes, 57, 199-209.

Rozenblat, E., Brown, J.L., Brown, A.K., Reeve, S.A., \& Reeve, K.F. (2009). Effects of adjusting DRO schedules on the reduction of stereotypic vocalizations in children with autism. Behavioral Interventions, 24, 1-15.

Sabatasso, A. P., \& Jacobson, L. I. (1970). Use of behavioral therapy in the reinstatement of verbal behavior in a mute psychotic with chronic brain syndrome: A case study. Journal of Abnormal Psychology, 76, 322-324.

Saldana, L., \& Neuringer, A. (1998). Is instrumental variability abnormally high in children exhibiting ADHD and aggressive behavior? Behavioural Brain Research, 94, 51-59.

Salzinger, K., \& Waller, M. B. (1962). The operant control of vocalization in the dog. Journal of the Experimental Analysis of Behavior, 5, 383-389.

Schlosser, R. W., \& Wendt, O. (2008). Effects of augmentative and alternative communication intervention on speech production in children with autism: A systematic review. American Journal of Speech-Language Pathology, 17, 212-230.

Schroeder, G. L., \& Baer, D. M. (1972). Effects of concurrent and serial training on generalized vocal imitation in retarded children. Developmental Psychology, 6, 293-301.

Schumacher, B.I., \& Rapp, J.T. (2011). Evaluation of the immediate and subsequent effects of response interruption and redirection on vocal stereotypy. Journal of Applied Behavior Analysis, 44, 681-685.

Schusterman, R. J., \& Reichmuth, C. (2008). Novel sound production through contingency learning in the Pacific walrus (Odobenus rosmarus divergens). Animal Cognition, 11, 319-327. 
Sherman, J. A. (1965). Use of reinforcement and imitation to reinstate verbal behavior in mute psychotics. Journal of Abnormal Psychology, 70, 155-164.

Skinner, B. F. (1953). Science and Human Behavior. New York: Macmillan.

Skinner, B. F. (1957). Verbal Behavior. New York: Appleton-Century-Crofts.

Skinner, B. F. (1981). Selection by consequences. Science, 213, 501-504.

Smith, R., Michael, J., \& Sundberg, M. L. (1996). Automatic reinforcement and automatic punishment in infant vocal behavior. The Analysis of Verbal Behavior, 13, 39-48.

Stock, R. A., Schulze, K. A., \& Mirenda, P. (2008). A comparison of stimulus-stimulus pairing, standard echoic training, and control procedures on the vocal behavior of children with autism. The Analysis of Verbal Behavior, 24, 123-133.

Stoel-Gammon, C. (1991). Normal and disordered phonology in two-year-olds. Topics in Language Disorders, 11, 21-32.

Stokes, P. D. (1995). Learned variability. Animal Learning \& Behavior, 23, 164-176.

Stokes, P. D. (1999). Learned variability levels: Implications for creativity. Creativity Research Journal, 12, 37-45.

Stokes, P. D. \& Balsam, P. (2001). An optimal period for setting sustained variability levels. Psychonomic Bulletin \& Review, 8, 177-184.

Stokes, P. D., \& Balsam, P. D. (2003). Effects of early strategic hints on sustained variability levels. Creativity Research Journal, 15, 331-341.

Stokes, P. D., \& Harrison, H. M. (2002). Constraints have different concurrent effects and aftereffects on variability. Journal of Experimental Psychology: General, 131, 552-566.

Stokes, P. D., Lai, B., Holtz, D., Rigsbee, E., \& Cherrick, D (2008). Effects of practice on variability, effects of variability on transfer. Journal of Experimental Psychology: Human 
Perception and Performance, 34, 640-659.

Sundberg, M. L., Michael, J., Partington, J. W., \& Sundberg, C. A. (1996). The role of automatic reinforcement in early language acquisition. The Analysis of Verbal Behavior, 13, 21-37.

Sundberg, C. T., \& Sundberg, M. L. (1990). Comparing topography-based verbal behavior with stimulus selection-based verbal behavior. The Analysis of Verbal Behavior, 8, 31-41.

Susa, C., \& Schlinger Jr., H.D. (in press). Using a lag schedule to increase variability of verbal responding in an individual with autism. The Analysis of Verbal Behavior.

Tatham, T. A., Wanchisen, B. A., \& Hineline, P. N. (1993). Effects of fixed and variable ratios on human behavioral variability. Journal of the Experimental Analysis of Behavior, 59, 349-359.

Taylor, B. A., Hoch, H., \& Weissman, M. (2005). The analysis and treatment of vocal stereotypy in a child with autism. Behavioral Interventions, 20, 239-253.

Thompson, T., Heistad, G. T., \& Palermo, D. S. (1963). Effect of amount of training on rate and duration of responding during extinction. Journal of the Experimental Analysis of Behavior, 6, 155-161.

Tincani, M. (2004). Comparing the Picture Exchange Communication System and sign language training for children with autism. Focus on Autism and Other Developmental Disabilities, $19,152-163$.

Tincani, M. (2009). Developing your child's speech: 'Will my child learn to talk?' In E. A. Boutot \& M. Tincani (Eds.), Autism encyclopedia: The complete guide to autism spectrum disorders. Waco, TX: Prufrock Press.

Tremont, P. J. (1984). Variability of force and interresponse time under random interval reinforcement schedules. Behavioural Processes, 9, 413-420. 
Vaughan, M. E., \& Michael, J. L. (1982). Automatic reinforcement: An important but ignored concept. Behaviorism, 10, 217-227.

Vignes, T. (2007). A comparison of topography-based and selection-based verbal behavior in typically developed children and developmentally disabled persons with autism. The Analysis of Verbal Behavior, 23, 113-122.

Volkert, V. M., Lerman, D. C., Call, N. A., \& Trosclair-Lasserre, N. (2009). An evaluation of resurgence during treatment with functional communication training. Journal of Applied Behavior Analysis, 42, 145-160.

Vollmer, T.R., Marcus, B.A., Ringdahl, J.E., \& Roane, H.S. (1995). Progressing from brief assessments to extended experimental analyses in the evaluation of aberrant behavior. Journal of Applied Behavior Analysis, 28, 561-576.

Wagner, K., \& Neuringer, A. (2006). Operant variability when reinforcement is delayed. Learning \& Behavior, 34, 111-123.

Ward, R. D., Kynaston, A. D., Bailey, E. M., \& Odum, A. L. (2008). Discriminative control of variability: Effects of successive stimulus reversals. Behavioural Processes, 78, 17-24.

Ward, S. J., Osnes, P. J., \& Partington, J. W. (2007). The effects of a delay of noncontingent reinforcement during a pairing procedure in the development of stimulus control of automatically reinforced vocalizations. The Analysis of Verbal Behavior, 23, 103-111.

Watkins, N., Paananen, L., Rudrud, E., \& Rapp, J.T. (2011). Treating vocal stereotypy with environmental enrichment and response cost. Clinical Case Studies, 10, 440-448.

Watt, N., Wetherby, A. M., Barber, A., \& Morgan, L. (2008). Repetitive and stereotyped behaviors in children with autism spectrum disorders in the second year of life. Journal of Autism and Developmental Disorders, 38, 1518-1533. 
Weiss, R. F., Boyer, J. L., Colwick, J. T., \& Moran, D. J. (1971). A delay of reinforcement gradient and correlated reinforcement in the instrumental conditioning of conversational behavior. Journal of Experimental Psychology, 90, 33-38.

Windsor, J., Doyle, S.S., \& Siegel, G.M. (1994). Language acquisition after mutism: A longitudinal case study of autism. Journal of Speech and Hearing Research, 37, 96-105.

Wong, S. E., Terranova, M. D., Bowen, L., Zarate, R., Massel, H. K., \& Liberman, R. P. (1987). Providing independent recreational activities to reduce stereotypic vocalization in chronic schizophrenics. Journal of Applied Behavior Analysis, 20, 77-81.

Wraikat, R., Sundberg, C. T., and Michael, J. (1991). Topography-based and selection-based verbal behavior: A further comparison. The Analysis of Verbal Behavior, 9, 1-17.

Yoon, S., \& Bennett, G. M. (2000). Effects of a stimulus-stimulus pairing procedure on conditioning vocal sounds as reinforcers. The Analysis of Verbal Behavior, 17, 75-88.

Yoon, S., \& Feliciano, G. M. (2007). Stimulus-stimulus pairing and subsequent mand acquisition of children with various levels of verbal repertoires. The Analysis of Verbal Behavior, 23, 3-16. 
Table 1.

Participant Characteristics, Study Inclusion and Settings, and Preferred Items Used as Reinforcers

\begin{tabular}{|c|c|c|c|c|c|c|c|}
\hline Participants & Sex & $\begin{array}{l}\text { Age } \\
\text { (years) }\end{array}$ & Race & Diagnoses & Studies & Study Settings & Preferred Items \\
\hline Nadia & Female & 2 & White & Autistic disorder & 1 & $\begin{array}{l}\text { Intensive service } \\
\text { clinic }\end{array}$ & $\begin{array}{l}\text { Apple juice, baked potato } \\
\text { chips }\end{array}$ \\
\hline Nathan & Male & 7 & White & $\begin{array}{l}\text { Autistic disorder, } \\
\text { encephalopathy }\end{array}$ & 1 & Public classroom & Liquid spray candy \\
\hline Kali & Female & 3 & White & $\begin{array}{l}\text { Autistic disorder, global } \\
\text { developmental delay }\end{array}$ & 1 & $\begin{array}{l}\text { University-based } \\
\text { laboratory }\end{array}$ & Fruit juice \\
\hline Dillon & Male & 14 & Black & Autistic disorder & 1 & $\begin{array}{l}\text { Hospital session } \\
\text { room }\end{array}$ & Diet ginger ale \\
\hline Nicholas & Male & 3 & White & Autistic disorder & 1,2 & $\begin{array}{l}\text { University-based } \\
\text { laboratory, bedroom } \\
\text { at home }\end{array}$ & $\begin{array}{l}\text { Fruit juice, Gerber® } \\
\text { puffs, baked potato chips }\end{array}$ \\
\hline Kristopher & Male & 8 & White & $\begin{array}{l}\text { Autistic disorder, seizure } \\
\text { disorder }\end{array}$ & 1 & Public classroom & Smarties ${ }^{\circledR}$ candy \\
\hline Owen & Male & 6 & Black & Autistic disorder & 1 & Public classroom & Fruit juice \\
\hline Remy & Male & 2 & White & Autistic disorder & 1,2 & $\begin{array}{l}\text { Intensive service } \\
\text { clinic }\end{array}$ & Gerber® puffs \\
\hline Nelson & Male & 6 & Black & $\begin{array}{l}\text { Pervasive developmental } \\
\text { disorder, gross motor delay, } \\
\text { congenital encephalopathy }\end{array}$ & 1 & $\begin{array}{l}\text { Hospital session } \\
\text { room }\end{array}$ & Fruit juice \\
\hline Isabel & Female & 4 & White & $\begin{array}{l}\text { Autistic disorder, seizure } \\
\text { disorder }\end{array}$ & $1,2,3$ & $\begin{array}{l}\text { University-based } \\
\text { laboratory }\end{array}$ & $\begin{array}{l}\text { White grape juice, Oreo } ® \\
\text { mint fudge cremes }\end{array}$ \\
\hline
\end{tabular}


Table 2.

Summary of Novel Vocalization Data for each Participant in Study 1

\begin{tabular}{|c|c|c|c|c|c|c|}
\hline Participants & $\begin{array}{l}\text { Number } \\
\text { of } \\
\text { Sessions }\end{array}$ & $\begin{array}{l}\text { Last Six } \\
\text { Sessions }\end{array}$ & $\begin{array}{c}\text { Mean Percentage of } \\
\text { Novel Vocalizations } \\
\text { (range) }\end{array}$ & $\begin{array}{c}\text { Number of } \\
\text { Cumulative } \\
\text { Novel } \\
\text { Vocalizations }\end{array}$ & $\begin{array}{c}\text { Percentage } \\
\text { of Cumulative } \\
\text { Novel } \\
\text { Vocalizations }\end{array}$ & $\begin{array}{c}\text { Novel } \\
\text { Vocalizations } \\
\text { per Session } \\
\end{array}$ \\
\hline Nadia & 20 & $15-20$ & $81.5 \%(73.7-90.9 \%)$ & 234 & $56.8 \%$ & 11.7 \\
\hline Nathan & 24 & $19-24$ & $73.6 \%(57.1-84.2 \%)$ & 260 & $52.4 \%$ & 10.8 \\
\hline Kali & 22 & $17-22$ & $65.2 \%(42.9-72.7 \%)$ & 177 & $39.6 \%$ & 8.0 \\
\hline Dillon & 20 & $15-20$ & $59.9 \%(52.6-68.4 \%)$ & 85 & $21.5 \%$ & 4.2 \\
\hline Nicholas & 40 & $35-40$ & $48.4 \%(30-65 \%)$ & 129 & $16.1 \%$ & 3.2 \\
\hline Kristopher & 21 & $16-21$ & $43.2 \%(40-45 \%)$ & 42 & $10.4 \%$ & 2.0 \\
\hline Owen & 20 & $15-20$ & $40.9 \%(23.8-59.1 \%)$ & 108 & $24.9 \%$ & 5.4 \\
\hline Remy & 37 & $32-37$ & $36.2 \%(30-50 \%)$ & 61 & $8.2 \%$ & 1.6 \\
\hline Nelson & 25 & $20-25$ & $25.8 \%(20-35 \%)$ & 19 & $4.2 \%$ & 0.8 \\
\hline Isabel & 32 & $27-32$ & $23.0 \%(17.4-30.4 \%)$ & 39 & $6.0 \%$ & 1.2 \\
\hline
\end{tabular}




\section{Table 3.}

Summary of Phoneme Frequency Data for each Participant in Study 1

\begin{tabular}{|c|c|c|c|c|c|c|c|}
\hline Participants & $\begin{array}{l}\text { Number of } \\
\text { Vocalizations } \\
\text { at Stability }\end{array}$ & $\begin{array}{l}\text { Number } \\
\text { of } \\
\text { Phonemes }\end{array}$ & $\begin{array}{l}\text { Mean Unique } \\
\text { Phonemes per } \\
\text { Vocalization } \\
\text { (range) }\end{array}$ & $\begin{array}{l}\text { Phonemes } \\
\text { Occurring } \\
\text { More than } \\
50 \text { Times }\end{array}$ & $\begin{array}{l}\text { Phonemes } \\
\text { Occurring } \\
30-49 \\
\text { Times }\end{array}$ & $\begin{array}{l}\text { Phonemes } \\
\text { Occurring } \\
\text { 10-29 Times }\end{array}$ & $\begin{array}{l}\text { Phonemes } \\
\text { Occurring Less } \\
\text { than } 10 \text { Times }\end{array}$ \\
\hline Nadia & 129 & 30 & $4.2(3.8-4.8)$ & & $\begin{array}{l}\text { /h/, } \mathrm{e}, / \mathrm{d} / \\
/ \mathrm{s} /, \breve{\mathrm{u}}, / \mathrm{n} / \\
/ \mathrm{oo} /, \mathrm{o}\end{array}$ & $\begin{array}{l}\overline{\mathrm{e}}, / \mathrm{m} /, \overline{\mathrm{o}}, / \mathrm{sh} /, \mathrm{1}, / \mathrm{g} /, \\
/ \mathrm{y} /, / \mathrm{t} /, / \mathrm{k} /, / \mathrm{w} /, / \mathrm{ch} /\end{array}$ & $\begin{array}{l}\overline{1}, / \mathrm{f} /, / \mathrm{th} /, / \mathrm{b} /, / \mathrm{j} /, / \mathrm{ow} / \\
\overline{\mathrm{a}}, / \mathrm{r} /, / \mathrm{p} /, / \mathrm{oy} /, / \mathrm{l} /\end{array}$ \\
\hline Nathan & 124 & 22 & $3.4(2.8-4.8)$ & $\breve{a}$ & $\overline{\mathrm{e}}, / \mathrm{y} /, / \mathrm{h} /, \mathrm{u}$ & $\begin{array}{l}/ \mathrm{w} /, / \mathrm{m} /, / \mathrm{l} /, / \mathrm{oo} /, \overline{\mathrm{a}} \\
/ \mathrm{d} /, / \mathrm{n} /, \overline{\mathrm{o}}, / \mathrm{b} /, / \mathrm{g} /\end{array}$ & $\mathrm{e}, / \mathrm{v} /, \overline{1}, / \mathrm{y} /, / \mathrm{p} /, / \mathrm{k} /, / \mathrm{ch} /$ \\
\hline Kali & 126 & 28 & $3.0(2.2-3.8)$ & & $\breve{\mathrm{u}}, / \mathrm{g} /, / \mathrm{h} /, \breve{\mathrm{o}}$ & $\begin{array}{l}/ \mathrm{d} /, \overline{\mathrm{e}}, / \mathrm{oo} /, \mathrm{e}, \overline{\mathrm{a}}, / \mathrm{n} /, \\
\overline{\mathrm{o}}, \breve{\mathrm{a}}\end{array}$ & $\begin{array}{l}\text { /y/, } 1, / \mathrm{w} /, / \mathrm{ow} /, / \mathrm{m} /, / \mathrm{t} /, \\
/ \mathrm{b} /, / \mathrm{p} /, / \mathrm{ng} /, / \mathrm{ew} /, / \mathrm{z} / \\
/ \mathrm{th} /, \mathrm{l}, / \mathrm{k} /, / \mathrm{oy} /, / \mathrm{l} /\end{array}$ \\
\hline Dillon & 117 & 19 & $2.5(2.0-3.2)$ & & $/ \mathrm{h} /, / \mathrm{n} /, \breve{\mathrm{u}}$ & $\overline{\mathrm{e}}, \breve{\mathrm{l}}, / \mathrm{m} /, \breve{\mathrm{e}}, / \mathrm{y} /, / \mathrm{oo} /$ & $\begin{array}{l}/ \mathrm{d} /, \breve{\mathrm{o}}, / \mathrm{w} /, / \mathrm{g} /, / \mathrm{b} /, \overline{\mathrm{o}}, \overline{1} \\
/ \mathrm{oy} /, / \mathrm{th} /, / \mathrm{ow} /\end{array}$ \\
\hline Nicholas & 122 & 16 & $2.2(1.9-2.5)$ & & $\breve{\mathrm{u}}, / \mathrm{h} /, / \mathrm{m} /, \overline{\mathrm{e}}$ & $\breve{\mathrm{a}}, / \mathrm{d} /, / \mathrm{g} /$ & $\begin{array}{l}\mathrm{e}, / \mathrm{n}, / \mathrm{b} /, \overline{\mathrm{a}}, / \mathrm{y} /, / \mathrm{w} /, \\
/ \mathrm{l} /, / \mathrm{ow} /, / \mathrm{k} /\end{array}$ \\
\hline Kristopher & 104 & 14 & $1.7(1.4-2.0)$ & & $/ \mathrm{m} /$, ĕ & $/ \mathrm{h} /, / \mathrm{y} /, \mathrm{u}, / \mathrm{oo} /, \overline{\mathrm{e}}$ & $\overline{\mathrm{a}}, / \mathrm{n} /, / \mathrm{b} /, / \mathrm{d} /, / \mathrm{w} /, / \mathrm{r} /, / \mathrm{p} /$ \\
\hline Owen & 132 & 16 & $2.1(1.6-2.9)$ & $/ \mathrm{m} /$ & & $\begin{array}{l}\overline{\mathrm{e}}, / \mathrm{d} /, \mathrm{a}, \breve{\mathrm{u}}, / \mathrm{h} /, / \mathrm{g} /, \\
\overline{\mathrm{a}}, / \mathrm{y} /, / \mathrm{oo} /\end{array}$ & $/ \mathrm{b} /, \overline{\mathrm{o}}, \breve{1}, / \mathrm{w} /, / \mathrm{n} /, \mathrm{e}$ \\
\hline Remy & 117 & 13 & $2.9(2.2-3.6)$ & $/ \mathrm{h} /, \overline{\mathrm{e}}, / \mathrm{y} /, \breve{\mathrm{o}}$ & & $/ \mathrm{n} /, \breve{1}, \breve{\mathrm{e}}$ & $/ \mathrm{oo} /, \breve{\mathrm{u}}, / \mathrm{sh} /, / \mathrm{m} /, \overline{1}, \overline{\mathrm{o}}$ \\
\hline Nelson & 113 & 9 & $1.3(1.0-1.6)$ & & $\breve{\mathrm{e}}, \breve{\mathrm{u}}$ & $\breve{o}, \breve{a}$ & $\overline{\mathrm{a}}, / \mathrm{m} /, / \mathrm{h} /, \breve{1}, / \mathrm{n} /$ \\
\hline Isabel & 126 & 11 & $2.3(1.8-2.6)$ & $/ \mathrm{h} /, / \mathrm{n} /$ & $\breve{a}, \breve{e}$ & $\breve{U}$ & $\overline{\mathrm{e}}, / \mathrm{d} /, / \mathrm{y} /, / \mathrm{g} /, \overline{\mathrm{a}}, / \mathrm{r} /$ \\
\hline
\end{tabular}


Table 4.

Order of Conditions in Study 2 for each Participant

\begin{tabular}{cccc}
\hline Participant & Condition A & Condition B & Condition C \\
\hline Nicholas & Baseline & Lag 1 & Lag 3 \\
Remy & Baseline & Lag 3 & Lag 5 \\
Isabel & Baseline & Lag 1 & Lag 3 \\
\hline
\end{tabular}




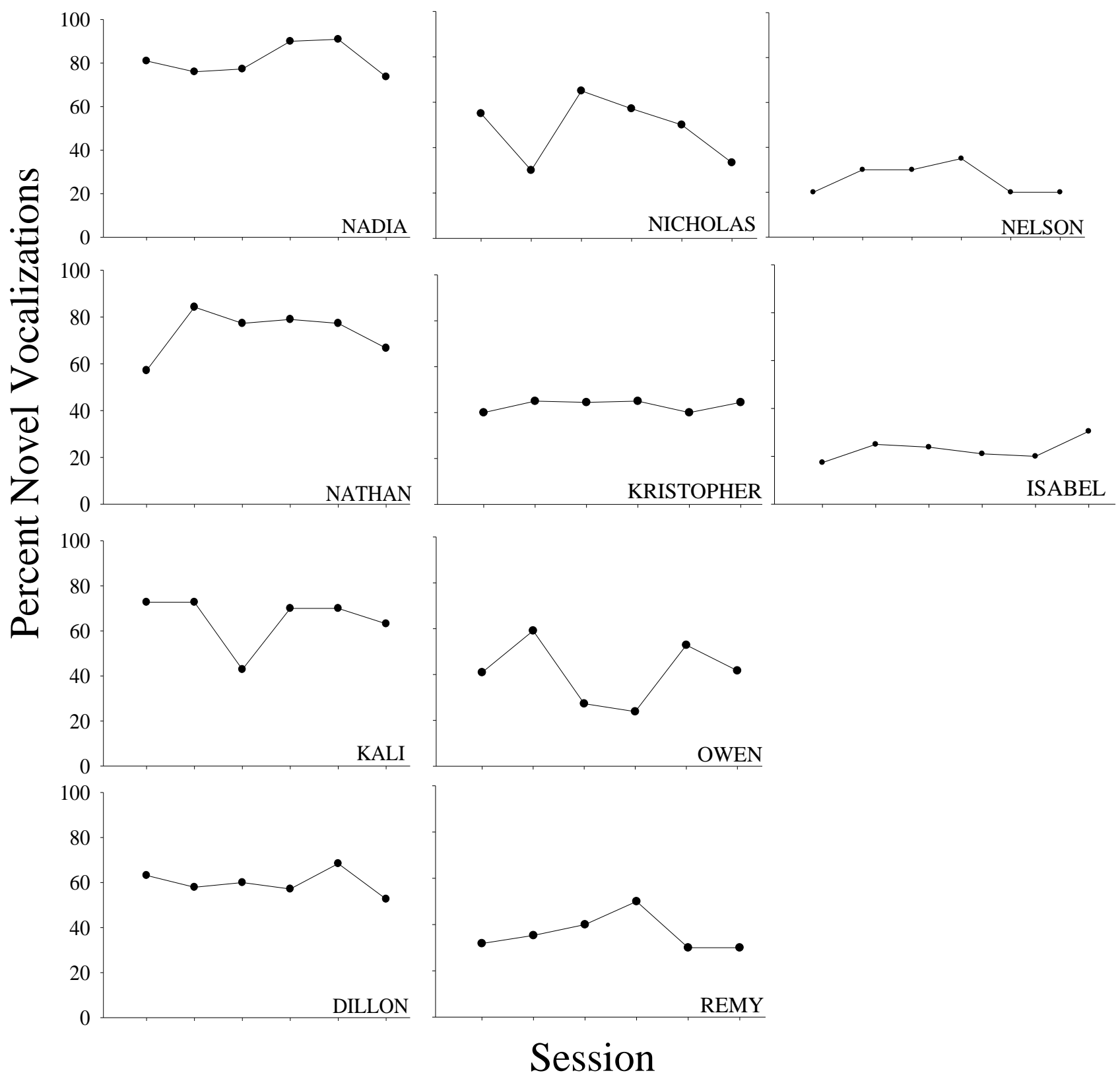

Figure 1. Percentage of novel vocalizations for high (left column), moderate (center column), and low (right column) vocal variability participants in Study 1. 


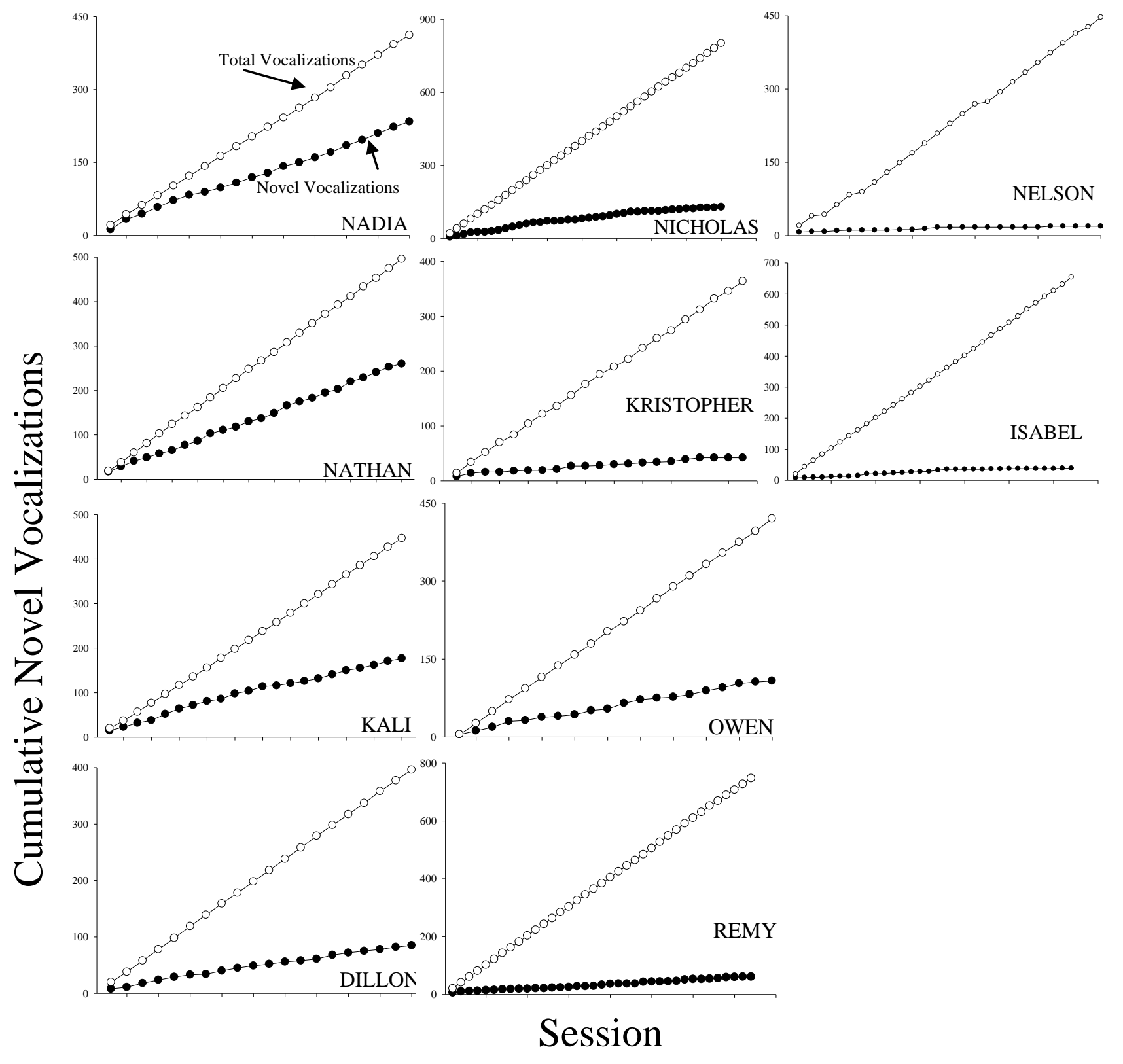

Figure 2. Cumulative total vocalizations (open circles) and novel vocalizations (closed circles) under baseline conditions for high (left column), moderate (center column), and low (right column) vocal variability participants in Study 1 . The steeper the slope of the line, the more total vocalizations and novel vocalizations that occurred per session. 

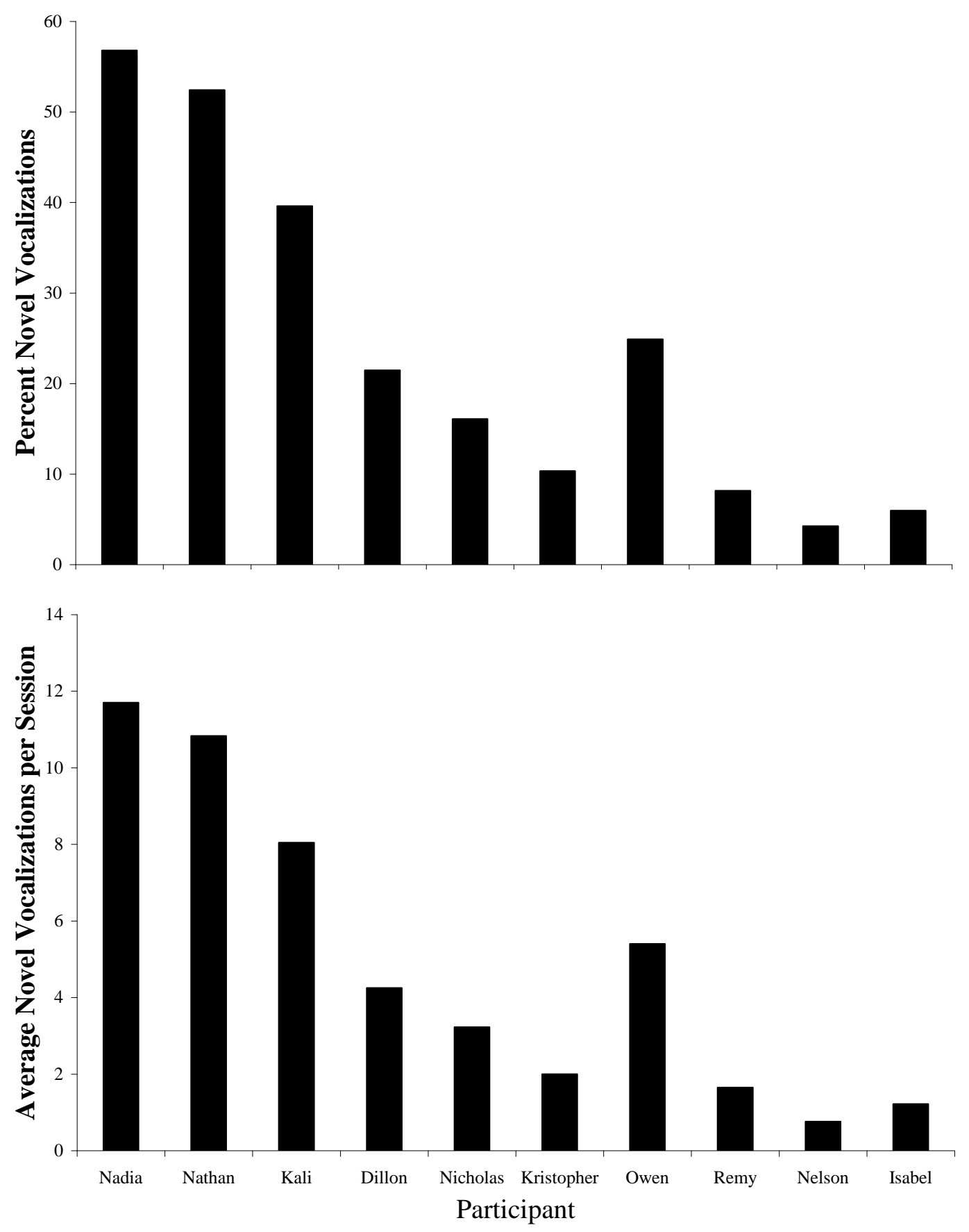

Figure 3. Two measures of novel vocalizations for each of the ten participants in Study 1, across all baseline sessions. The top panel displays the percent of vocalizations that were novel, out of all vocalizations. The bottom panel presents the average number of novel vocalizations per session. 


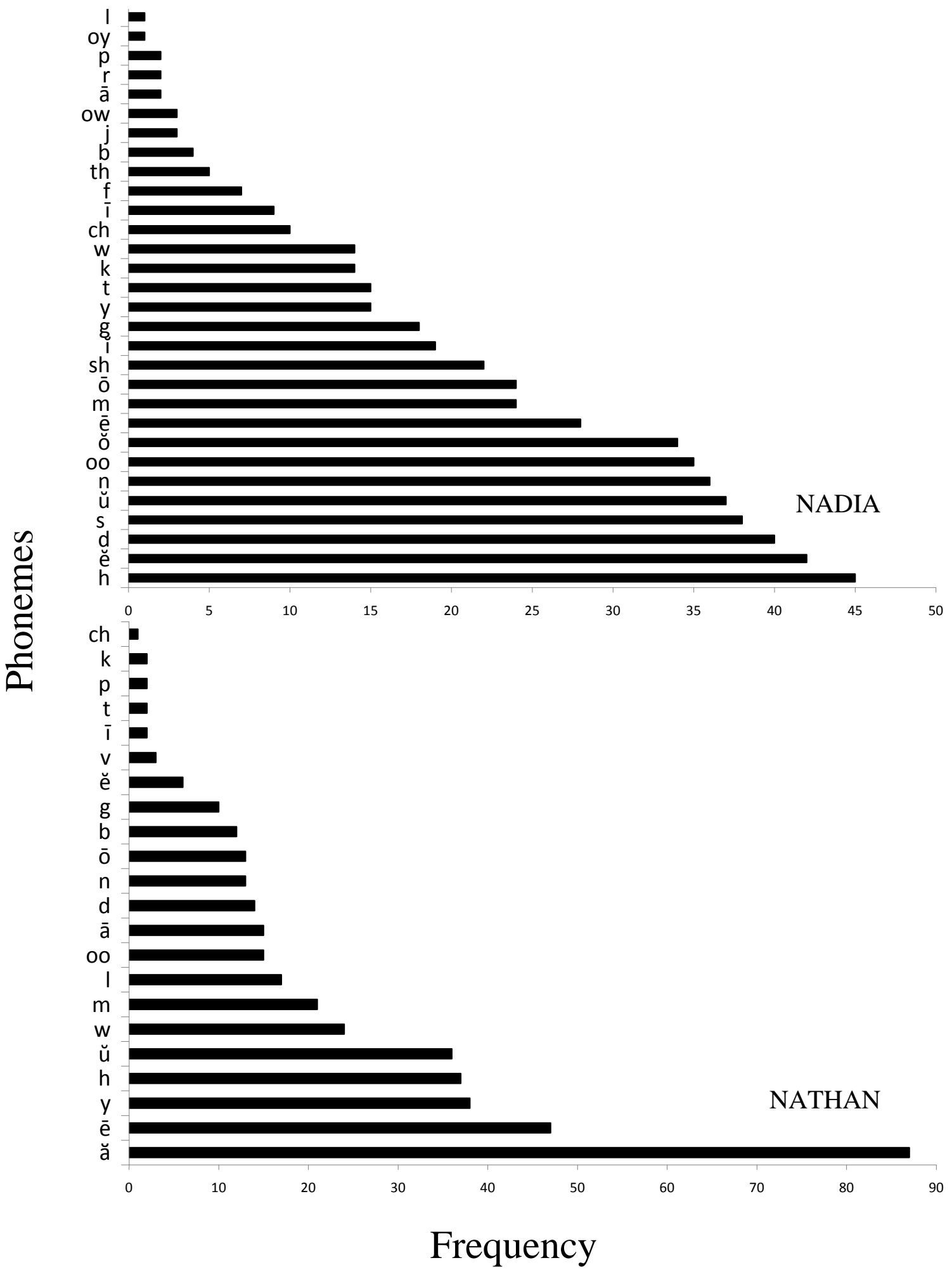

Figure 4. Phoneme frequency during the last six sessions of baseline in Study 1 for Nadia and Nathan. 


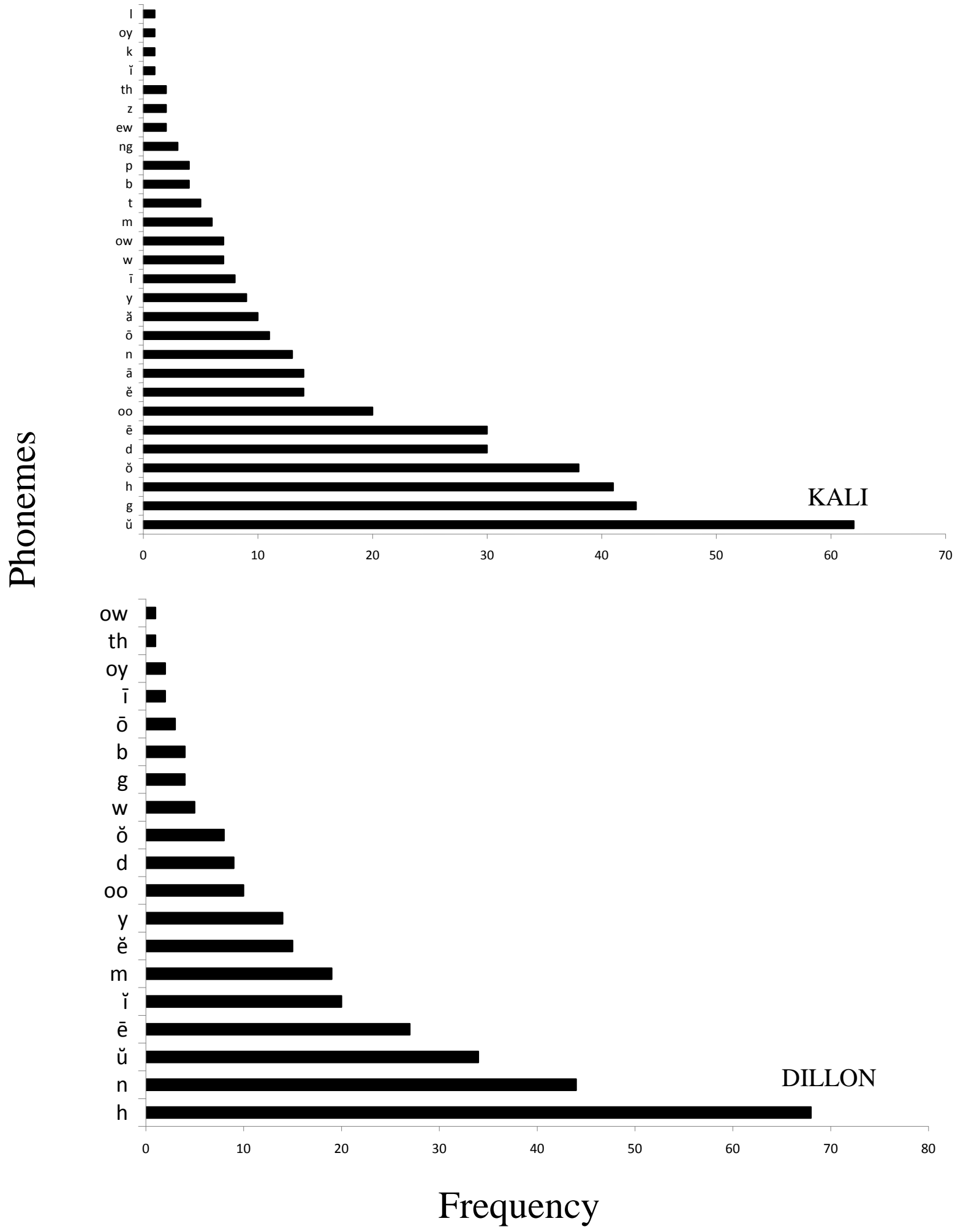

Figure 5. Phoneme frequency during the last six sessions of baseline in Study 1 for Kali and Dillon. 


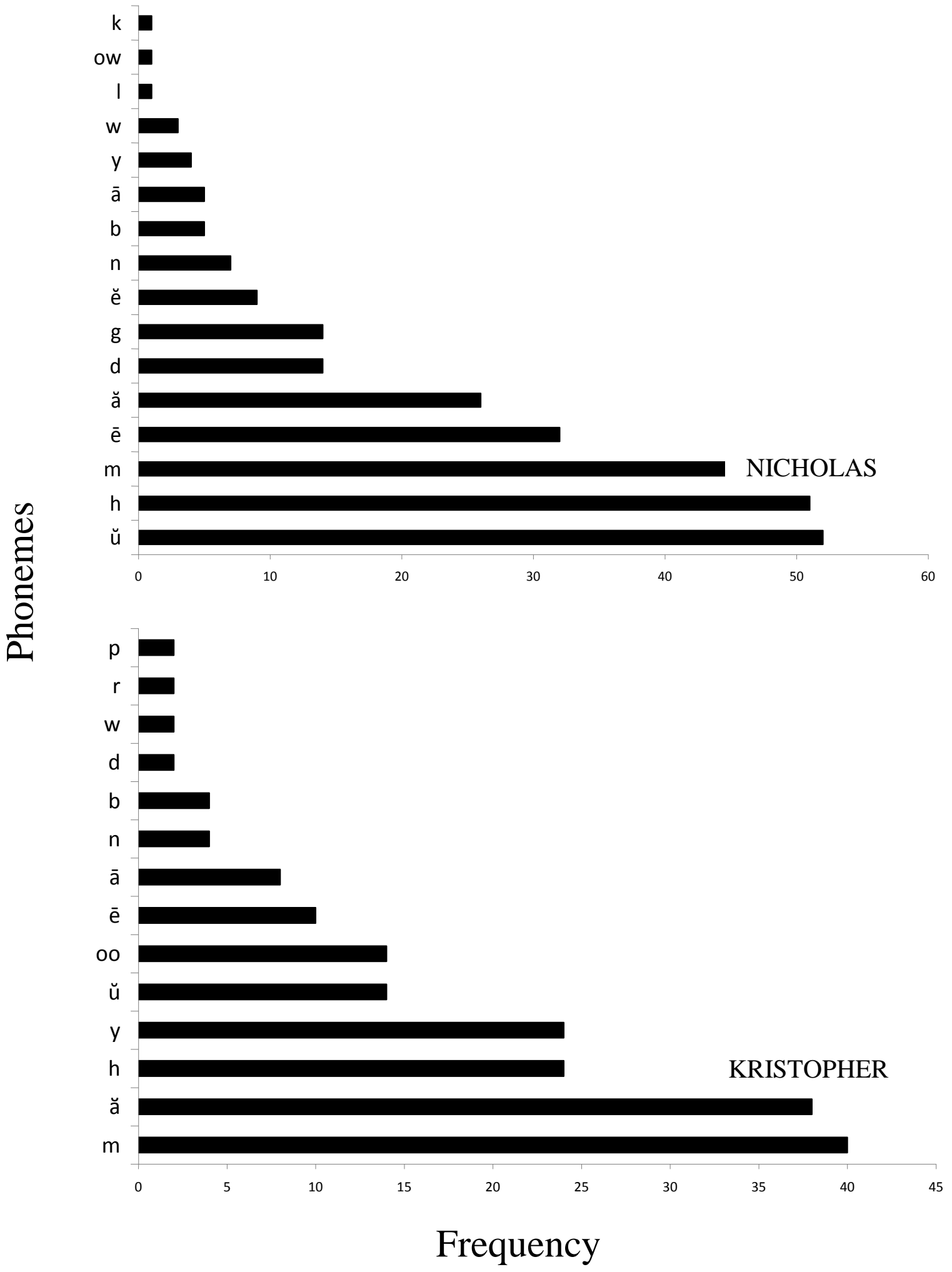

Figure 6. Phoneme frequency during the last six sessions of baseline in Study 1 for Nicholas and Kristopher. 


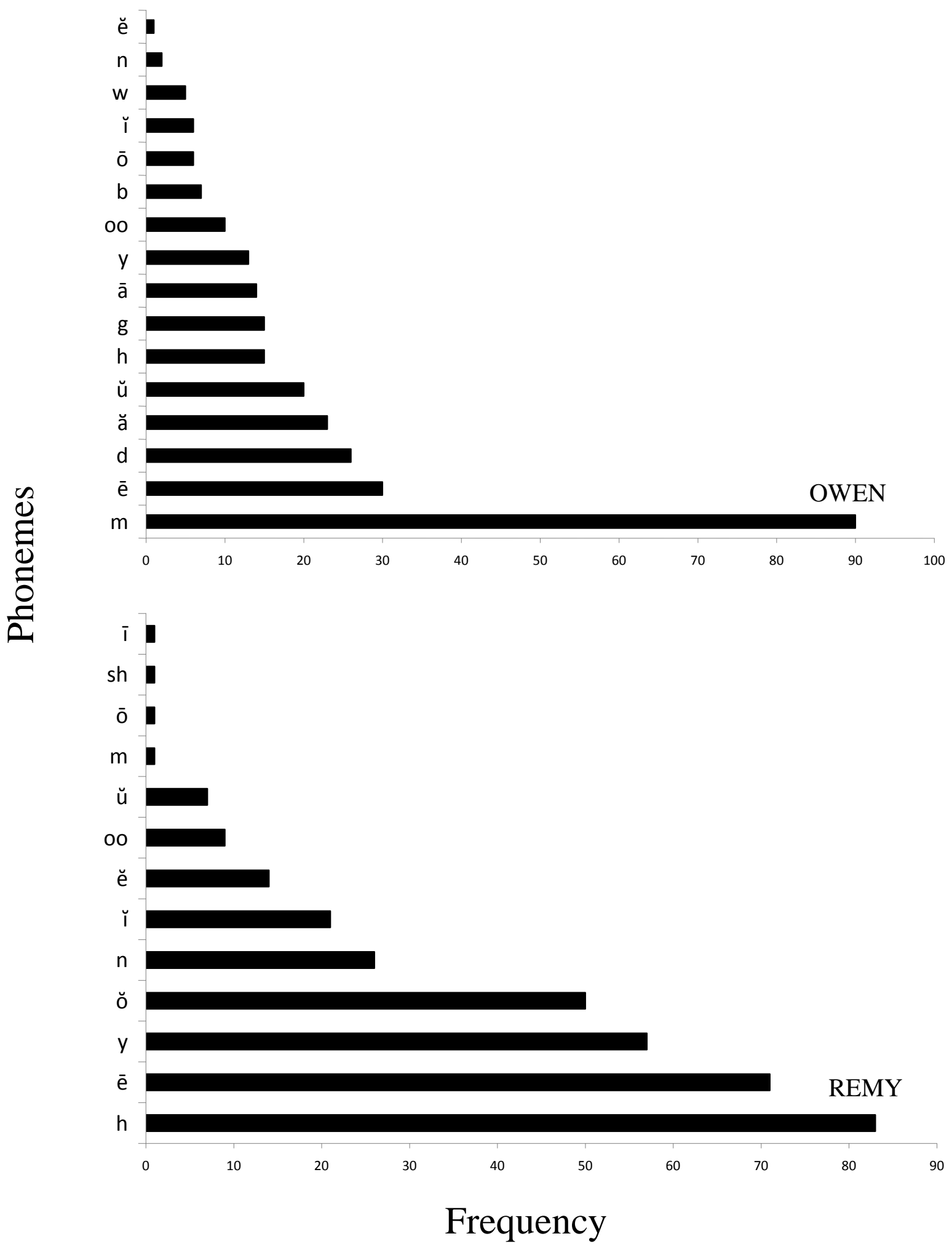

Figure 7. Phoneme frequency during the last six sessions of baseline in Study 1 for Owen and Remy. 


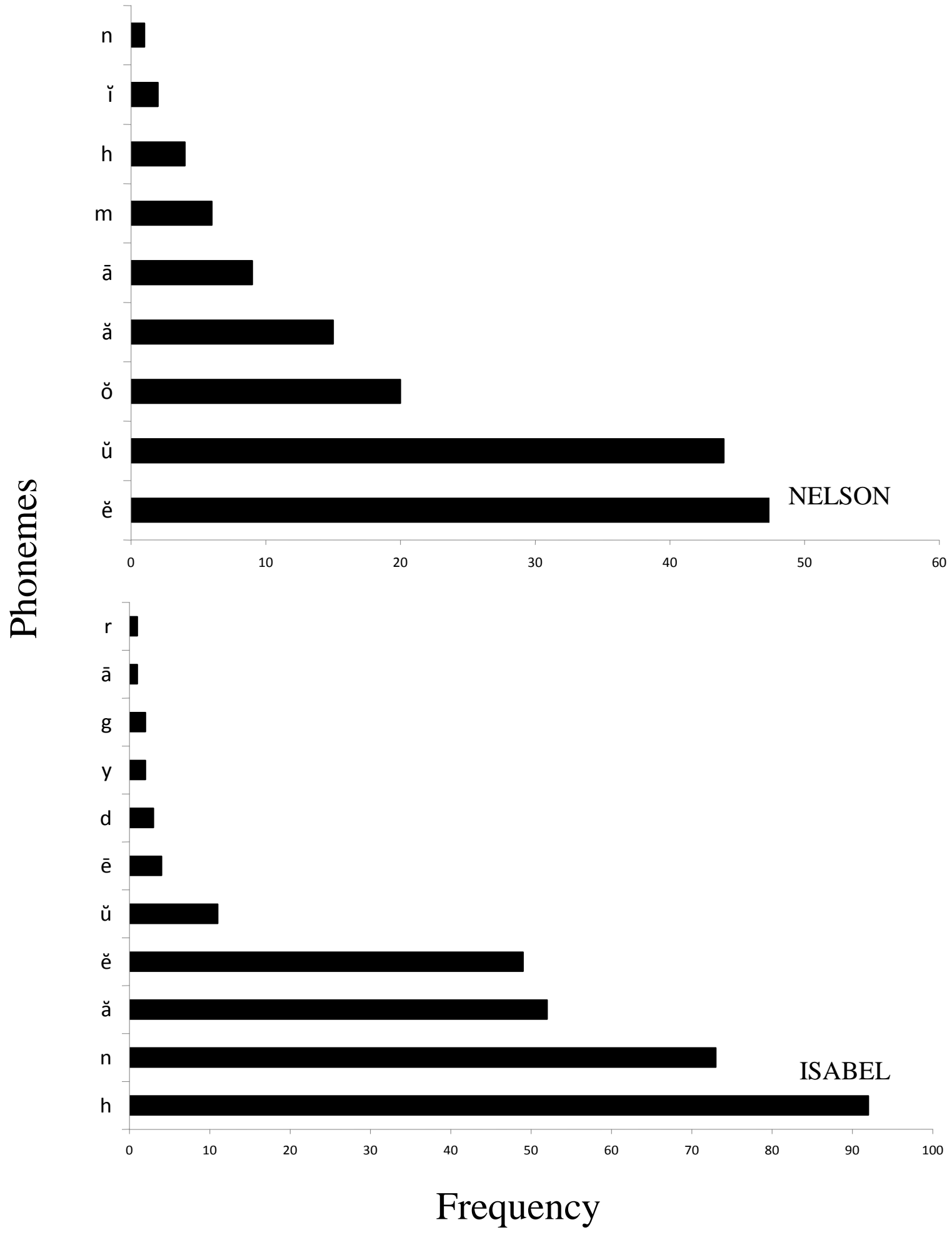

Figure 8. Phoneme frequency during the last six sessions of baseline in Study 1 for Nelson and Isabel. 


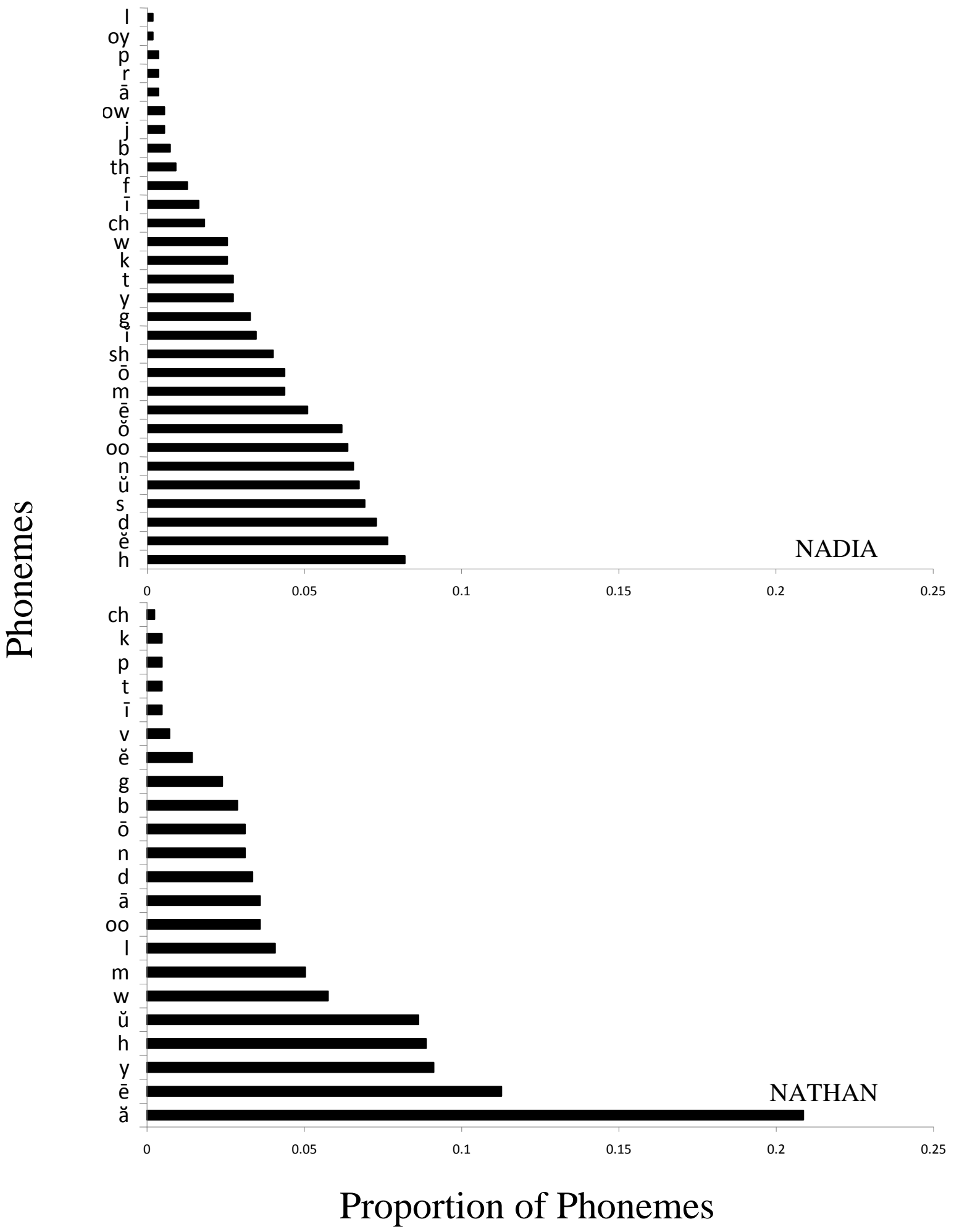

Figure 9. Proportional distribution of phonemes, out of all phonemes produced, during the last six sessions of baseline in Study 1 for Nadia and Nathan. 


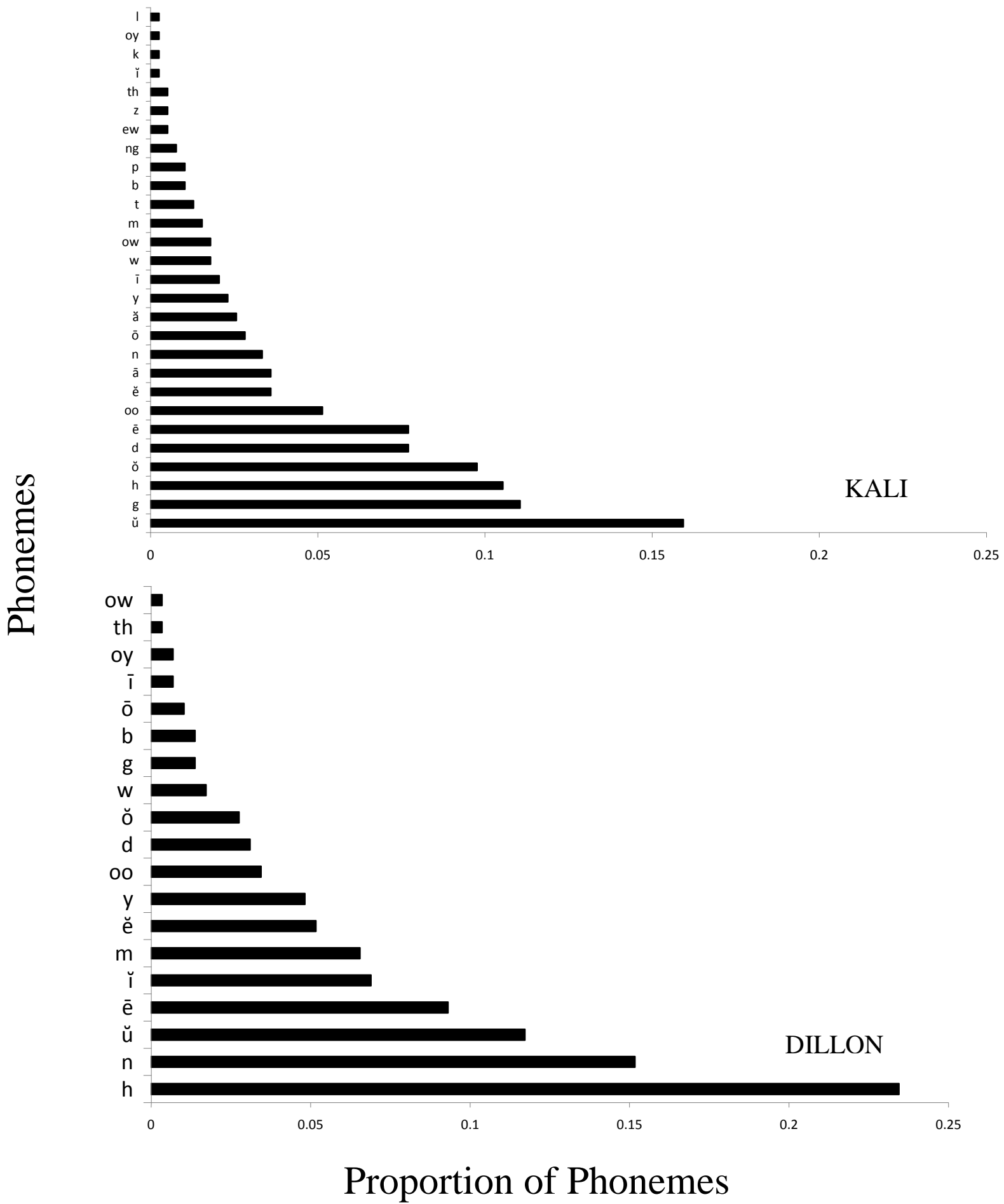

Figure 10. Proportional distribution of phonemes, out of all phonemes produced, during the last six sessions of baseline in Study 1 for Kali and Dillon. 


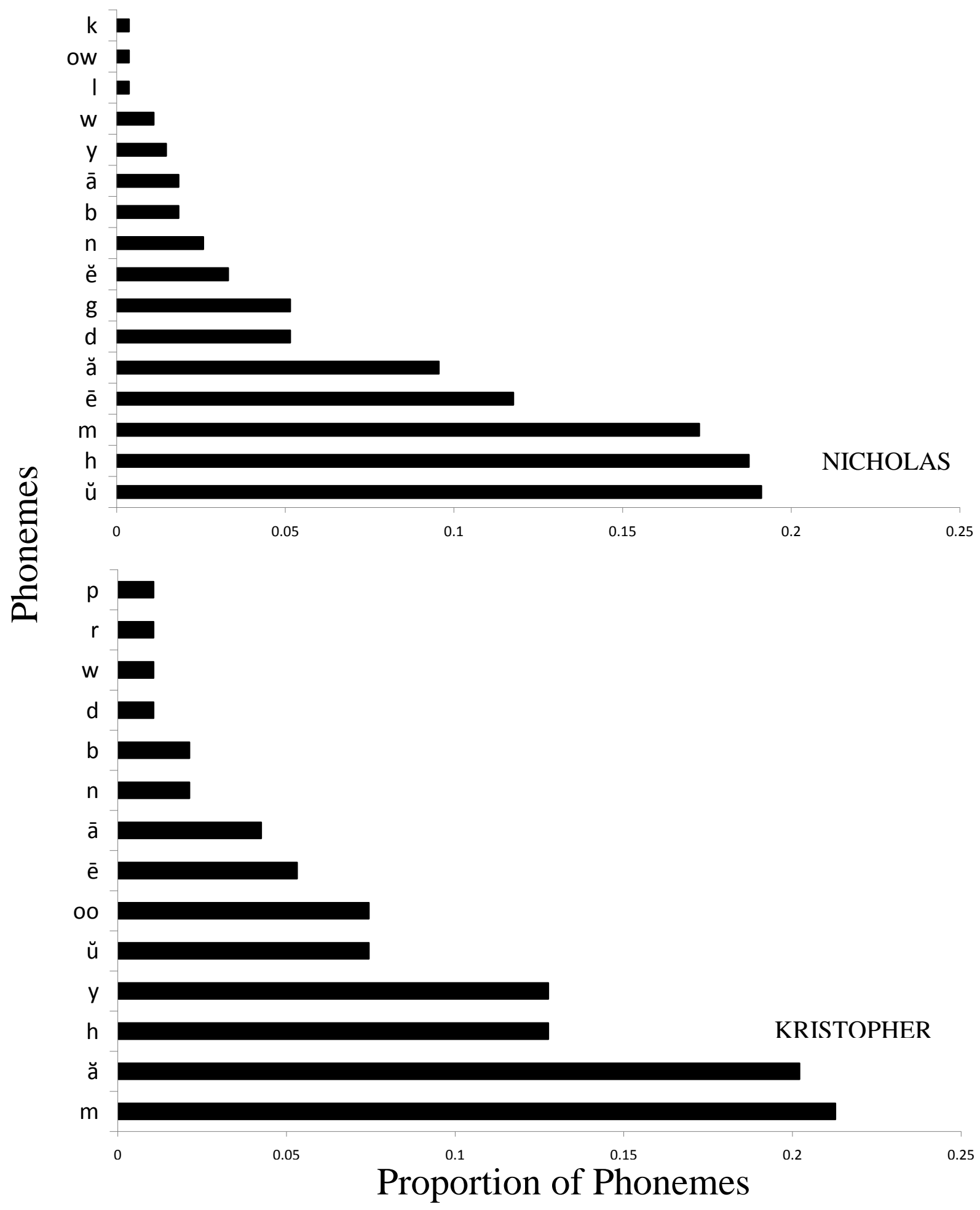

Figure 11. Proportional distribution of phonemes, out of all phonemes produced, during the last six sessions of baseline in Study 1 for Nicholas and Kristopher. 


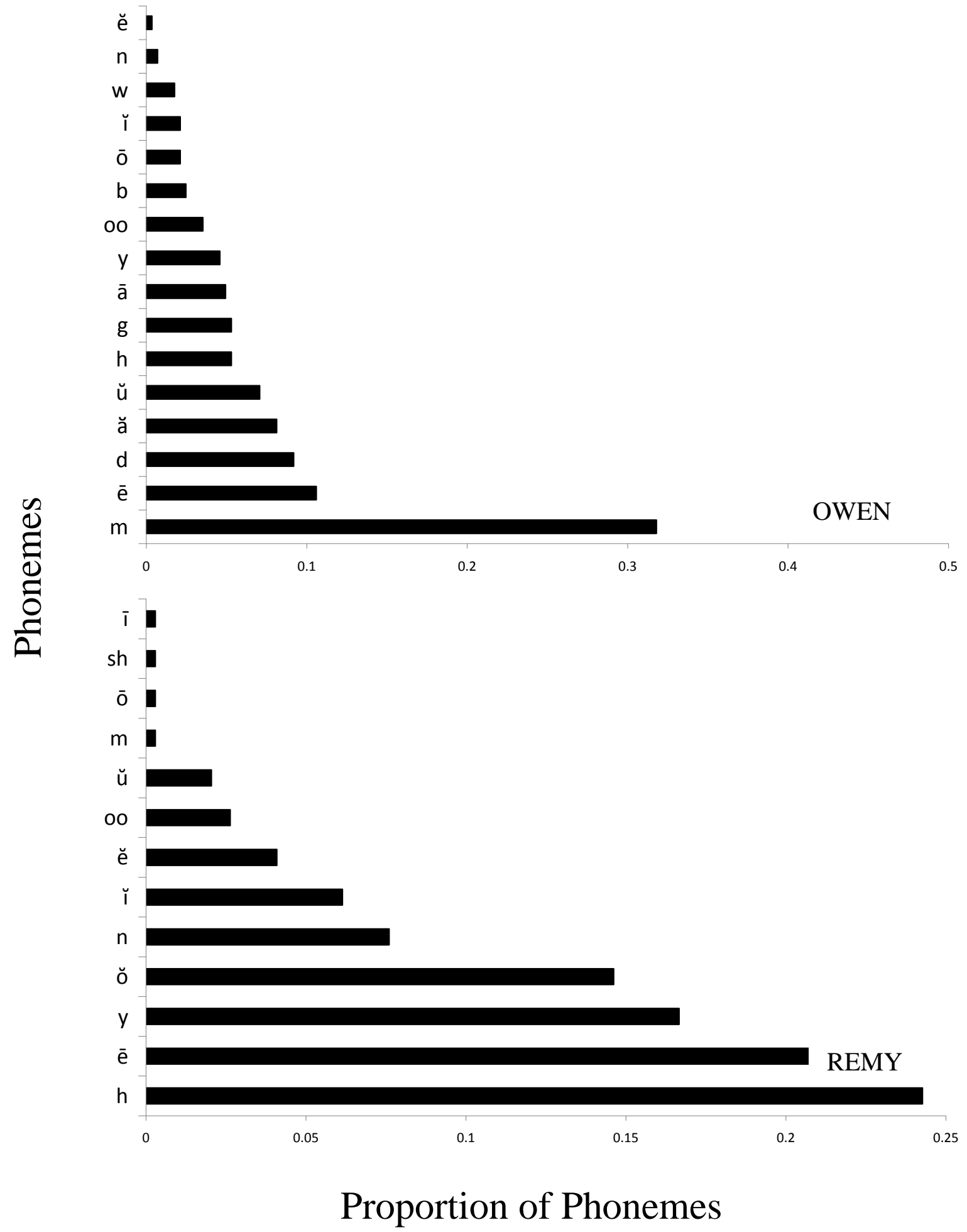

Figure 12. Proportional distribution of phonemes, out of all phonemes produced, during the last six sessions of baseline in Study 1 for Owen and Remy. 


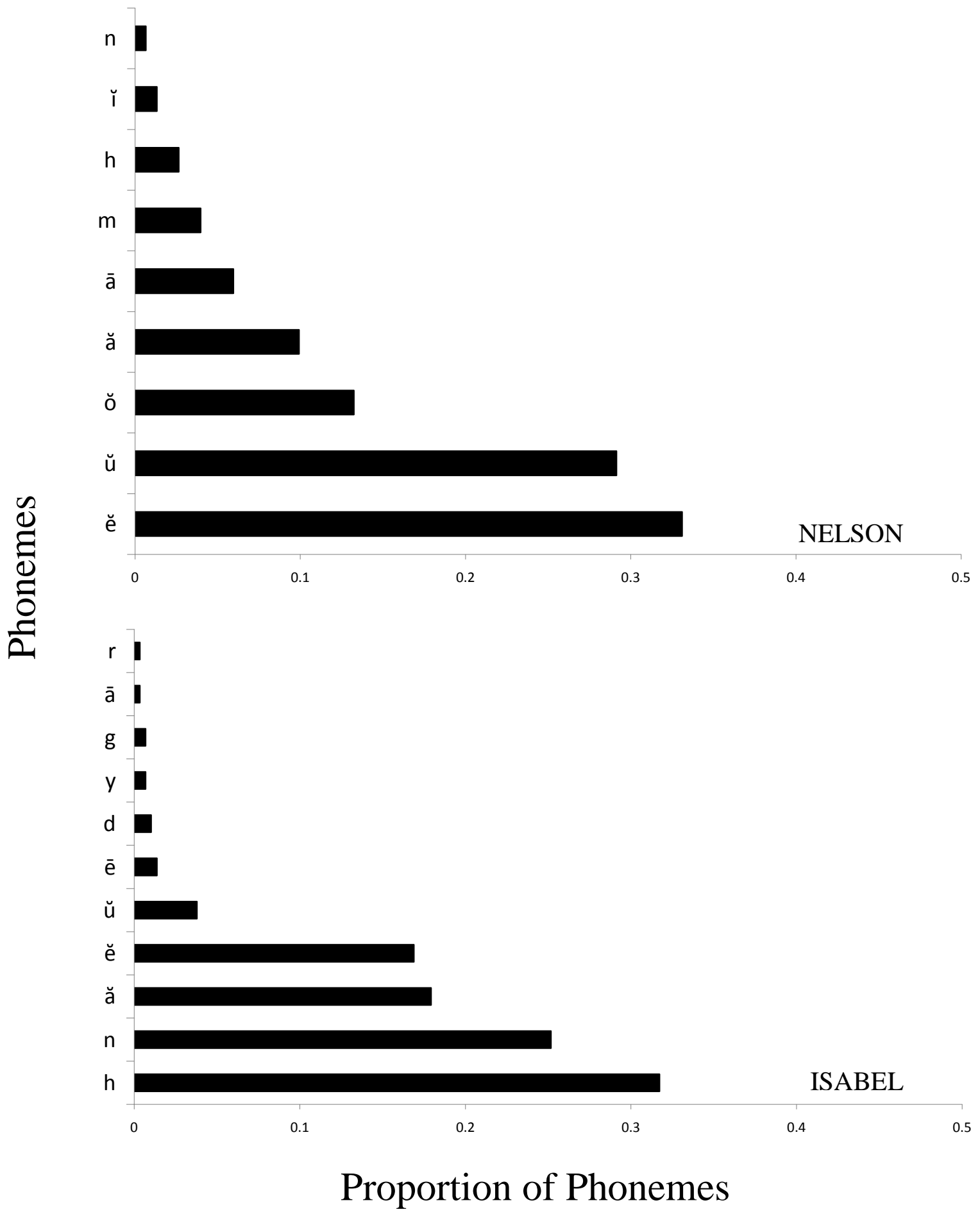

Figure 13. Proportional distribution of phonemes, out of all phonemes produced, during the last six sessions of baseline in Study 1 for Nelson and Isabel. 


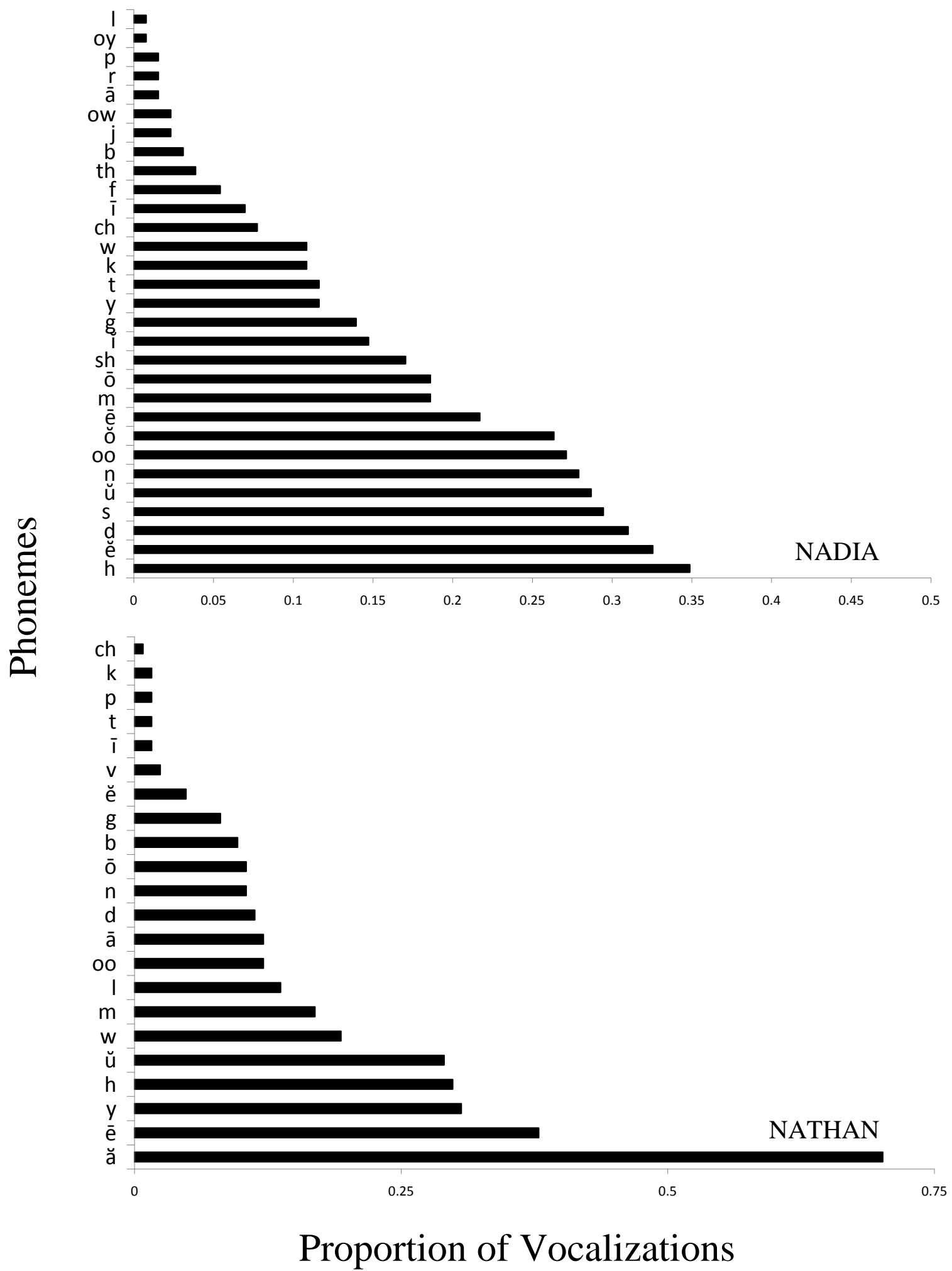

Figure 14. Proportional distribution of phonemes, out of all vocalizations produced, during the last six sessions of baseline in Study 1 for Nadia and Nathan. 


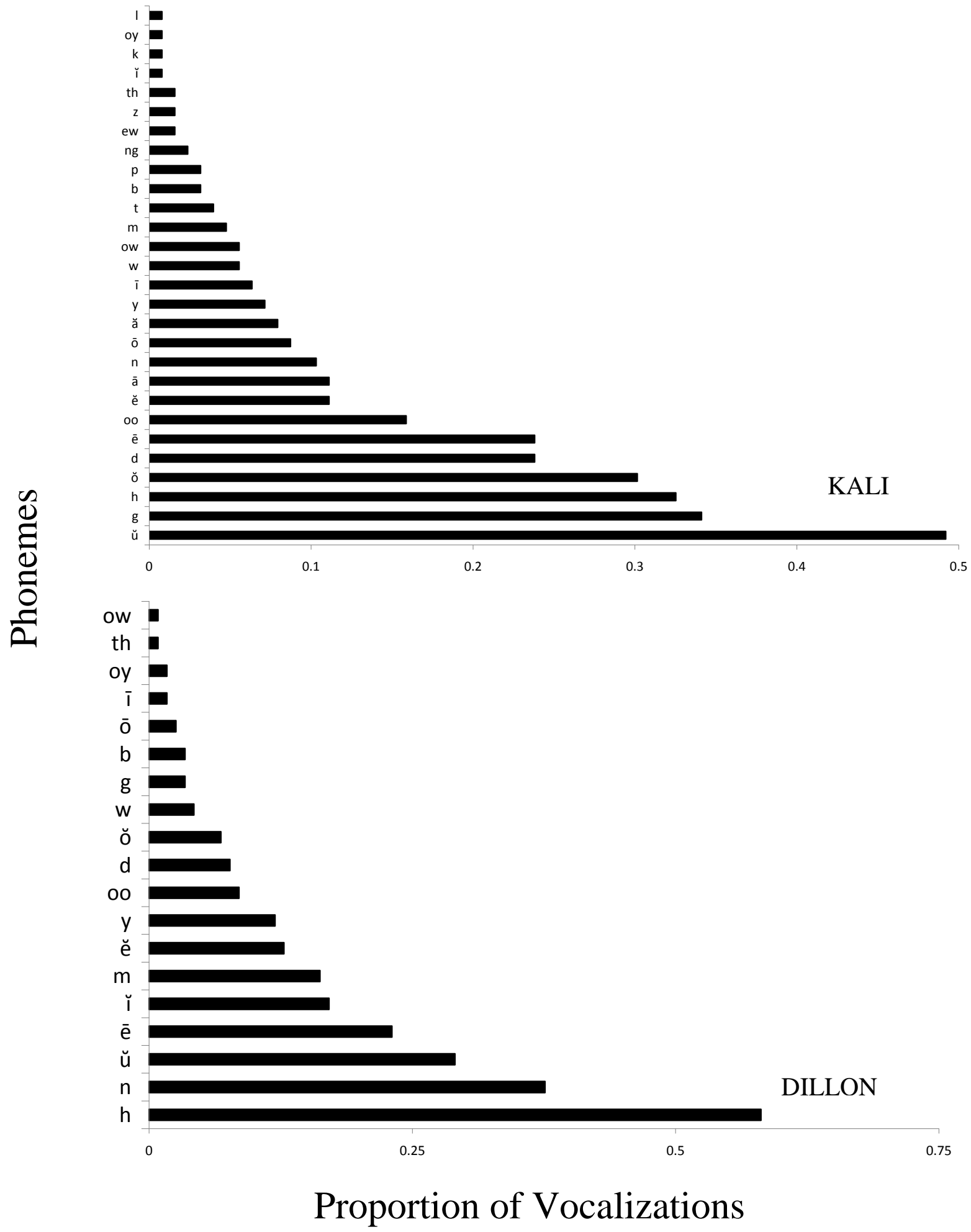

Figure 15. Proportional distribution of phonemes, out of all vocalizations produced, during the last six sessions of baseline in Study 1 for Kali and Dillon. 


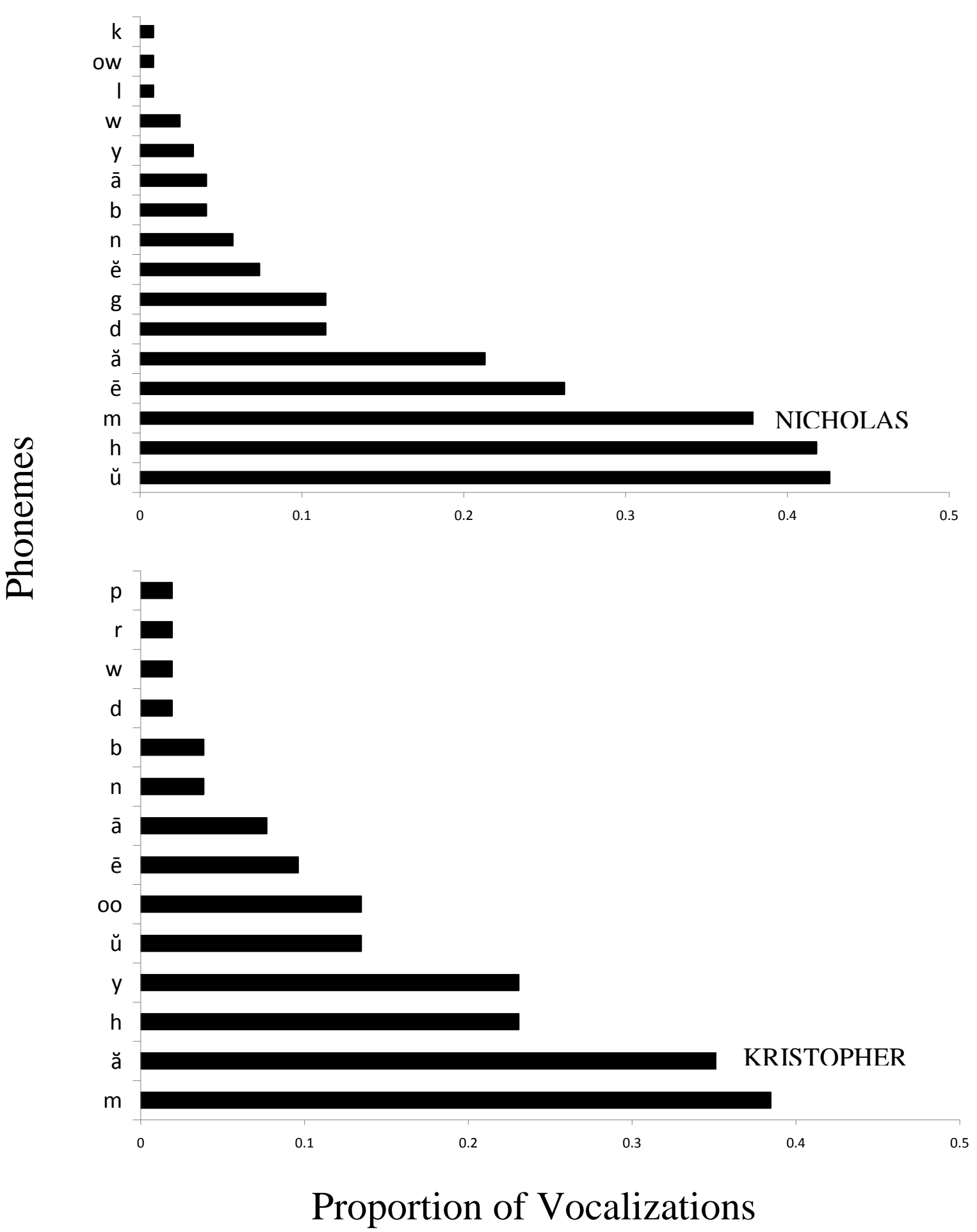

Figure 16. Proportional distribution of phonemes, out of all vocalizations produced, during the last six sessions of baseline in Study 1 for Nicholas and Kristopher. 


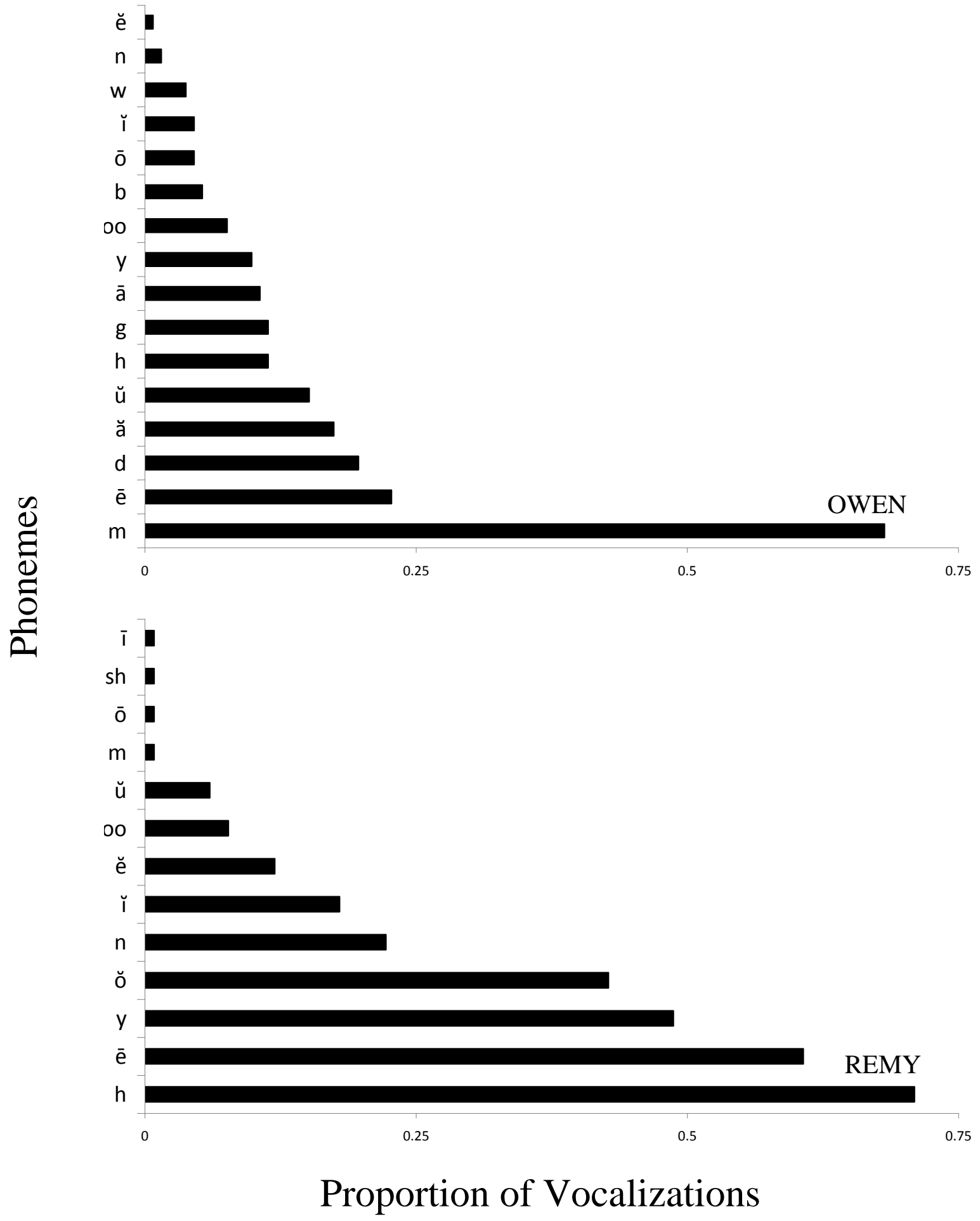

Figure 17. Proportional distribution of phonemes, out of all vocalizations produced, during the last six sessions of baseline in Study 1 for Owen and Remy. 


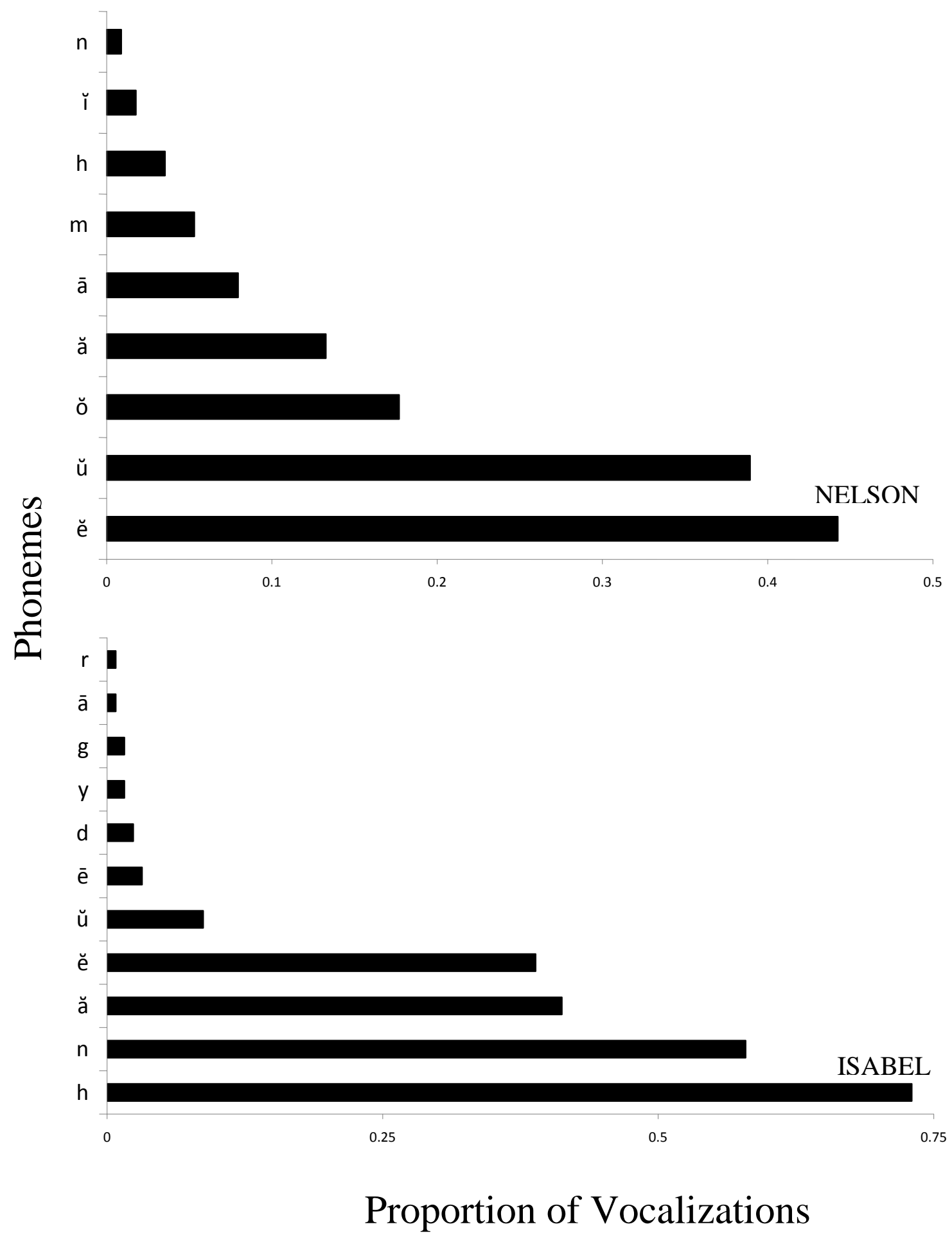

Figure 18. Proportional distribution of phonemes, out of all vocalizations produced, during the last six sessions of baseline in Study 1 for Nelson and Isabel. 

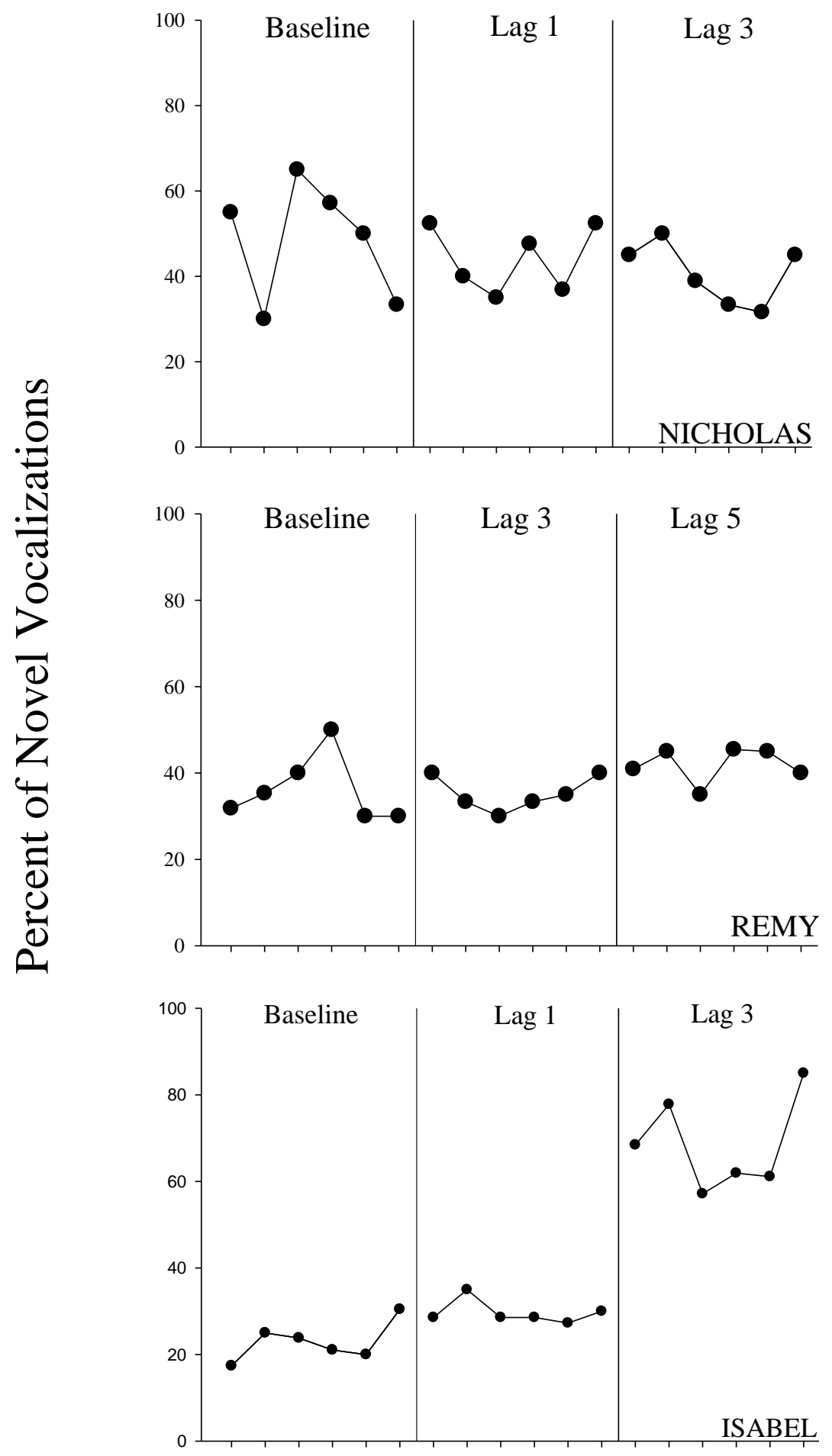

Session

Figure 19. Percentage of novel vocalizations during the last six sessions of the baseline and lag schedule conditions in Study 2 for Nicholas, Remy and Isabel. 


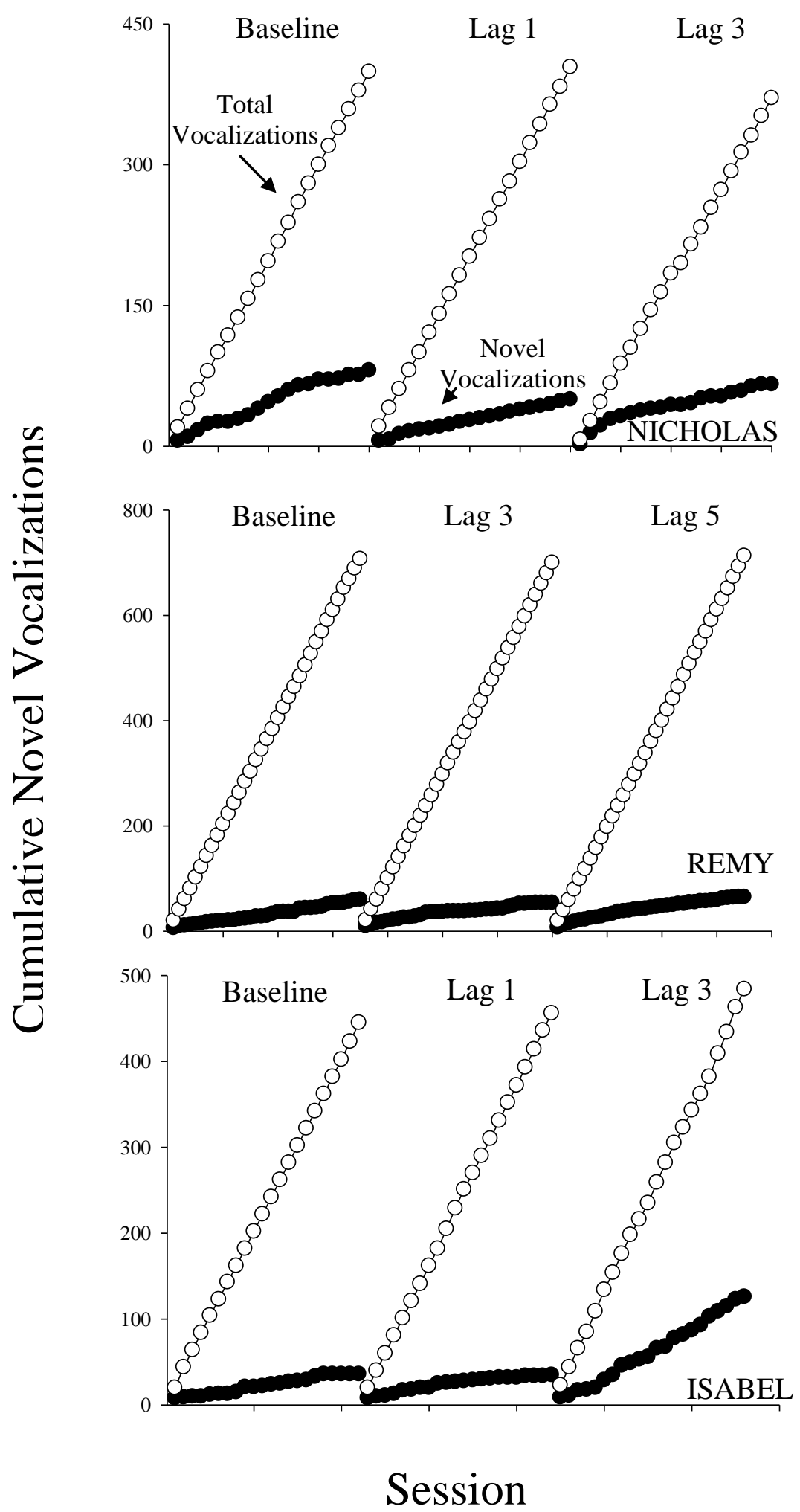

Figure 20. Cumulative total vocalizations (open circles) and novel vocalizations (closed circles) across all sessions of the baseline and lag schedule conditions in Study 2 for Nicholas, Remy, and Isabel. 

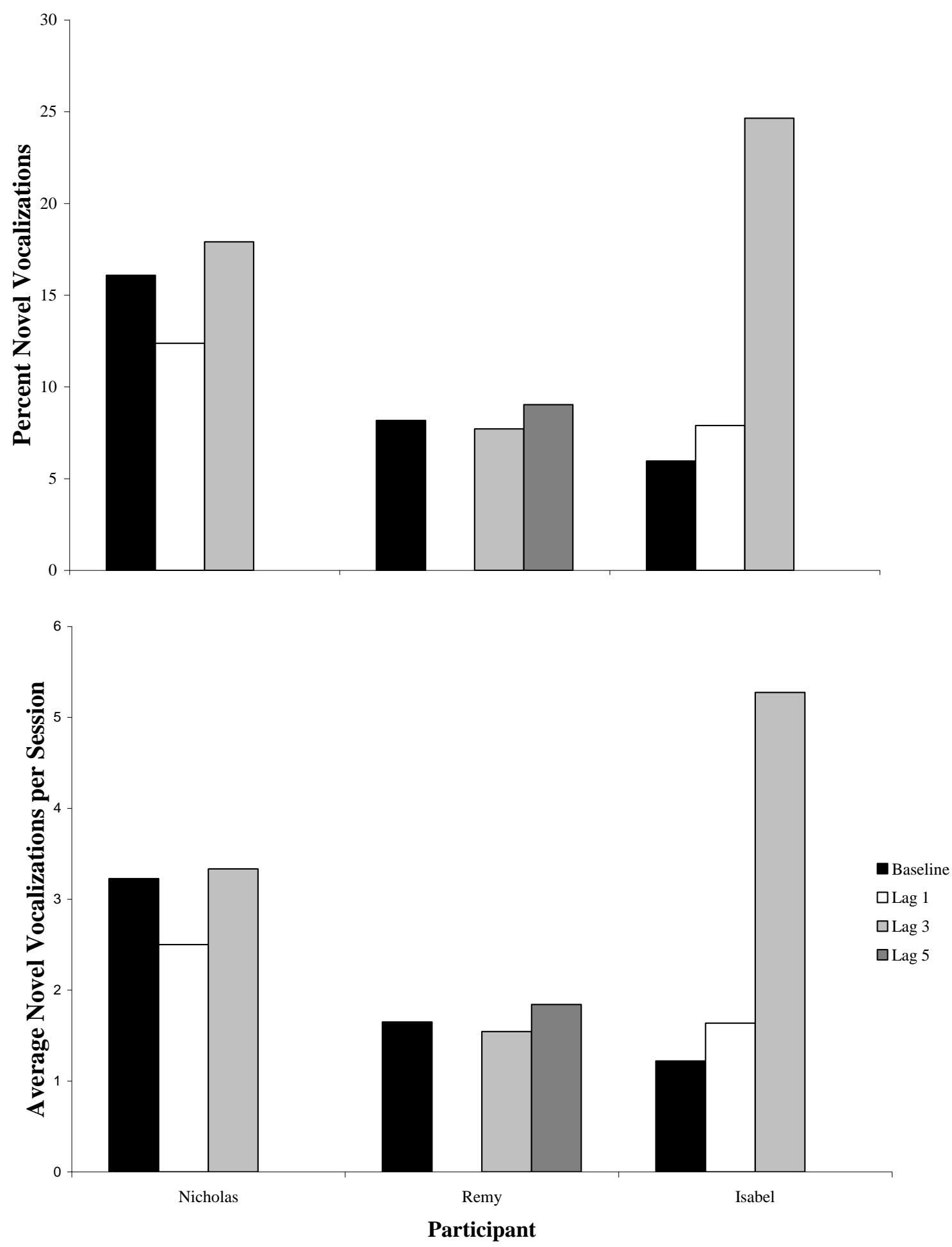

Figure 21. Two measures of novel vocalizations for each of the three participants in Study 2, across all sessions of each condition (baseline and lag schedules). The top panel displays the percent of vocalizations that were novel, out of all vocalizations. The bottom panel presents the average number of novel vocalizations per session. 


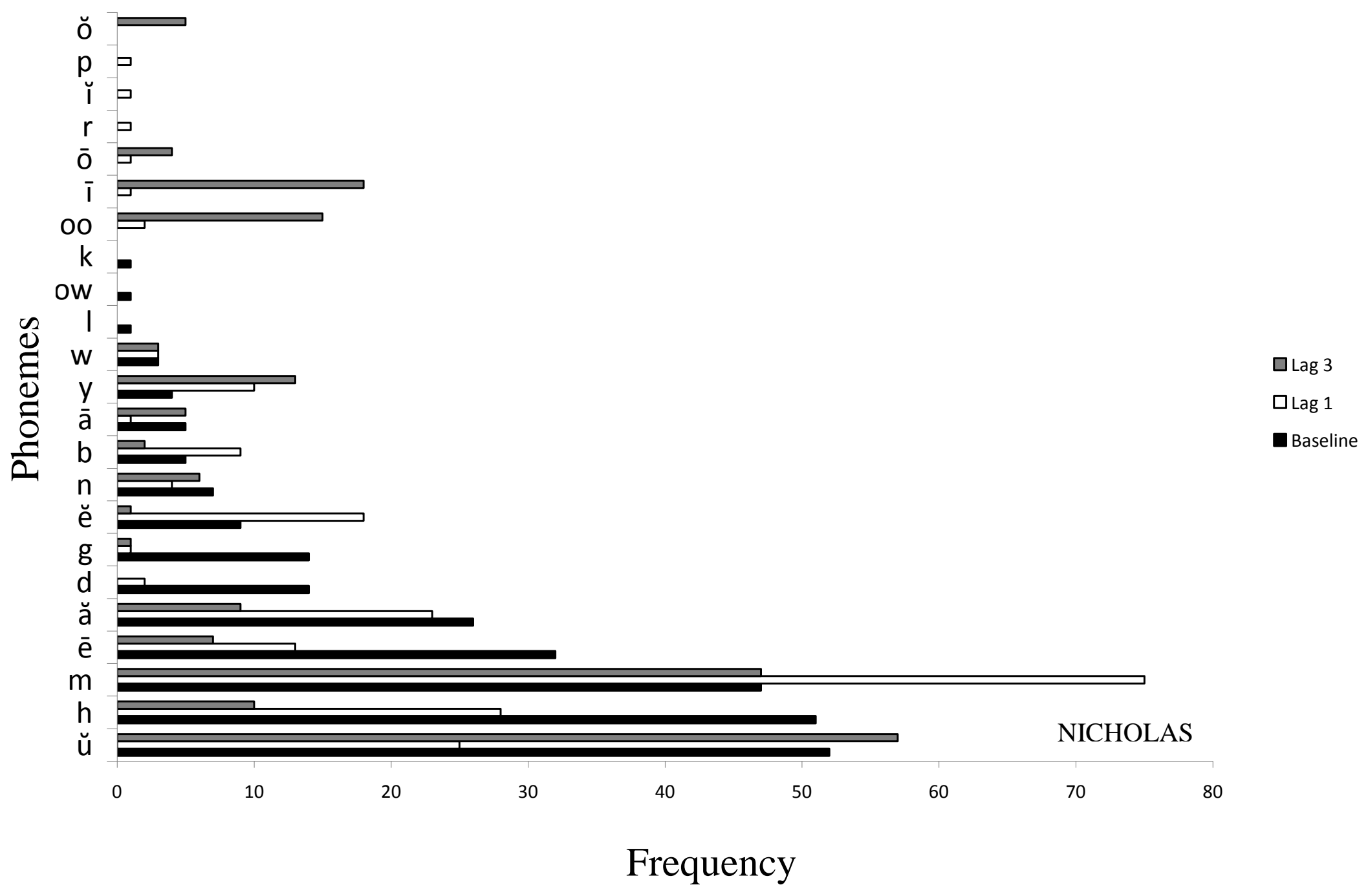

Figure 22. Phoneme frequency during the last six sessions of the baseline and lag schedule conditions in Study 2 for Nicholas. 


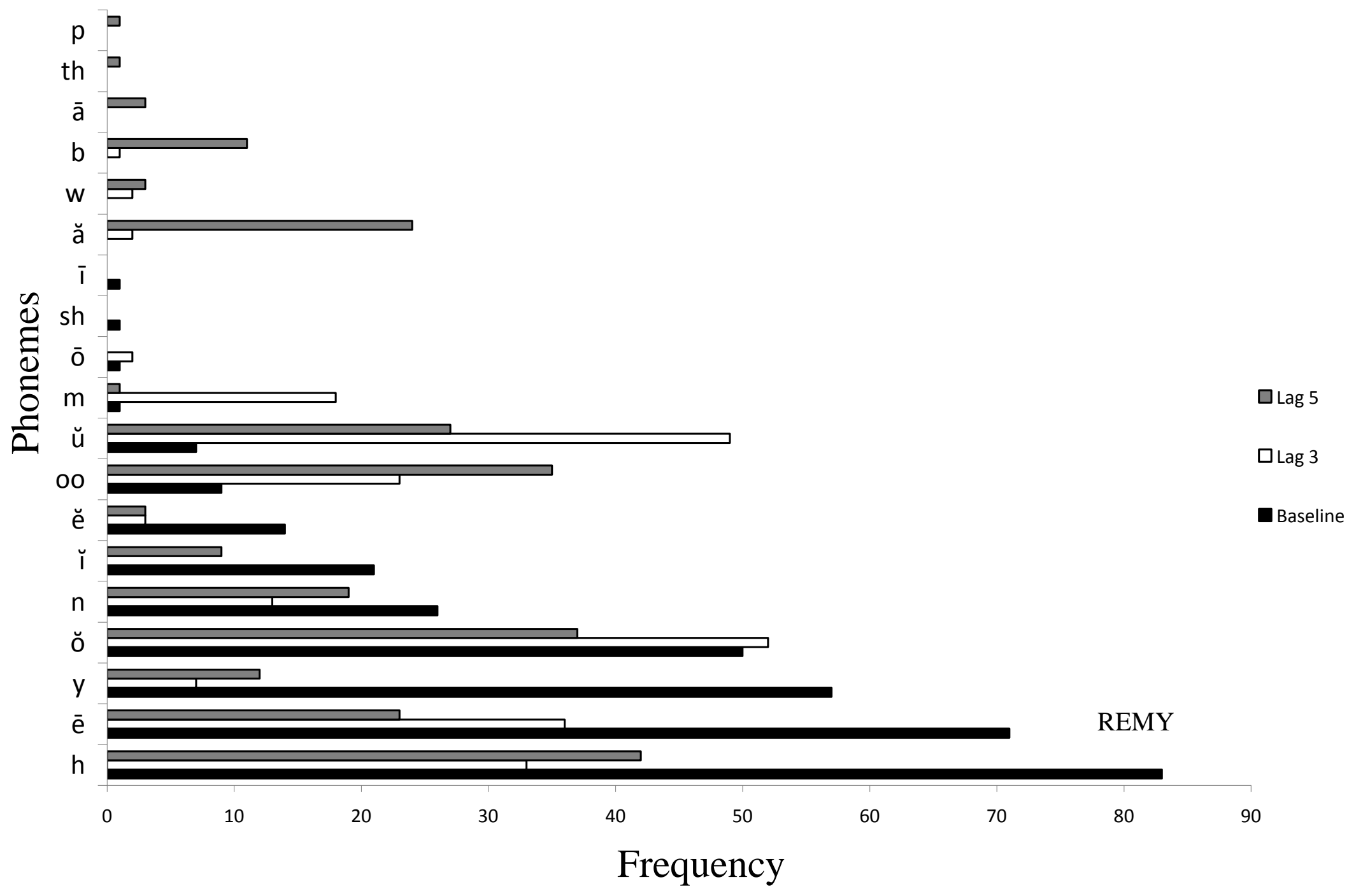

Figure 23. Phoneme frequency during the last six sessions of the baseline and lag schedule conditions in Study 2 for Remy. 


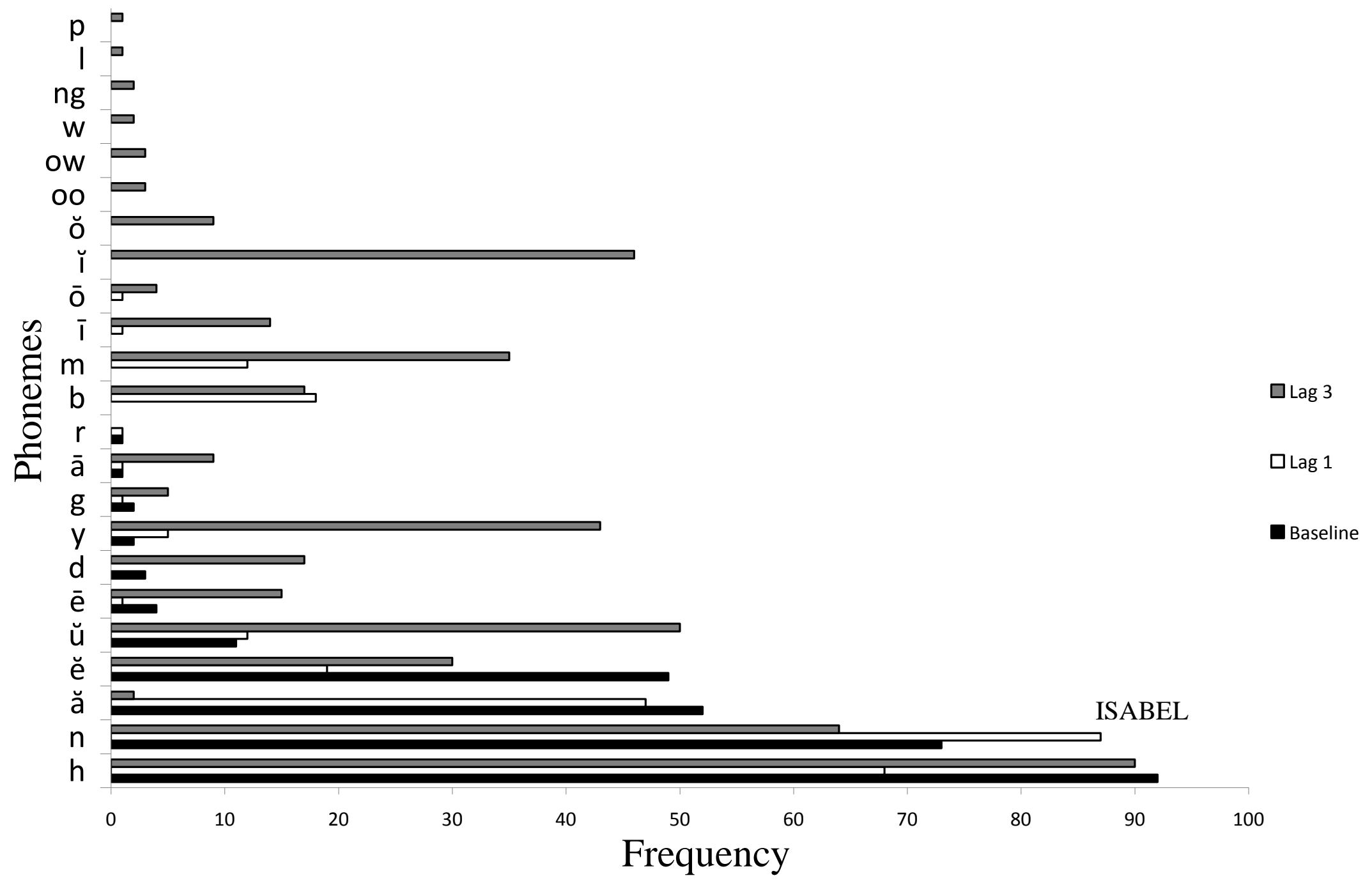

Figure 24. Phoneme frequency during the last six sessions of the baseline and lag schedule conditions in Study 2 for Isabel. 


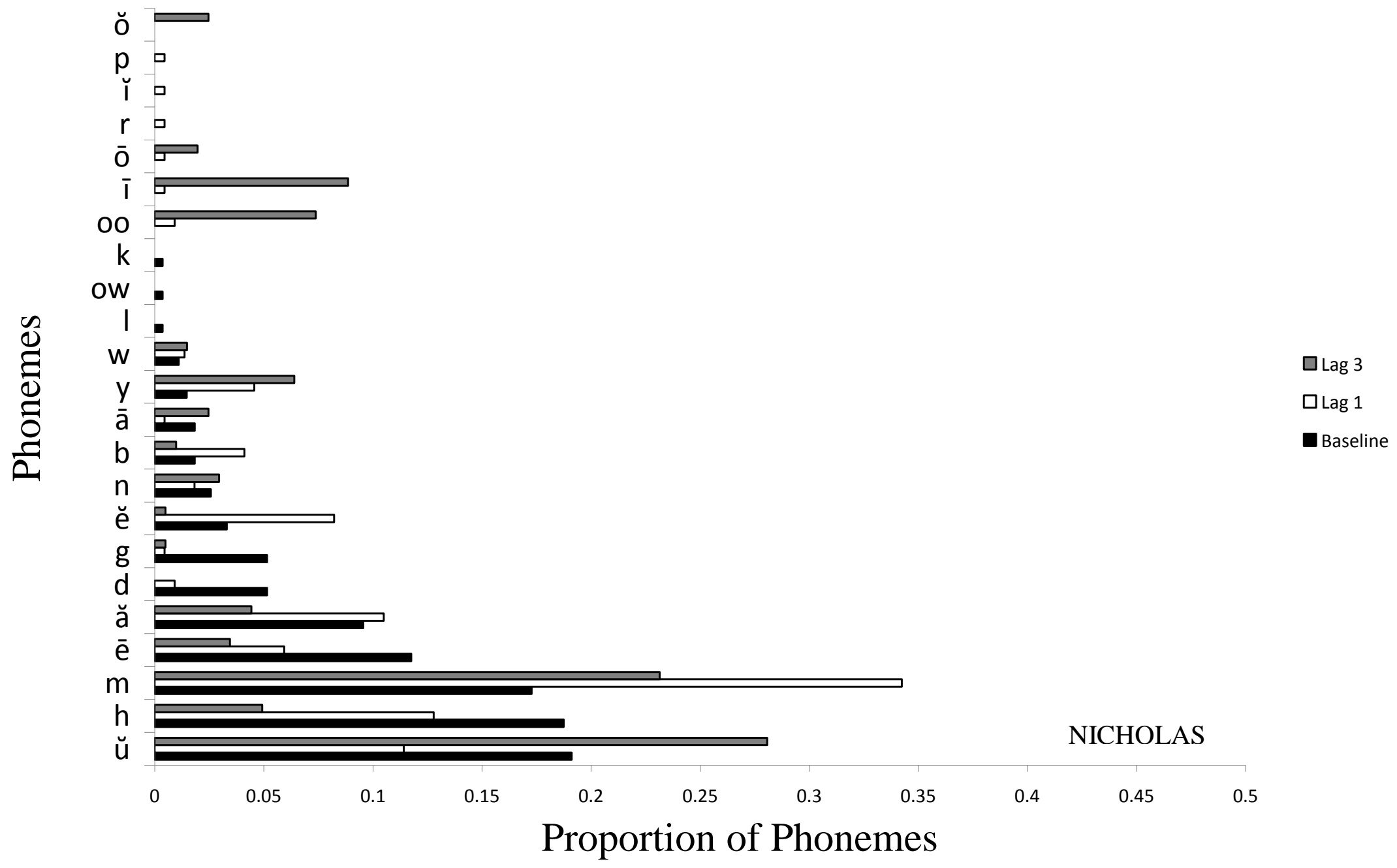

Figure 25. Proportional distribution of phonemes, out of all phonemes produced, during the last six sessions of the baseline and lag schedule conditions in Study 2 for Nicholas. 


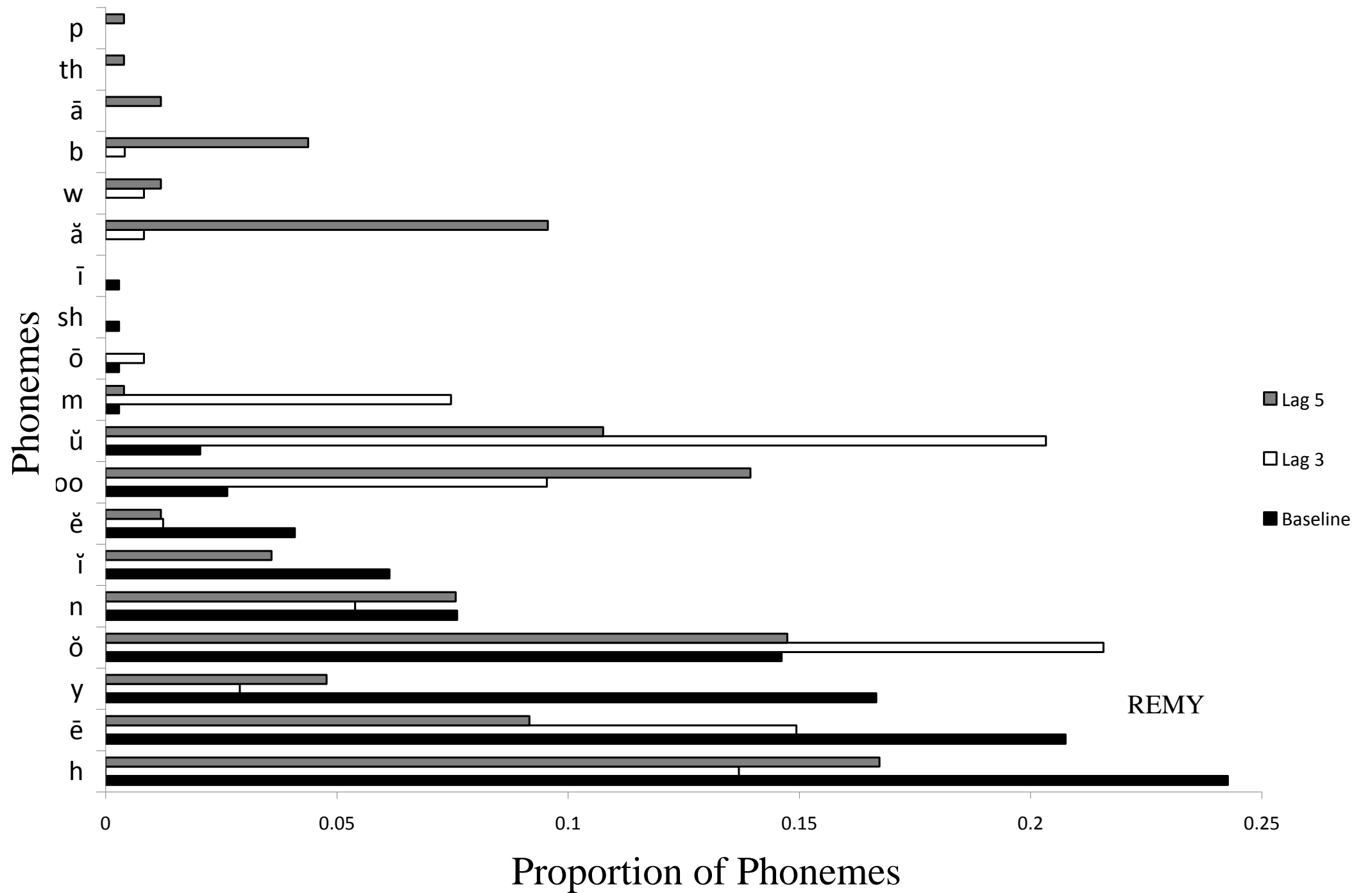

Figure 26. Proportional distribution of phonemes, out of all phonemes produced, during the last six sessions of the baseline and lag schedule conditions in Study 2 for Remy. 


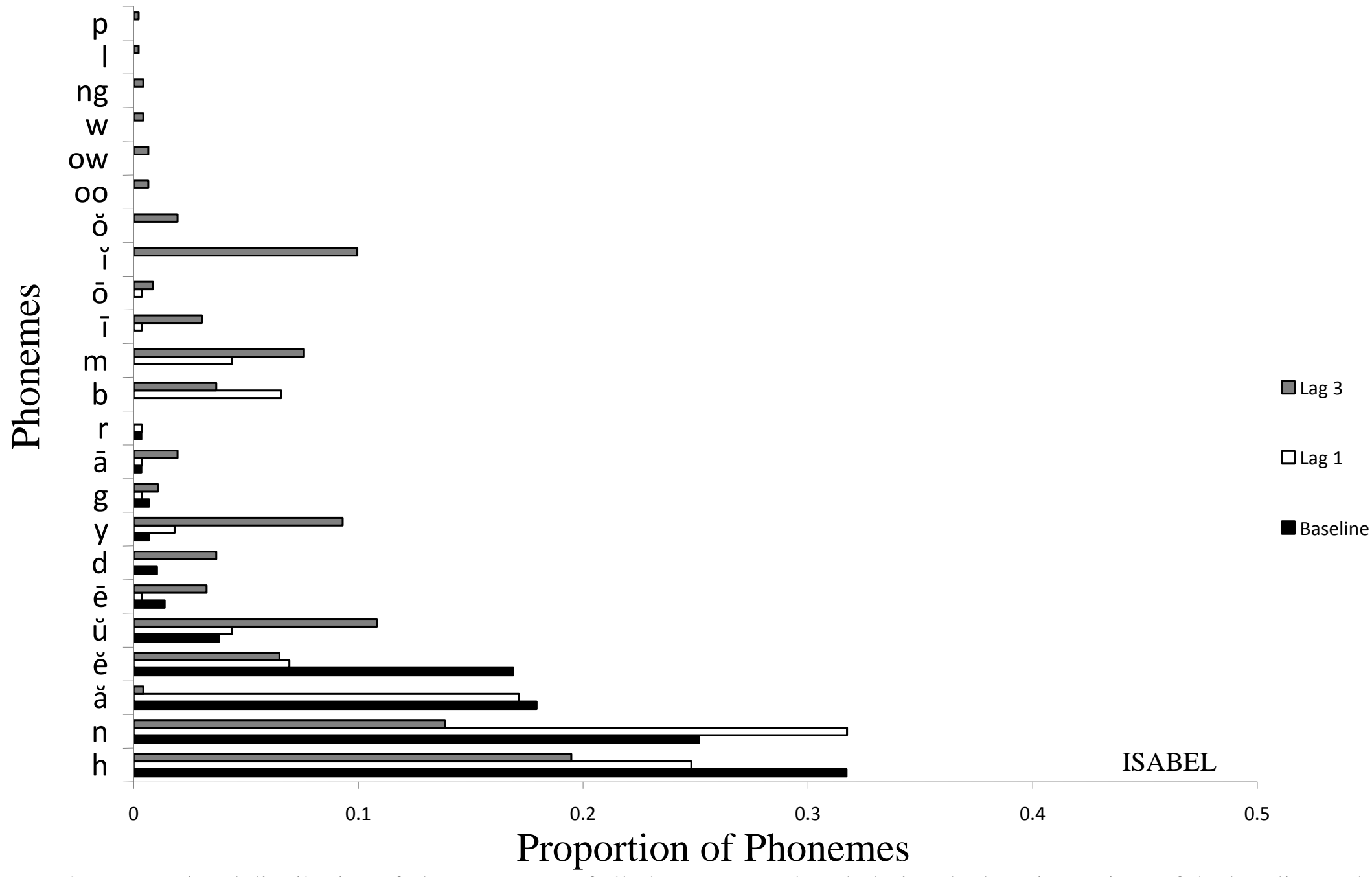

Figure 27. Proportional distribution of phonemes, out of all phonemes produced, during the last six sessions of the baseline and lag schedule conditions in Study 2 for Isabel. 


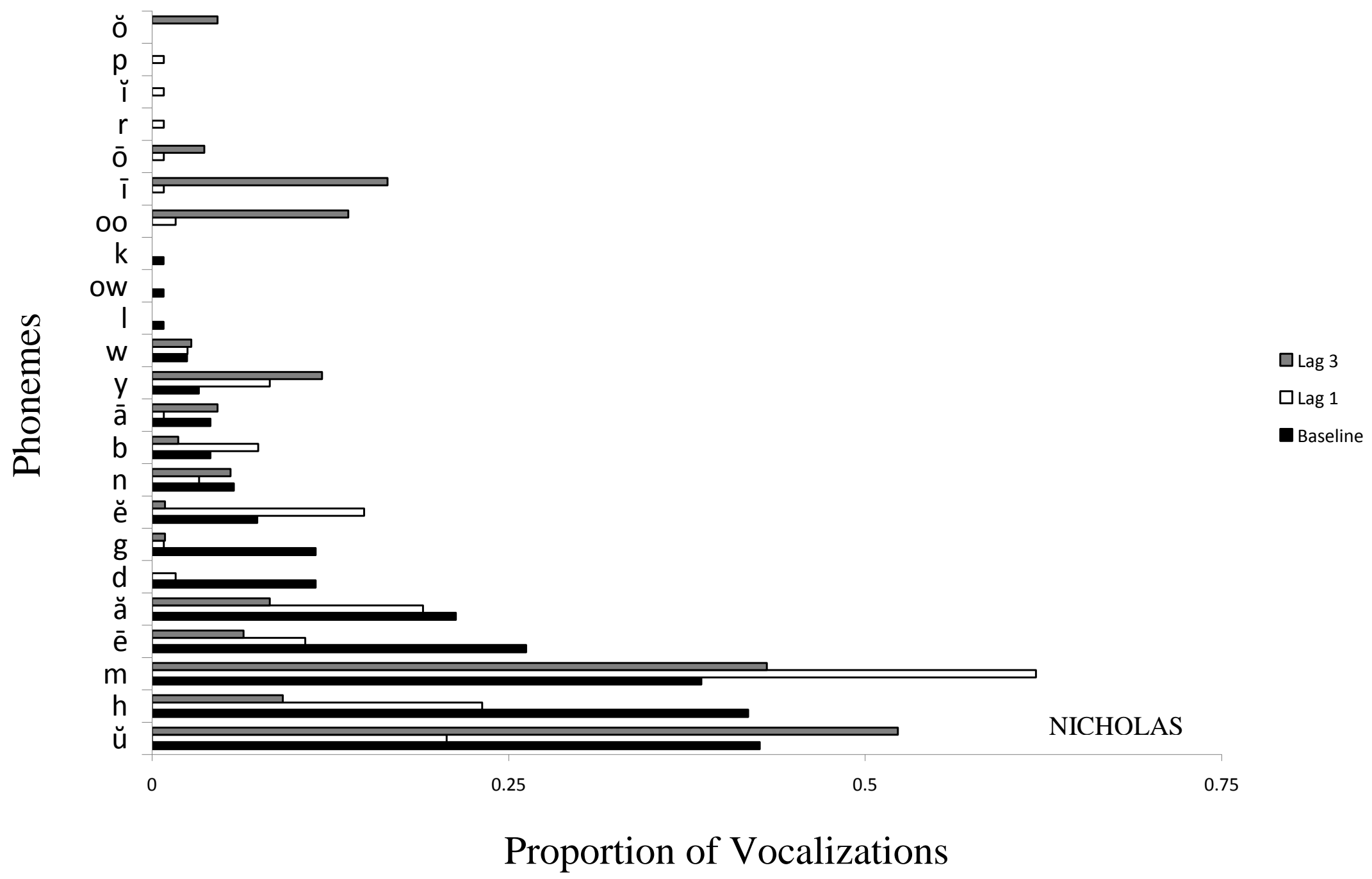

Figure 28. Proportional distribution of phonemes, out of all vocalizations produced, during the last six sessions of the baseline and lag schedule conditions in Study 2 for Nicholas. 


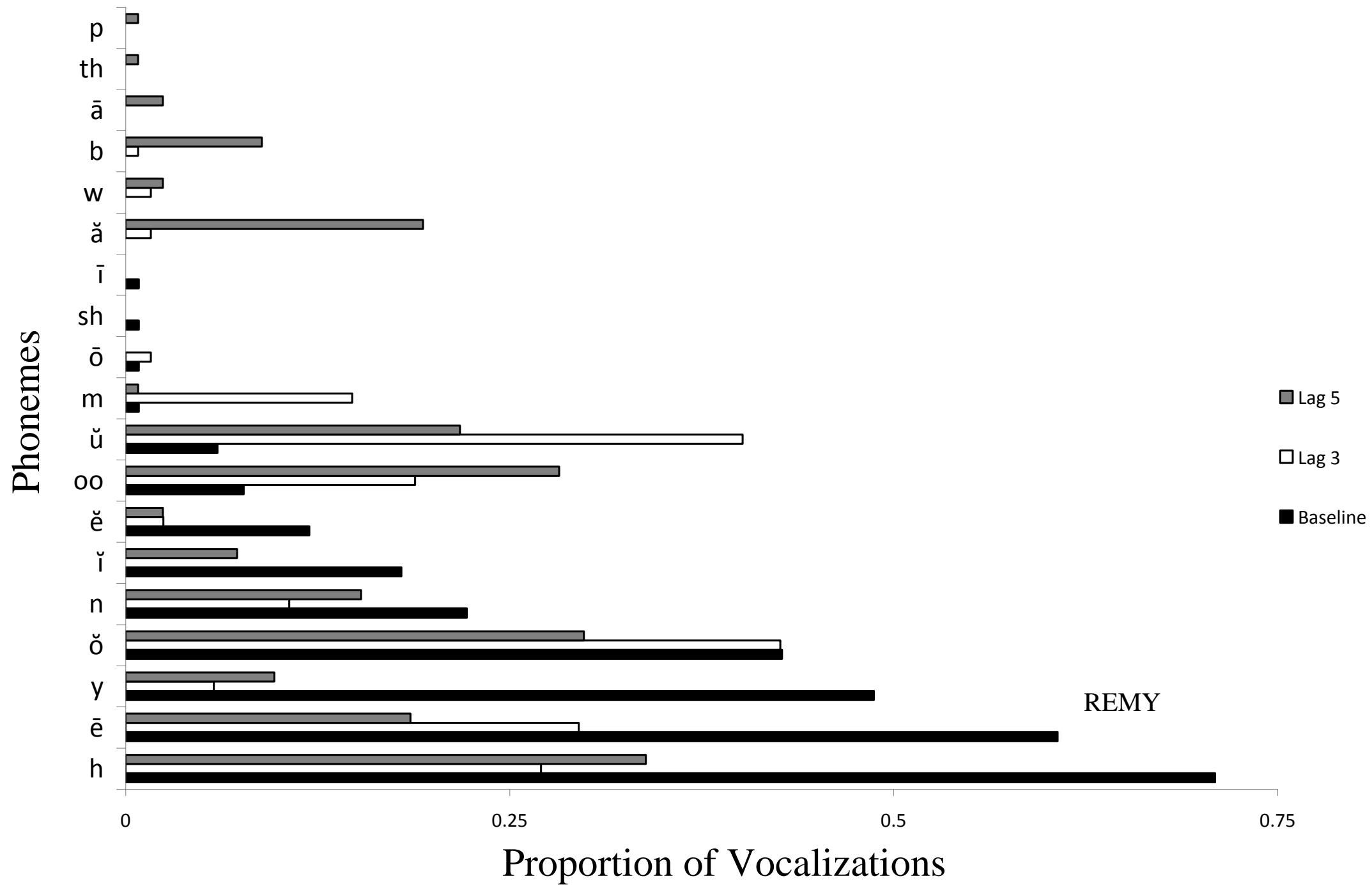

Figure 29. Proportional distribution of phonemes, out of all vocalizations produced, during the last six sessions of the baseline and lag schedule conditions in Study 2 for Remy. 


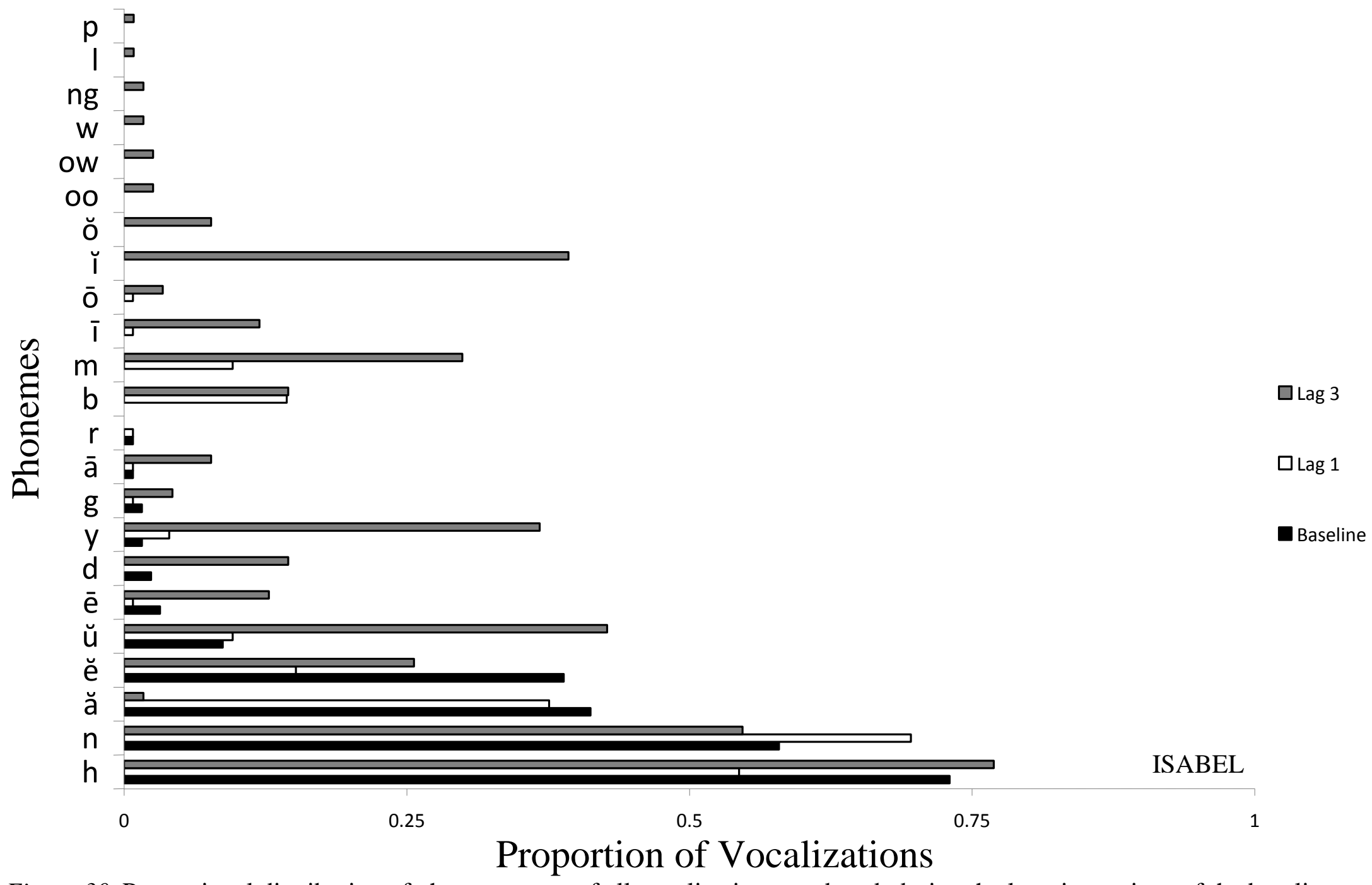

Figure 30. Proportional distribution of phonemes, out of all vocalizations produced, during the last six sessions of the baseline and lag schedule conditions in Study 2 for Isabel. 


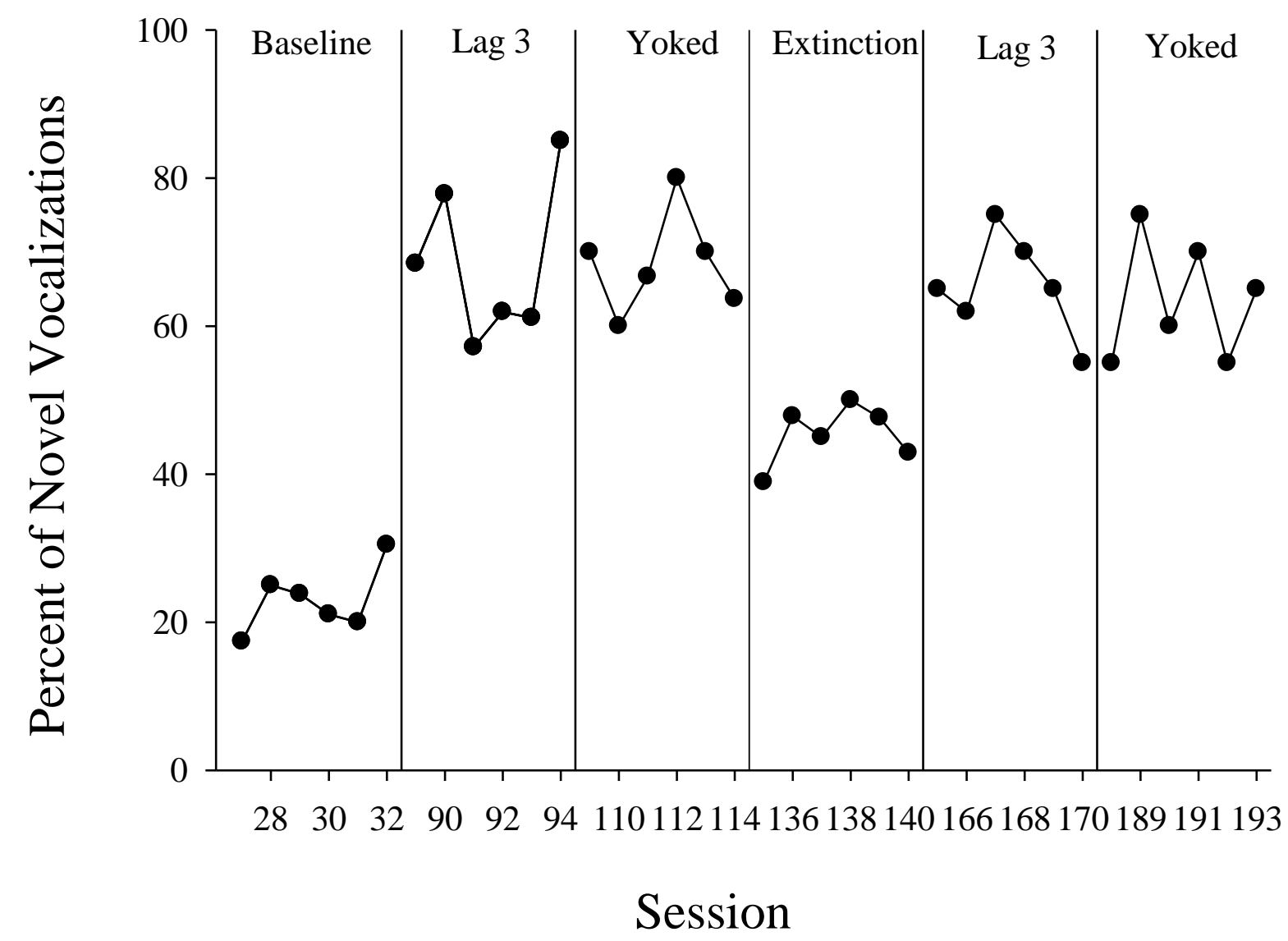

Figure 31. Percentage of novel vocalizations (last six sessions) under the baseline/extinction, Lag 3 and yoked-control conditions in Study 3 for Isabel. 


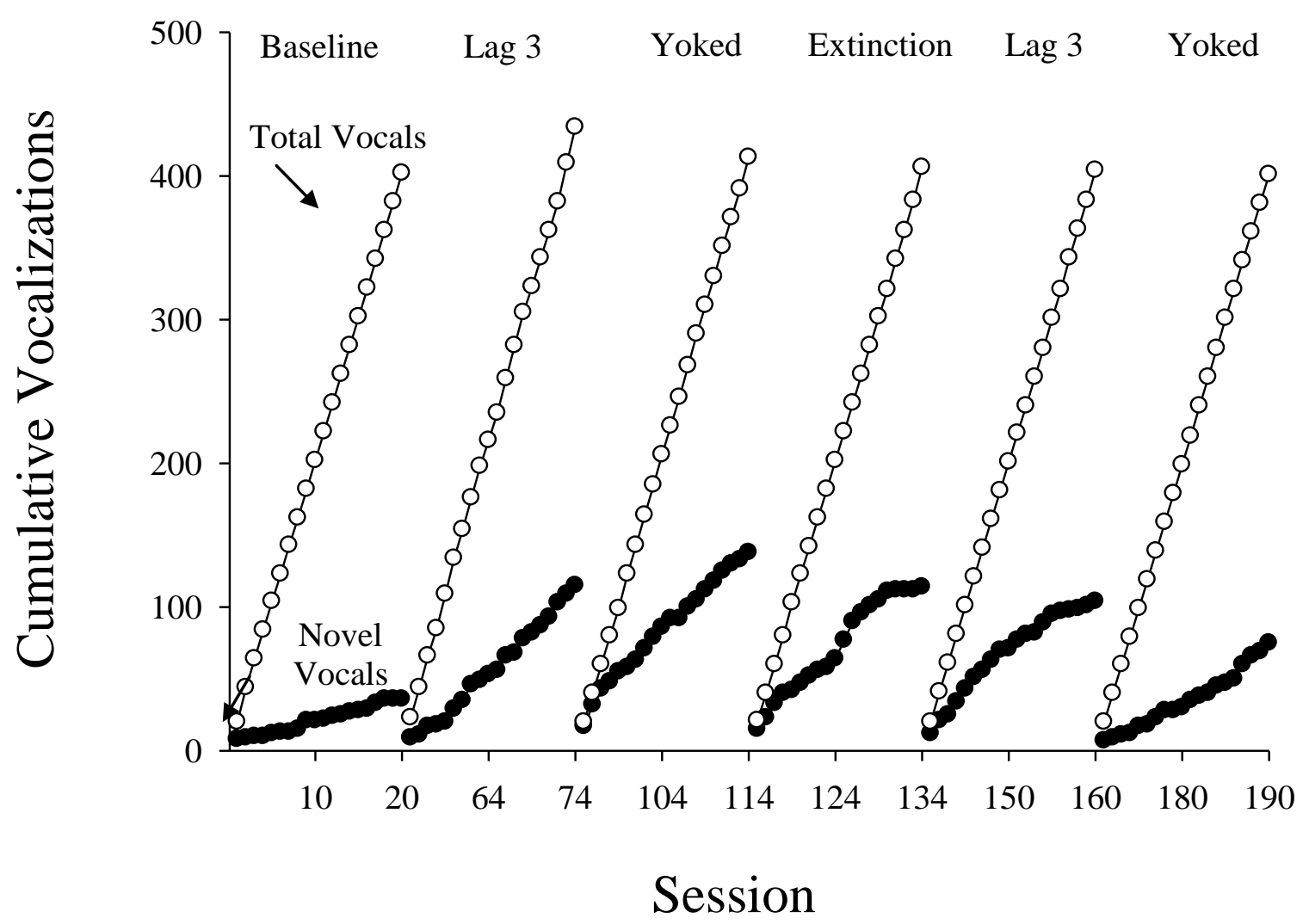

Figure 32. Cumulative total vocalizations (open circles) and novel vocalizations (closed circles) across all sessions of baseline/extinction, $\mathrm{Lag}$ 3, and yoked-control conditions in Study 3 for Isabel. 

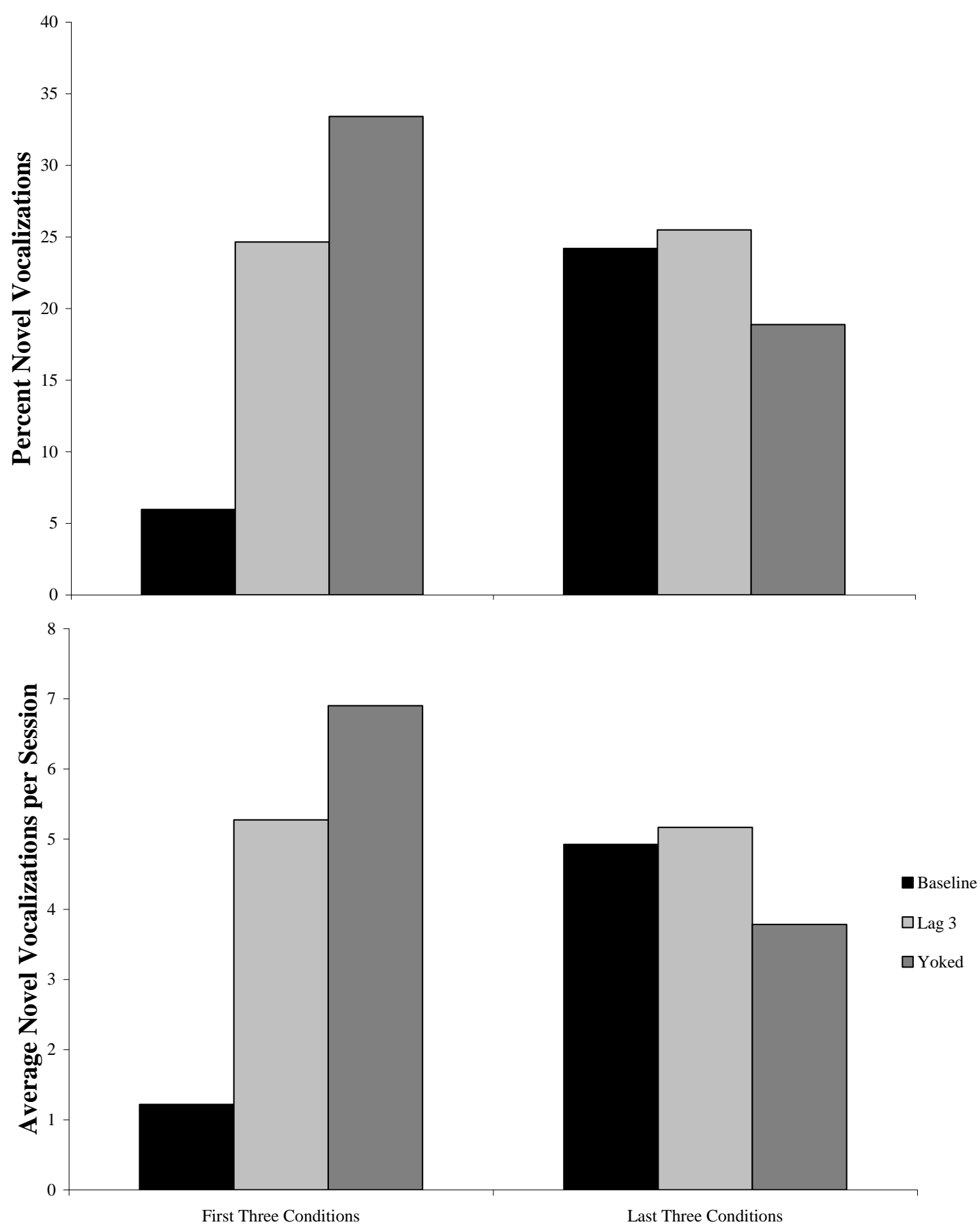

Figure 33. Two measures of novel vocalizations for Isabel in Study 3, across all across all sessions of each condition (baseline, Lag3, and yoked-control). The top panel displays the percent of vocalizations that were novel, out of all vocalizations. The bottom panel presents the average number of novel vocalizations per session. 


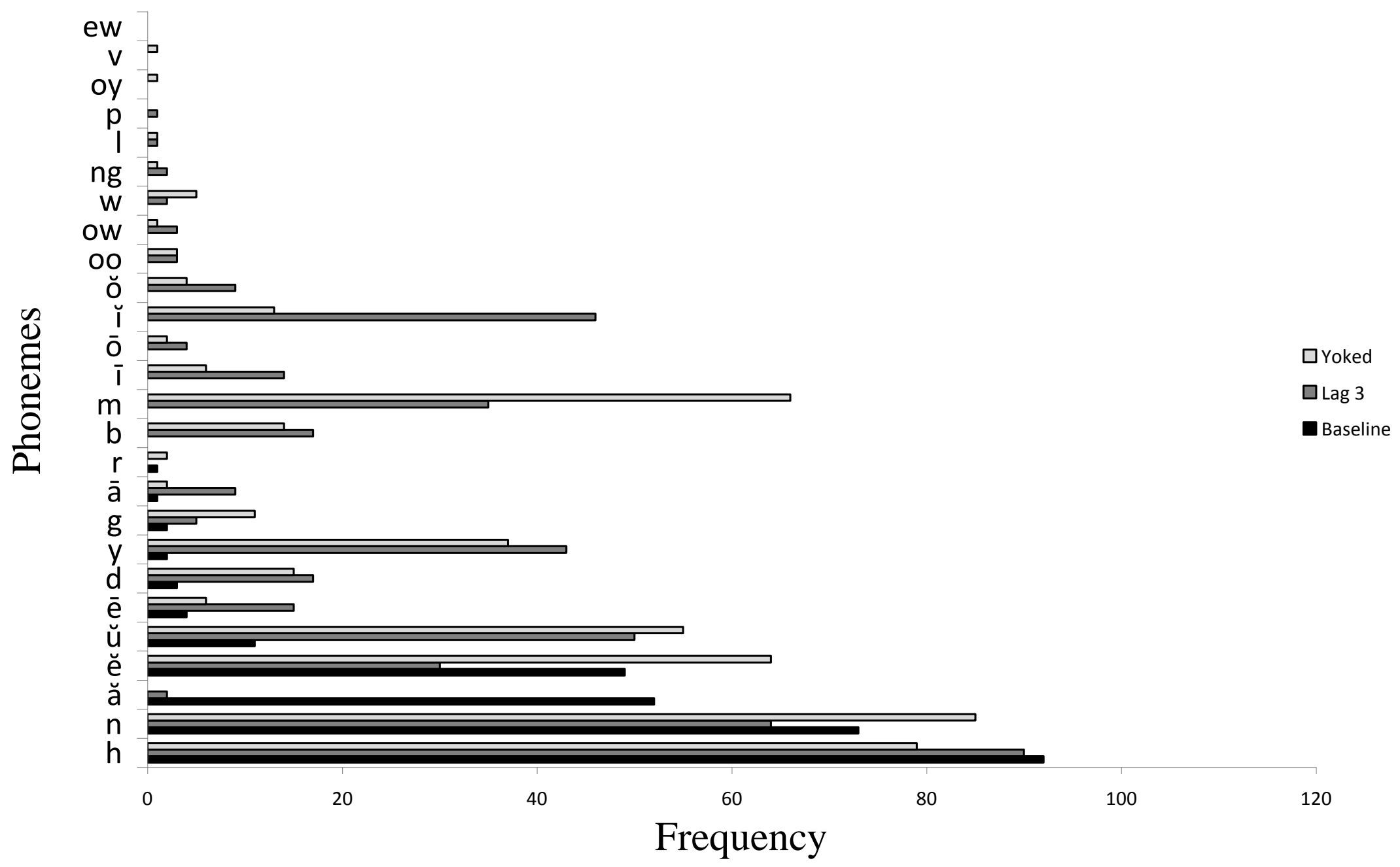

Figure 34. Phoneme frequency during the last six sessions of the first three conditions (baseline, Lag 3, yoked-control) in Study 3 for Isabel. 


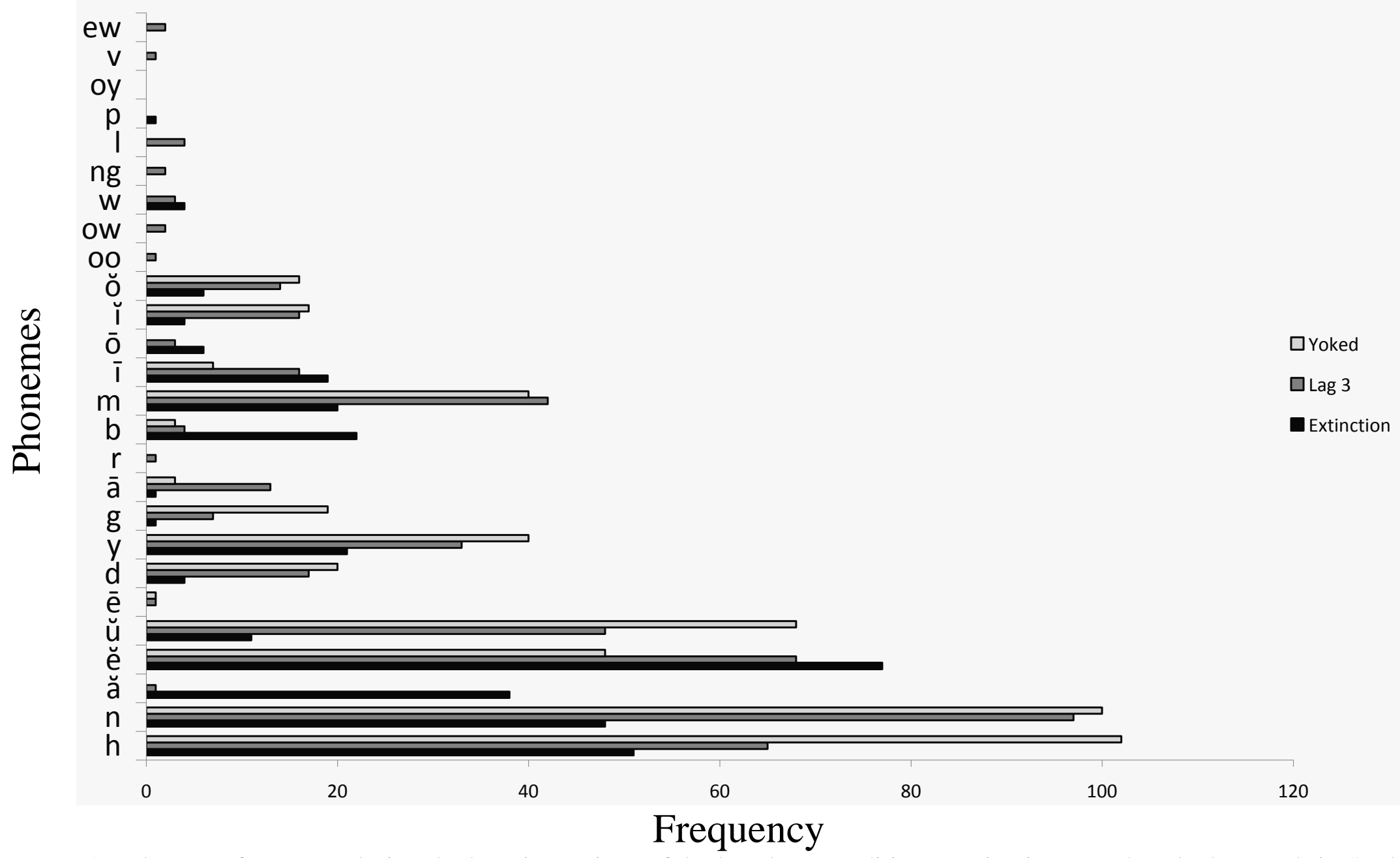

Figure 35. Phoneme frequency during the last six sessions of the last three conditions (extinction, Lag 3, yoked-control) in Study 3 for Isabel. 


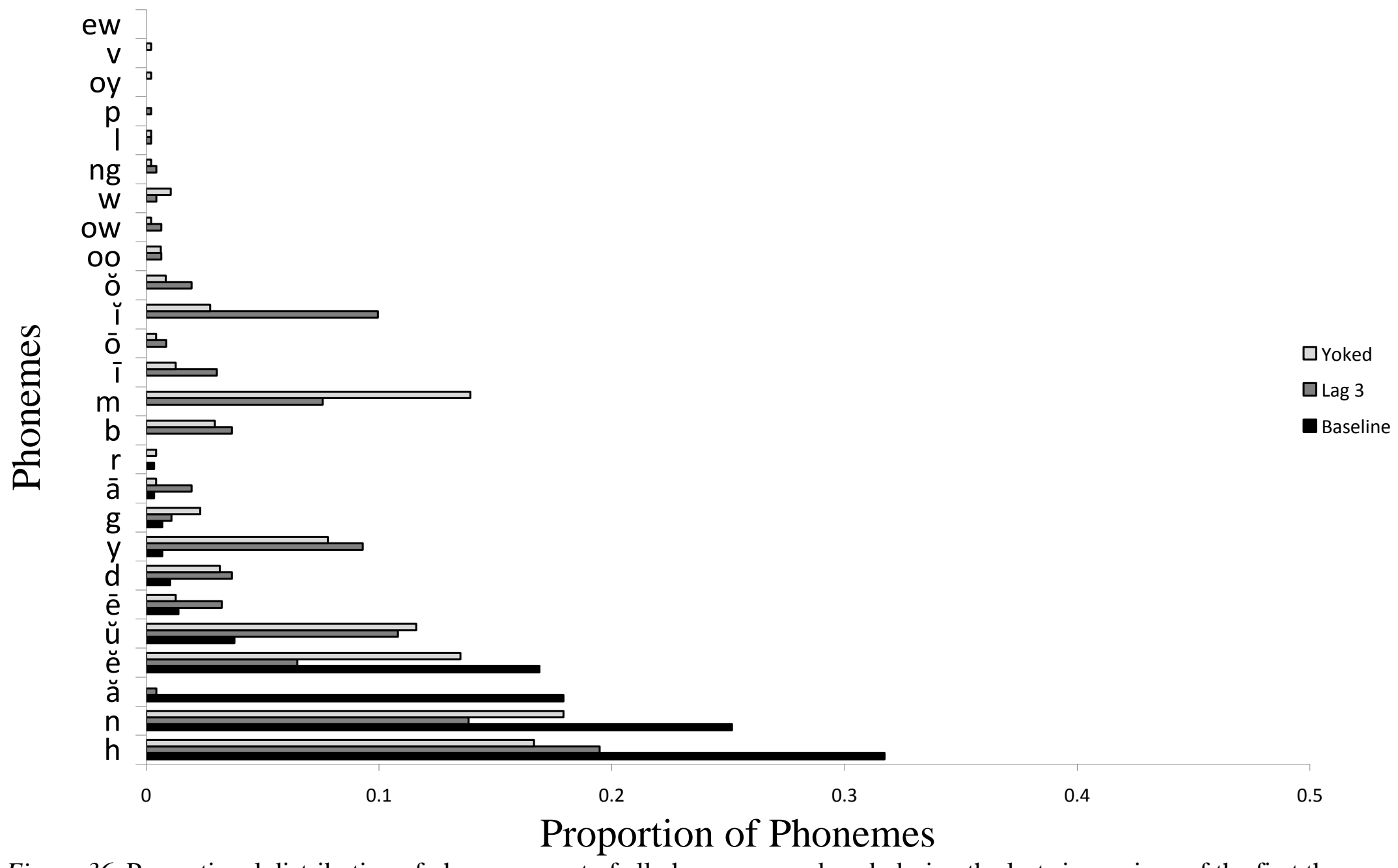

Figure 36. Proportional distribution of phonemes, out of all phonemes produced, during the last six sessions of the first three conditions (baseline, Lag 3, yoked-control) in Study 3 for Isabel. 


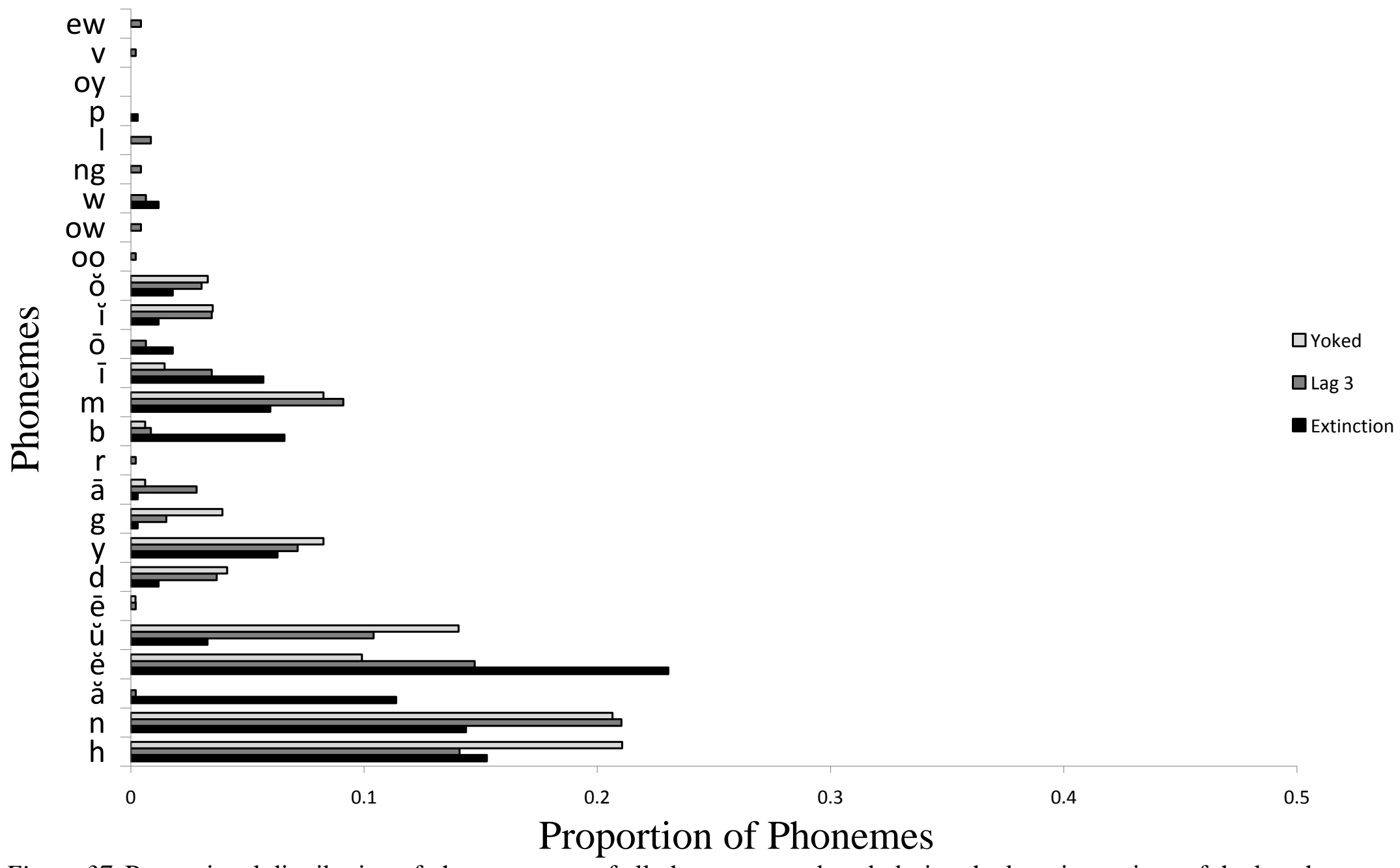

Figure 37. Proportional distribution of phonemes, out of all phonemes produced, during the last six sessions of the last three conditions (extinction, Lag 3, yoked-control) in Study 3 for Isabel. 


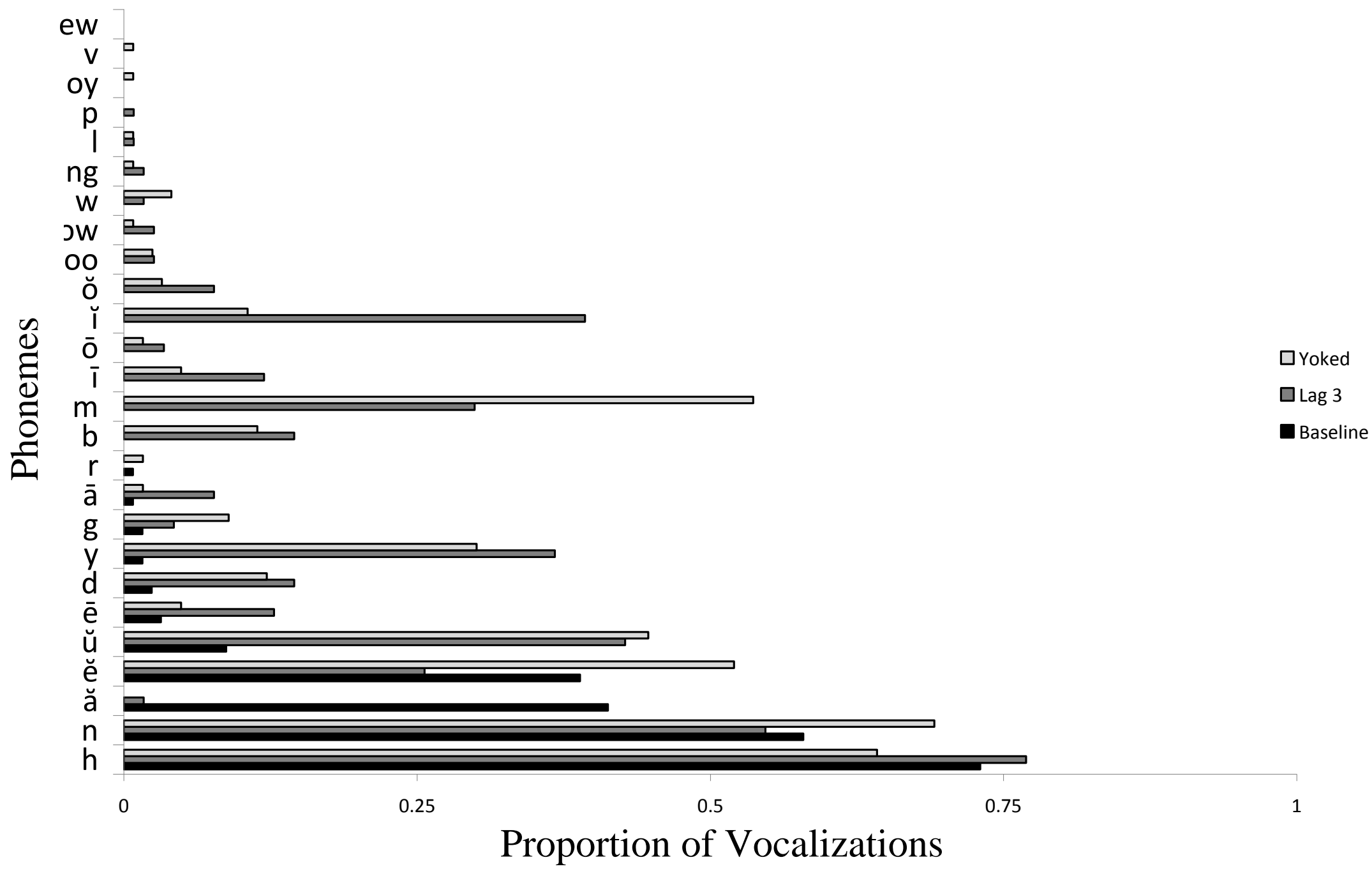

Figure 38. Proportional distribution of phonemes, out of all vocalizations produced, during the last six sessions of the first three conditions (baseline, Lag 3, yoked-control) in Study 3 for Isabel. 


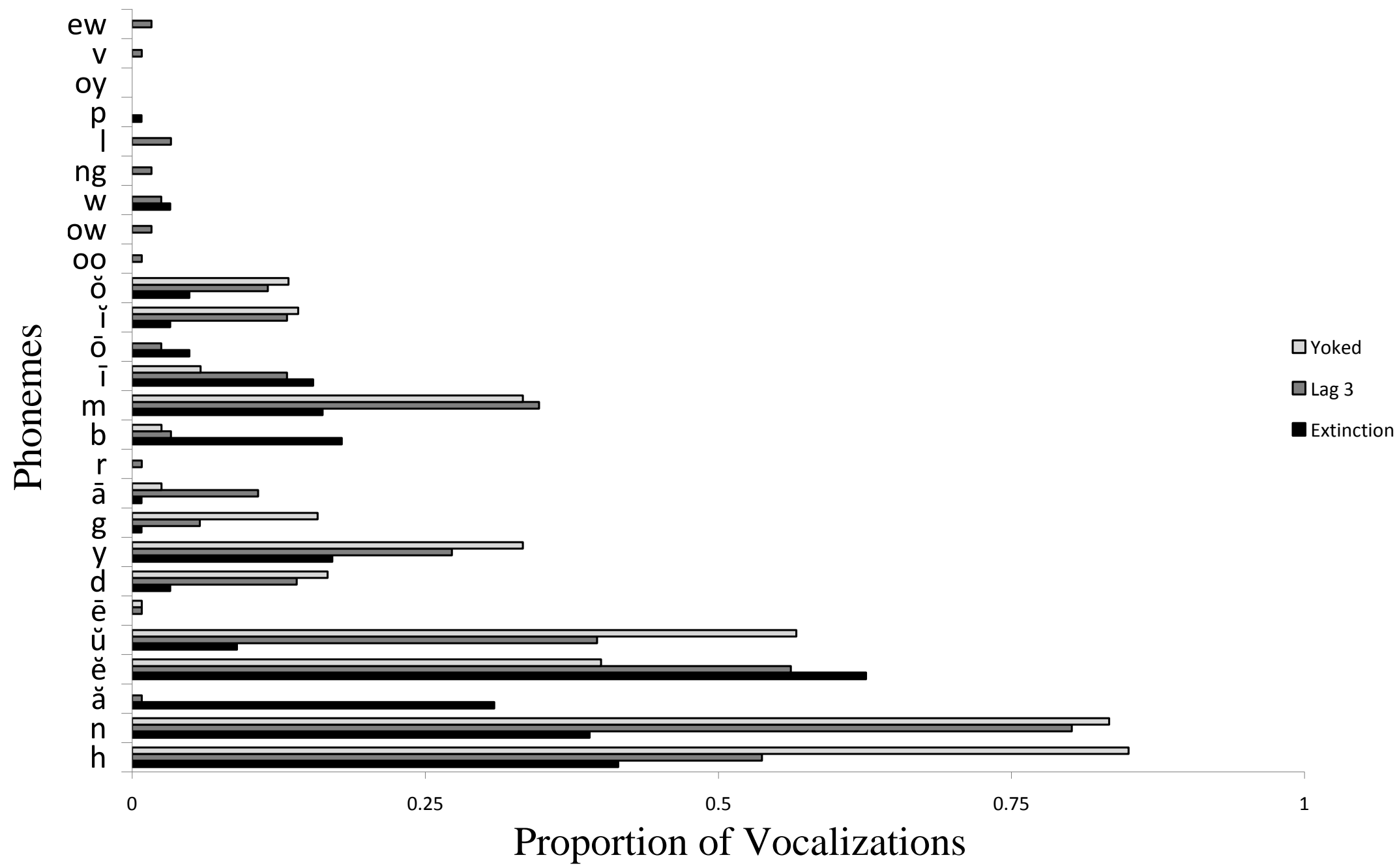

Figure 39. Proportional distribution of phonemes, out of all vocalizations produced, during the last six sessions of the last three conditions (extinction, Lag 3, yoked-control) in Study 3 for Isabel. 


\begin{tabular}{|c|c|c|c|c|c|c|c|c|c|c|c|}
\hline \multirow{2}{*}{ Phoneme } & \multirow[b]{2}{*}{ IPA } & \multirow{2}{*}{$<24 \operatorname{mos}$} & \multirow{2}{*}{$24 \operatorname{mos}$} & \multirow{2}{*}{$28 \mathrm{mos}$} & \multirow{2}{*}{$32 \operatorname{mos}$} & \multirow{2}{*}{$36 \mathrm{mos}$} & \multirow{2}{*}{40 mos } & \multirow{2}{*}{$44 \operatorname{mos}$} & \multirow{2}{*}{$48 \operatorname{mos}$} & \multirow{2}{*}{$>48 \operatorname{mos}$} & \multirow[b]{2}{*}{ Articulation } \\
\hline & & & & & & & & & & & \\
\hline ă & $æ$ & \multicolumn{4}{|c|}{ Nathan, Kali, Nicholas, Kristopher, Owen, Nelson, Isabel } & & & & & & Monopthong \\
\hline$\overline{\mathrm{e}}$ & $\mathrm{i}$ & \multicolumn{4}{|c|}{ Nadia, Nathan, Kali, Dillon, Nicholas, Kristopher, Owen, Remy, Isabel } & & & & & & Monopthong \\
\hline ĕ & $\varepsilon$ & \multicolumn{4}{|c|}{ Nadia, Nathan, Kali, Dillon, Nicholas, Owen, Remy, Nelson, Isabel } & & & & & & Monopthong \\
\hline$\breve{\imath}$ & I & \multicolumn{4}{|c|}{ Nadia, Kali, Dillon, Owen, Remy, Nelson } & & & & & & Monopthong \\
\hline ŏ & $a, 0$ & \multicolumn{4}{|c|}{ Nadia, Kali, Dillon, Remy, Nelson } & & & & & & Monopthong \\
\hline$\breve{\mathrm{u}}$ & $\partial, \Lambda$ & \multicolumn{4}{|c|}{ Nadia, Nathan, Kali, Dillon, Nicholas, Kristopher, Owen, Remy, Nelson, Isabel } & & & & & & Monopthong \\
\hline oo & $\mathrm{u}$ & \multicolumn{4}{|c|}{ Nadia, Nathan, Kali, Dillon, Kristopher, Owen, Remy } & & & & & & Monopthong \\
\hline $\bar{a}$ & eI & \multicolumn{4}{|c|}{ Nathan, Kali, Nicholas, Kristopher, Owen, Nelson, Isabel } & & & & & & Diphthong \\
\hline $\bar{i}$ & aI & \multicolumn{4}{|c|}{ Nadia, Nathan, Kali, Dillon, Remy } & & & & & & Diphthong \\
\hline$\overline{\mathrm{o}}$ & ov & \multicolumn{4}{|c|}{ Nadia, Nathan, Kali, Dillon, Owen, Remy } & & & & & & Diphthong \\
\hline ow & av & \multicolumn{4}{|c|}{ Nadia, Dillon, Nicholas } & & & & & & Diphthong \\
\hline oy & כI & \multicolumn{4}{|c|}{ Nadia, Kali, Dillon } & & & & & & Diphthong \\
\hline er & 2,3 & \multicolumn{9}{|c|}{ not observed } & R-Colored \\
\hline ar & ar & \multicolumn{9}{|c|}{ not observed } & R-Colored \\
\hline or & or & \multicolumn{9}{|c|}{ not observed } & R-Colored \\
\hline ur & चr & \multicolumn{9}{|c|}{ not observed } & R-Colored \\
\hline
\end{tabular}

Figure 40. Developmental chart of vowel production. Ages (in months) are displayed in the top row; each partition corresponds to a

four-month interval. Each row corresponds to a phoneme (with IPA code and articulation pattern)), with the gray bars representing typical development for that phoneme. The leftmost boundary of the bar represents the earliest documented occurrence in typically developing children, and the rightmost boundary of the bar represents the latest time at which typically developing children master that sound. The names of Study 1 participants who produced a given phoneme are listed within each bar. 


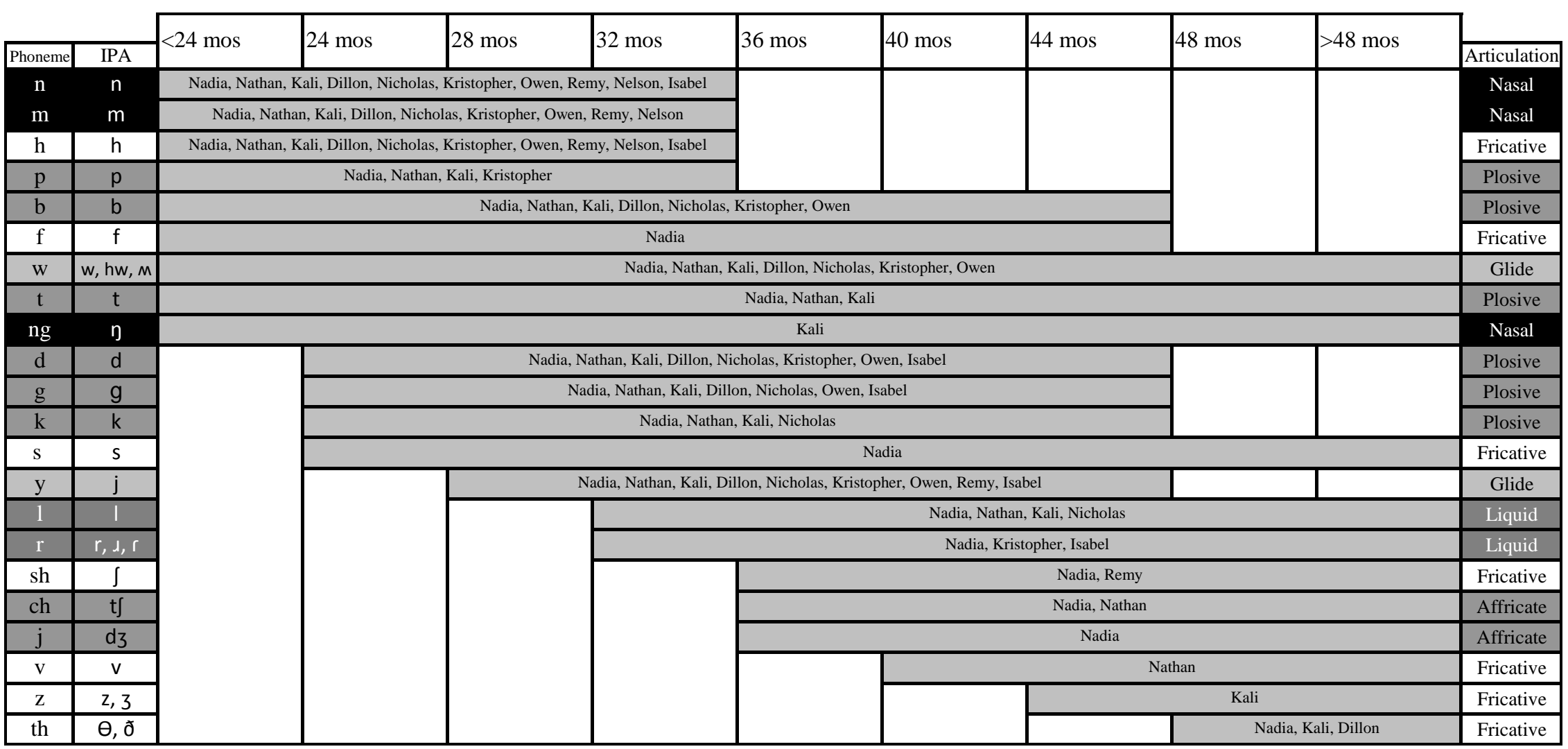

Figure 41. Developmental chart of consonant production. Ages (in months) are displayed in the top row; each partition corresponds to

a four-month interval. Each row corresponds to a phoneme (with IPA code and articulation pattern)), with the gray bars representing

typical development for that phoneme. The leftmost boundary of the bar represents the earliest documented occurrence in typically

developing children, and the rightmost boundary of the bar represents the latest time at which typically developing children master

that sound. The names of Study 1 participants who produced a given phoneme are listed within each bar. 


\begin{tabular}{|c|c|c|c|c|c|c|c|c|c|c|c|}
\hline Phoneme & $\overline{\mathrm{IPA}}$ & $<24 \operatorname{mos}$ & $24 \mathrm{mos}$ & $28 \mathrm{mos}$ & $32 \mathrm{mos}$ & $36 \mathrm{mos}$ & $40 \mathrm{mos}$ & $44 \mathrm{mos}$ & $48 \mathrm{mos}$ & $>48 \mathrm{mos}$ & \begin{tabular}{|l|} 
Articulation \\
\end{tabular} \\
\hline ă & $æ$ & & & & & & & & & & Monopthong \\
\hline$\overline{\mathrm{e}}$ & $\mathrm{i}$ & & & & & & & & & & Monopthong \\
\hline ĕ & $\varepsilon$ & & & & & & & & & & Monopthong \\
\hline ı̀ & I & & & & & & & & & & Monopthong \\
\hline ŏ & $a, 0$ & & & & & & & & & & Monopthong \\
\hline ŭ & $\partial, \Lambda$ & & & & & & & & & & Monopthong \\
\hline oo & $\mathrm{u}$ & & & & & & & & & & Monopthong \\
\hline $\bar{a}$ & eI & & & & & & & & & & Diphthong \\
\hline $\bar{i}$ & aI & & & & & & & & & & Diphthong \\
\hline ō & ov & & & & & & & & & & Diphthong \\
\hline ow & av & & & & & & & & & & Diphthong \\
\hline oy & ग1 & & & & & & & & & & Diphthong \\
\hline er & 2,3 & & & & & & & & & & R-Colored \\
\hline ar & ar & & & & & & & & & & R-Colored \\
\hline or & or & & & & & & & & & & R-Colored \\
\hline ur & vr & & & & & & & & & & R-Colored \\
\hline
\end{tabular}

\begin{tabular}{|c|c|}
\hline Baseline & \\
\hline Lag 1 & \\
\hline Lag 3 & \\
\hline Not Observed & \\
\hline
\end{tabular}

Figure 42. Developmental chart of vowel production across the last six sessions of conditions in Study 2 for Nicholas. Bars with dots represent sounds produced in baseline, bars with diagonal lines represent phonemes produced under Lag 1, and bars with crosshatch represent phonemes produced in Lag 3. Phonemes not observed in any condition are shaded black. 


\begin{tabular}{|c|c|c|c|c|c|c|c|c|c|c|c|}
\hline Phoneme & $\overline{\mathrm{IPA}}$ & $<24 \mathrm{mos}$ & $24 \mathrm{mos}$ & $28 \mathrm{mos}$ & $32 \mathrm{mos}$ & $36 \mathrm{mos}$ & $40 \mathrm{mos}$ & $44 \mathrm{mos}$ & $48 \mathrm{mos}$ & $>48 \mathrm{mos}$ & $\overline{\text { Articulation }}$ \\
\hline $\mathrm{n}$ & $n$ & & & & & & & & & & Nasal \\
\hline $\mathrm{m}$ & $\mathrm{m}$ & & & & & & & & & & Nasal \\
\hline $\mathrm{h}$ & $\mathrm{h}$ & & & & & & & & & & Fricative \\
\hline $\bar{p}$ & $p$ & & & & & & & & & & Plosive \\
\hline b & b & & & & & & & & & & Plosive \\
\hline $\mathrm{f}$ & $f$ & & & & & & & & & & Fricative \\
\hline w & $w, h w, M$ & & & & & & & & & & Glide \\
\hline $\mathrm{t}$ & $\mathrm{t}$ & & & & & & & & & & Plosive \\
\hline ng & n & & & & & & & & & & Nasal \\
\hline $\mathrm{d}$ & d & & & & & & & & & & Plosive \\
\hline $\mathrm{g}$ & g & & & & & & & & & & Plosive \\
\hline $\mathrm{k}$ & $\mathrm{k}$ & & & & & & & & & & Plosive \\
\hline $\mathrm{s}$ & $\mathrm{s}$ & & & & & & & & & & Fricative \\
\hline $\mathrm{y}$ & $j$ & & & & & & & & & & Glide \\
\hline 1 & 1 & & & & & & & & & & Liquid \\
\hline $\mathrm{r}$ & $r, d, r$ & & & & & & & & & & Liquid \\
\hline sh & J & & & & & & & & & & Fricative \\
\hline ch & t5 & & & & & & & & & & Affricate \\
\hline $\mathrm{j}$ & d3 & & & & & & & & & & Affricate \\
\hline $\mathrm{v}$ & $\mathrm{v}$ & & & & & & & & & & Fricative \\
\hline $\mathrm{z}$ & $z, 3$ & & & & & & & & & & Fricative \\
\hline th & $\theta, \delta$ & & & & & & & & & & Fricative \\
\hline
\end{tabular}

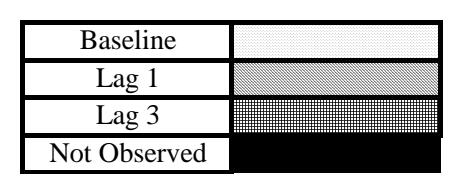

NICHOLAS

Figure 43. Developmental chart of consonant production across the last six sessions of conditions in Study 2 for Nicholas. Bars with dots represent sounds produced in baseline, bars with diagonal lines represent phonemes produced under Lag 1, and bars with crosshatch represent phonemes produced in Lag 3. Phonemes not observed in any condition are shaded black. 


\begin{tabular}{|c|c|c|c|c|c|c|c|c|c|c|c|}
\hline Phoneme & $\overline{\mathrm{IPA}}$ & $<24 \operatorname{mos}$ & $24 \mathrm{mos}$ & $28 \mathrm{mos}$ & $32 \mathrm{mos}$ & $36 \mathrm{mos}$ & $40 \mathrm{mos}$ & $44 \mathrm{mos}$ & $48 \mathrm{mos}$ & $>48 \mathrm{mos}$ & \begin{tabular}{|l|} 
Articulation \\
\end{tabular} \\
\hline ă & $æ$ & & & & & & & & & & Monopthong \\
\hline$\overline{\mathrm{e}}$ & $\mathrm{i}$ & & & & & & & & & & Monopthong \\
\hline ĕ & $\varepsilon$ & & & & & & & & & & Monopthong \\
\hline$\breve{\imath}$ & I & & & & & & & & & & Monopthong \\
\hline ŏ & $a, 0$ & & & & & & & & & & Monopthong \\
\hline ŭ & $\partial, \Lambda$ & & & & & & & & & & Monopthong \\
\hline oo & $\mathrm{u}$ & & & & & & & & & & Monopthong \\
\hline $\bar{a}$ & eI & & & & & & & & & & Diphthong \\
\hline $\bar{i}$ & aI & & & & & & & & & & Diphthong \\
\hline ō & ov & & & & & & & & & & Diphthong \\
\hline ow & av & & & & & & & & & & Diphthong \\
\hline oy & ग1 & & & & & & & & & & Diphthong \\
\hline er & 2,3 & & & & & & & & & & R-Colored \\
\hline ar & ar & & & & & & & & & & R-Colored \\
\hline or & or & & & & & & & & & & R-Colored \\
\hline ur & vr & & & & & & & & & & R-Colored \\
\hline
\end{tabular}

\begin{tabular}{|c|c|}
\hline Baseline & \\
\hline Lag 3 & \\
\hline Lag 5 & \\
\hline Not Observed & \\
\hline
\end{tabular}

Figure 44. Developmental chart of vowel production across the last six sessions of conditions in Study 2 for Remy. Bars with dots represent sounds produced in baseline, bars with diagonal lines represent phonemes produced under Lag 1, and bars with crosshatch represent phonemes produced in Lag 3. Phonemes not observed in any condition are shaded black. 


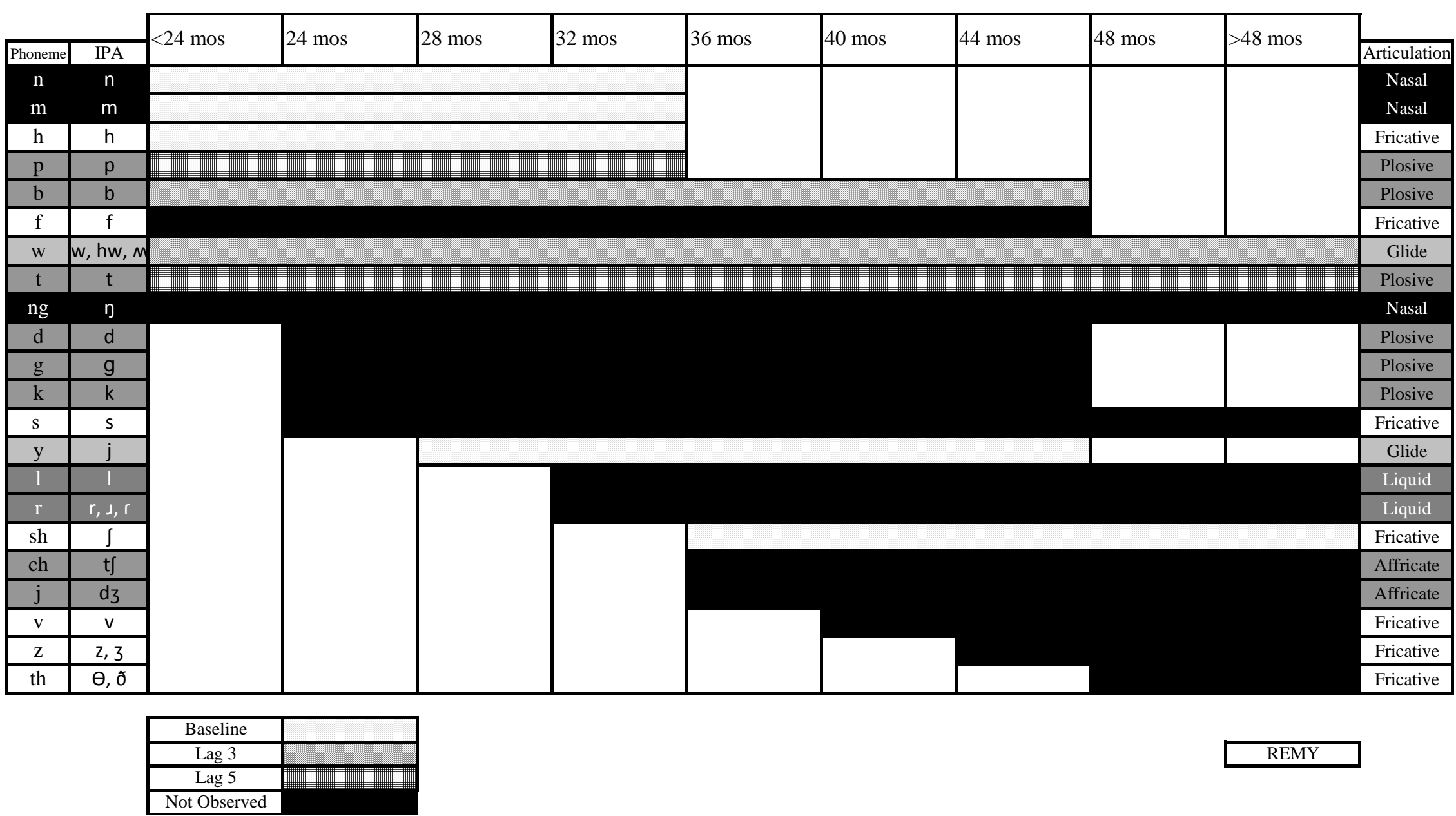

Figure 45. Developmental chart of consonant production across the last six sessions of conditions in Study 2 for Remy. Bars with dots represent sounds produced in baseline, bars with diagonal lines represent phonemes produced under Lag 1, and bars with crosshatch represent phonemes produced in Lag 3. Phonemes not observed in any condition are shaded black. 


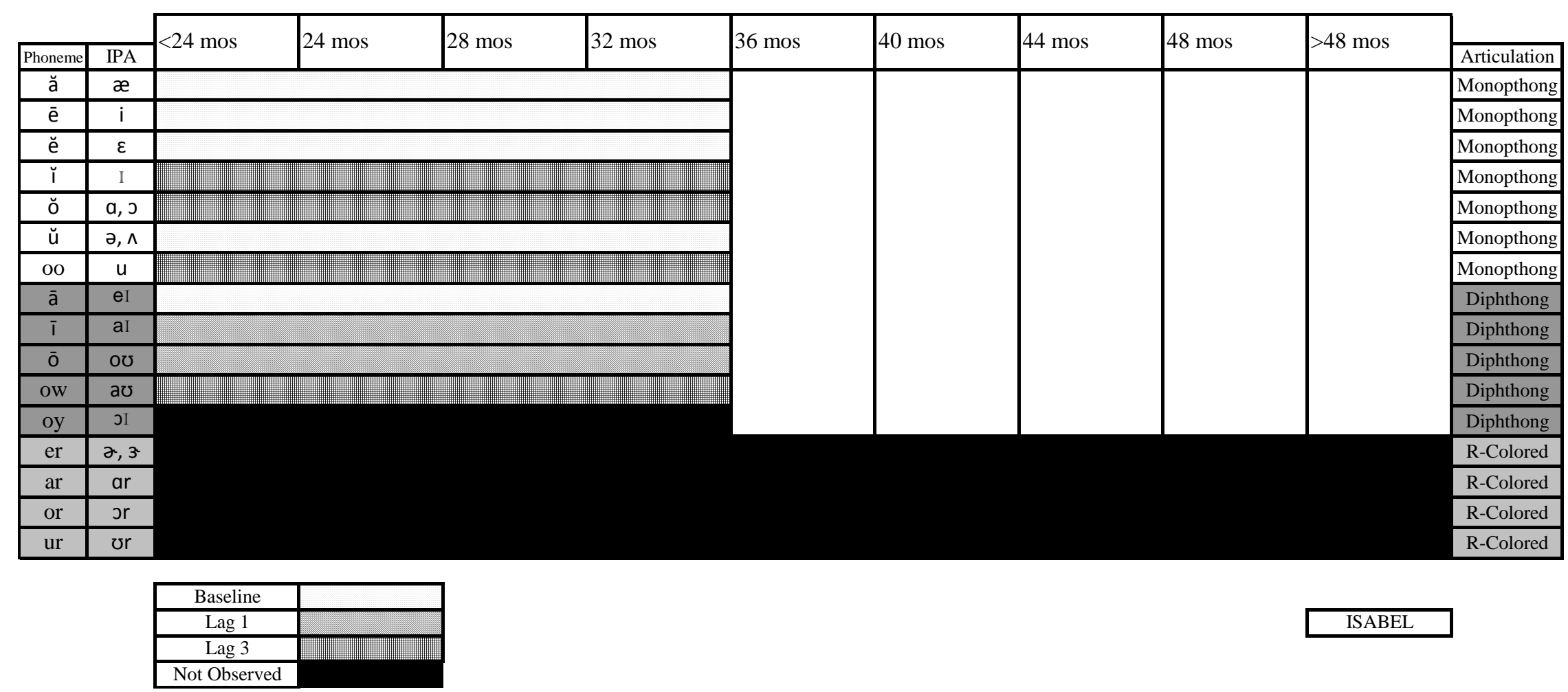

Figure 46. Developmental chart of vowel production across the last six sessions of conditions in Study 2 for Isabel. Bars with dots represent sounds produced in baseline, bars with diagonal lines represent phonemes produced under Lag 1, and bars with crosshatch represent phonemes produced in Lag 3. Phonemes not observed in any condition are shaded black. 


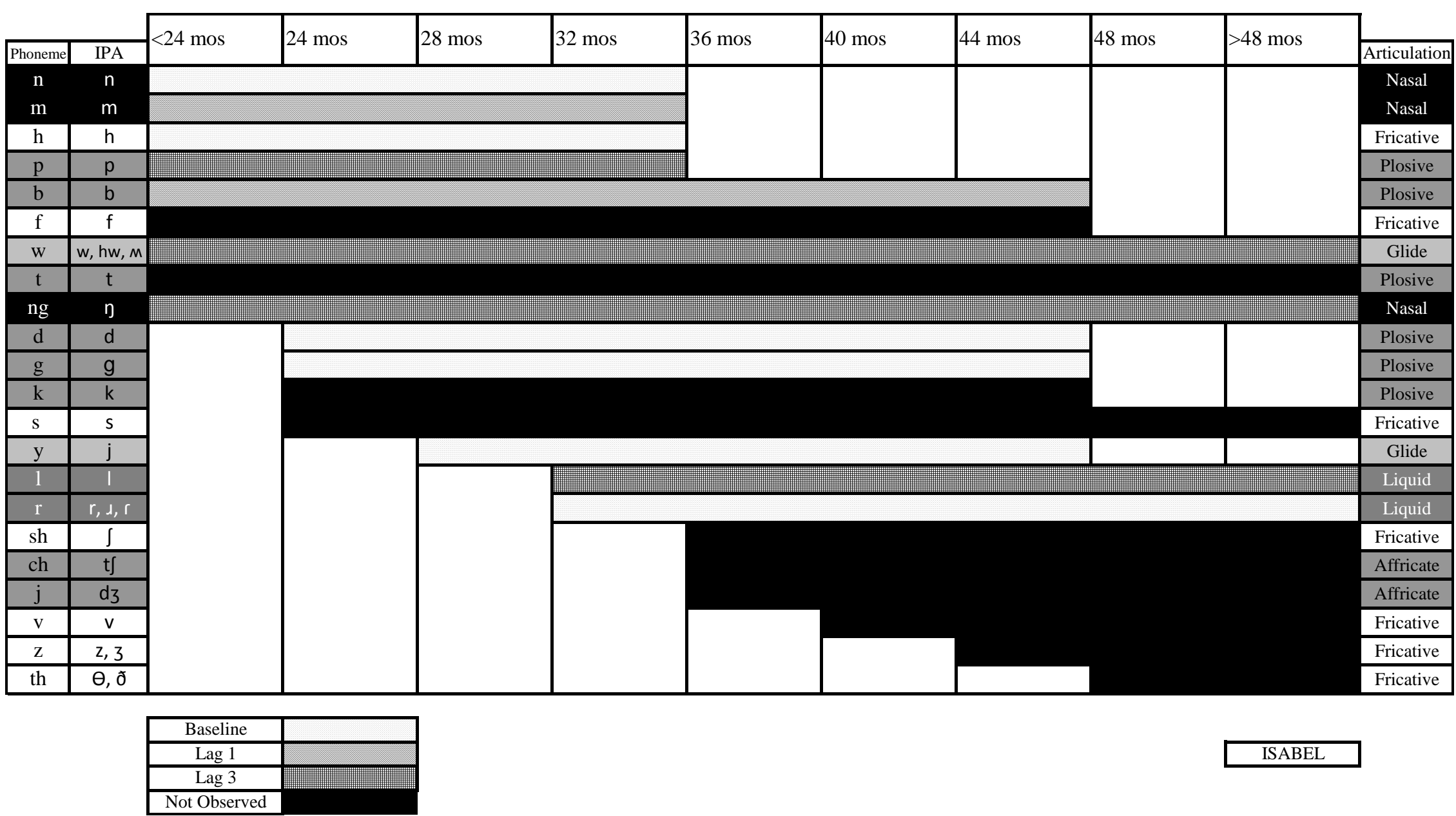

Figure 47. Developmental chart of consonant production across the last six sessions of conditions in Study 2 for Isabel. Bars with dots represent sounds produced in baseline, bars with diagonal lines represent phonemes produced under Lag 1, and bars with crosshatch represent phonemes produced in Lag 3. Phonemes not observed in any condition are shaded black. 


\begin{tabular}{|c|c|c|c|c|c|c|c|c|c|c|c|}
\hline Phoneme & $\overline{\mathrm{IPA}}$ & $<24 \mathrm{mos}$ & $24 \mathrm{mos}$ & $28 \mathrm{mos}$ & $32 \mathrm{mos}$ & $36 \mathrm{mos}$ & $40 \mathrm{mos}$ & $44 \mathrm{mos}$ & $48 \mathrm{mos}$ & $>48$ mos & \begin{tabular}{|l} 
Articulation \\
\end{tabular} \\
\hline ă & $æ$ & & & & & & & & & & Monopthong \\
\hline$\overline{\mathrm{e}}$ & $\mathrm{i}$ & & & & & & & & & & Monopthong \\
\hline ĕ & $\varepsilon$ & & & & & & & & & & Monopthong \\
\hline$\breve{\imath}$ & $\mathrm{I}$ & & & & & & & & & & Monopthong \\
\hline ŏ & $a, 0$ & 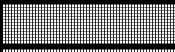 & in & & & & & & & & \begin{tabular}{|l|} 
Monopthong \\
\end{tabular} \\
\hline$\breve{u}$ & $\partial, \Lambda$ & & & & & & & & & & Monopthong \\
\hline oo & $\mathrm{u}$ & & & & & & & & & & \begin{tabular}{|l|} 
Monopthong \\
\end{tabular} \\
\hline $\bar{a}$ & eI & 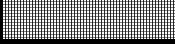 & 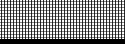 & . & 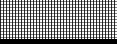 & & & & & & \begin{tabular}{|l} 
Diphthong \\
\end{tabular} \\
\hline $\bar{i}$ & aI & & & & & & & & & & Diphthong \\
\hline $\bar{o}$ & ov & & & & & & & & & & Diphthong \\
\hline ow & av & ( & & & & & & & & & Diphthong \\
\hline oy & गI & 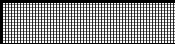 & & & & & & & & & Diphthong \\
\hline er & $\partial^{2,3}$ & & & & & & & & & & R-Colored \\
\hline ar & ar & & & & & & & & & & R-Colored \\
\hline or & or & & & & & & & & & & R-Colored \\
\hline ur & or & & & & & & & & & & R-Colored \\
\hline & & Baseline & & & & & & & & ISABEL & \\
\hline & & $\mathrm{S}^{\mathrm{R+}}$ & & & & & & & & & \\
\hline & & Not Observe & & & & & & & & & \\
\hline
\end{tabular}

Figure 48. Developmental chart of vowel production across the last six sessions of conditions in Study 3 for Isabel. Bars with dots represent sounds produced in baseline, and bars with crosshatch represent phonemes produced under reinforcement for variability conditions. Phonemes not observed in any condition are shaded black. 


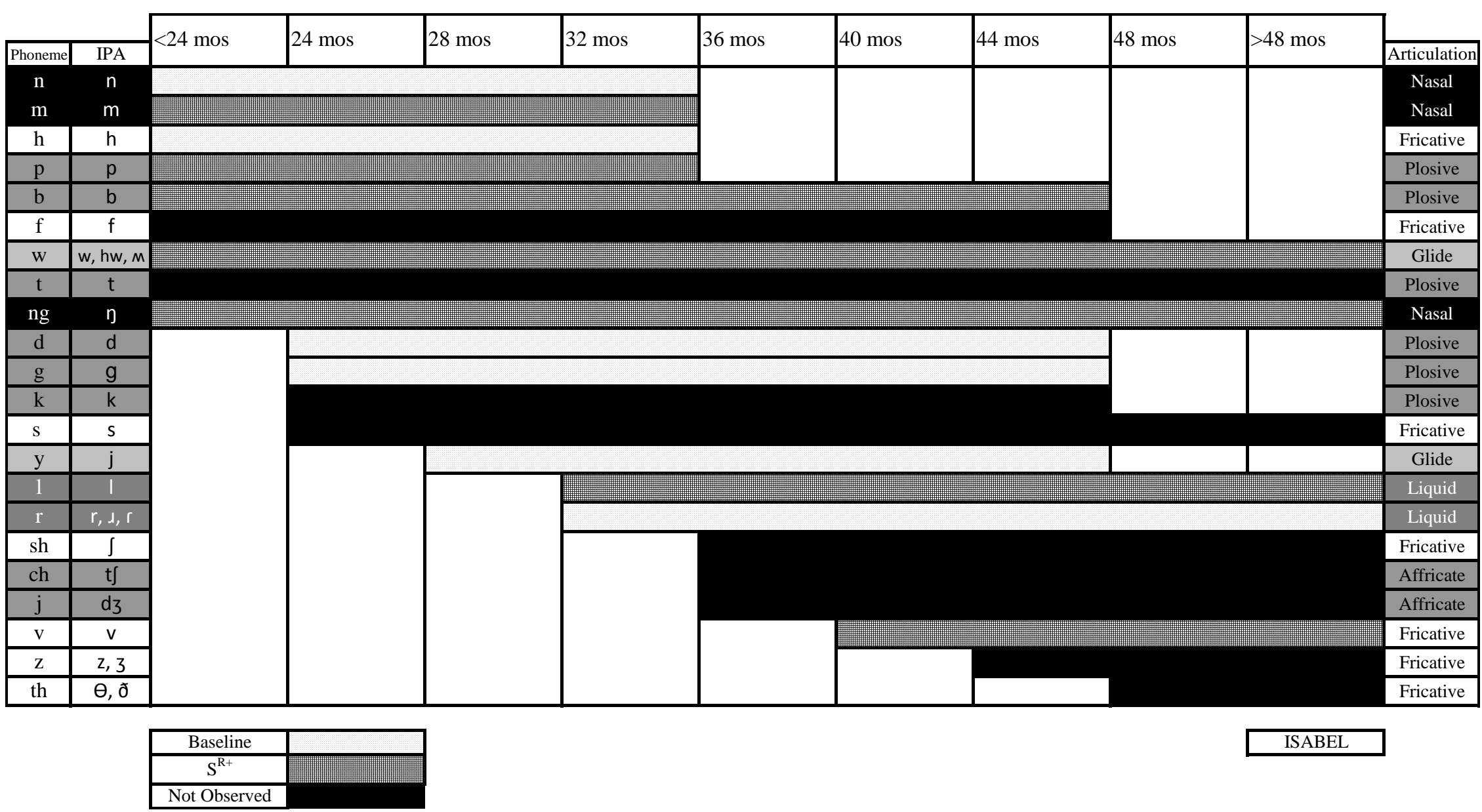

Figure 49. Developmental chart of consonant production across the last six sessions of conditions in Study 3 for Isabel. Bars with dots represent sounds produced in baseline, and bars with crosshatch represent phonemes produced under reinforcement for variability conditions. Phonemes not observed in any condition are shaded black. 